\title{
ANALYSIS OF CONTENT AND PEDAGOGICAL CONTENT KNOWLEDGE IN SECONDARY MATHEMATICS TEACHERS' PREPARATION PROGRAMS: PERCEPTIONS OF NOVICE TEACHERS, COOPERATING TEACHERS, AND UNIVERSITY PROFESSORS
}

A Dissertation
presented to
the Faculty of the Graduate School
at the University of Missouri-Columbia
In Partial Fulfillment
of the Requirements for the Degree
Doctor of Education
ANGELA DORSEY
July 2018
Carole Edmonds, Dissertation Supervisor
Dr.


C Copyright by Angela K. Dorsey 2018

All Rights Reserved 
The undersigned, appointed by the dean of the Graduate School, have examined the dissertation entitled

\section{ANALYSIS OF CONTENT AND PEDAGOGICAL CONTENT KNOWLEDGE IN SECONDARY MATHEMATICS TEACHERS' PREPARATION PROGRAMS: PERCEPTIONS OF NOVICE TEACHERS, COOPERATING TEACHERS, AND UNIVERSITY PROFESSORS}

presented by Angela K. Dorsey

a candidate for the degree of doctor of education, and hereby certify that, in their opinion, it is worthy of acceptance.

$\$$

Dr. Carol Edmonds

\section{Dr. Tim Wall}

Dr. Jennee Barnes-Gregory

Dr. Virgil Freeman 


\section{DEDICATION}

I dedicate this research to all future students with the ambition to teach students mathematics. Also, to all students taking math classes with novice teachers who deserve the best-prepared teacher to engage their learning and develop their appreciation for mathematics. Last but not least, this is dedicated to Matt, Tyler, and Abby who understand my passion for learning and to help others learn. 


\section{ACKNOWLDEGMENTS}

I never felt the use of words ever accurately express the depth of my emotions. However, I will attempt to do so in this acknowledgement. Actions speak louder than words and through the actions and words of family, friends and educators, I have been able to accomplish my goal.

To my friend, my life, my love, Matt. I could not have become the person I am without your love and support. You are steadfast in your love for me and your support for my professional choices. Each level of my career, we have had to discuss, adjust and shuffle family responsibilities. You have always been agreeable to do what needed to be done to support me. I really could not have done it without you! Thank you and I love you with all my heart.

Tyler and Abby, my amazing, strong, independent kids. Your support gave me strength to continue working and persevering. Abby, your notes on the walls and under the door while I was working meant so much to me and forever will leave an imprint on my heart. Tyler, your visits during my work time, even though it was to pet the dog, is a treasure I will always remember. It was a balance to make sure I was the mom you needed and work on this degree. You made it easy through your support and understanding. You helped me become DAD. I'd be remiss if I didn't give a shout out to my third kid, Sparky. He laid by my side and kept me company through all the hours of writing.

To my sister, Luanne, the tears in my eyes right now would show my love and appreciation better. You are my role model. You showed me a professional path through undergraduate, masters, and doctorate degrees. You led I followed! Thank you for 
reading, editing, and commenting, in a timely manner, on pretty much everything I wrote. Thank you for listening to my frustrations and providing suggestions when you could. Thank you for being my mentor, sister, and friend. Thank you for you!

Thank you to my parents, Bud and Lucille. Although they are not physically here with me I know they are in my heart. I have felt their guidance. My mom instilled in me the belief that an education is a gift no one can take away from you. My dad instilled in me a positive work ethic and dedication mixed with a little fun. Mom and Dad, I love you, thank you for supplying me with the desire and tools to accomplish this feat.

To Kim, Ryan, and Ben, thank you so much for not only opening up your home but your hearts. I appreciate your hospitality by letting me stay in your home for two summers. I always felt welcomed and your home became my home away from home. Thank you for the various meals, beverages, and conversations. Playing hide and seek with Ben was a wonderful way to end a long day of lectures and coursework. Somehow, I always found him. You always have all my love.

To Steve, Julie, Bryan, Brad, Brycen, Cassie, and Skylar, thank you for always being there fore me. Your thoughts, prayers, support and unconditional love was very much appreciated. Our family card nights helped me more than you know. Maybe now we can have them more often and Brad will let me win. I love you!

Thank you to the Skirts, the Davis', \& my exercise friends. Each of you helped me through this endeavor in your own unique ways. Whether it be some silly bantering on Grope Me, card games, hot tub nights, or checking in to see if I was going to make time to exercise. I treasured each of these moments since it gave me an opportunity to turn my mind off of coursework or papers. 
To Becky, my partner in crime, I am so thankful we were able to climb this mountain together. I don't believe I could have done this without you and your support and encouragement. To the remaining St. Joe crew, Vicky, Ramsey, Chris, and Ashly, thank you for being there and your willingness to help in various ways. The remaining members of Cohort X, I was fortunate to be included is such an amazing group. We all worked together, had some amazing conversations, and produced some profound work. To my committee Co-Chairs, Dr. Edmonds and Dr. Wall, as well as committee members, Dr. Barnes-Gregory and Dr. Freeman, your knowledge, time, advice, and reassurance have been greatly appreciated. I feel honored to have your leadership and academic foundation for my future ventures. A special thank you to Dr. Edmonds for the perpetual time spent reading, reviewing, revising, reflecting, guiding, supporting, and encouraging my work. You have been the rock that kept my pace steady.

For all these people in my life, I thank God. I also offer Him thanks for all the blessings He has bestowed upon me. I am humbled by his mercy and believe it was His will for me to take this journey with such great people. My loving Father, I give you thanks and praise, now and forever. 


\section{TABLE OF CONTENTS}

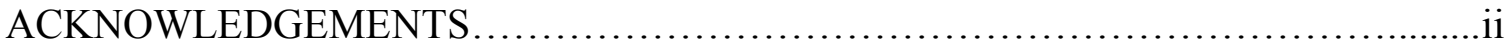

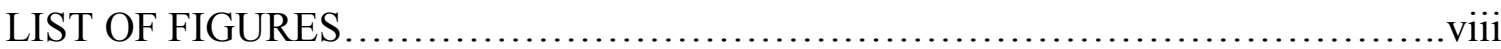

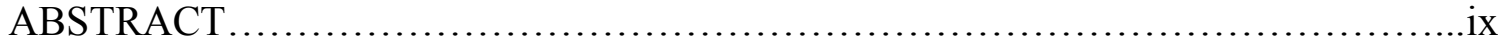

SECTION

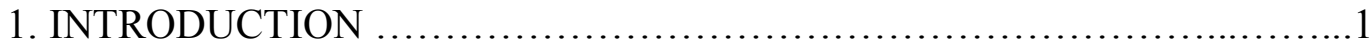

Problem Statement................................................ 3

Purpose of the Study....................................................5

Research Questions..............................................5

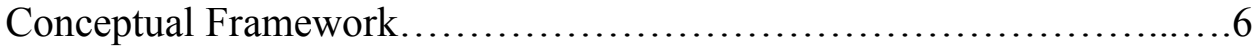

Internal Process of Change.................................... 7

External Process of Change................................... 8

Personal Process of Change................................... 9

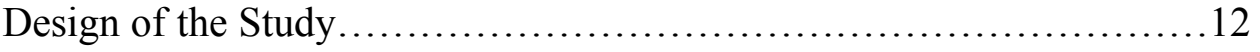

Setting................................................... 13

Participants...............................................13

Data-Collection.................................................. 14

Data Analysis..............................................16

Limitations, Delimitations and Assumptions.......................... 17

Limitations............................................... 17

Delimitations.................................................. 18

Assumptions................................................18

Definitions of Key Terms..........................................18

Significance of the Study......................................... 19

Practice.......................................................

Scholarship ...................................................20

Summary..................................................20

2: PRACTITIONER SETTING FOR THE STUDY $\ldots \ldots \ldots \ldots \ldots \ldots \ldots \ldots \ldots . \ldots . \ldots \ldots$

History of the Organizations........................................ 21

Organizational Analysis.............................................28

Leadership Analysis................................................32

Implications for Research in the Practitioner Setting................... 35

Summary........................................................ 35 


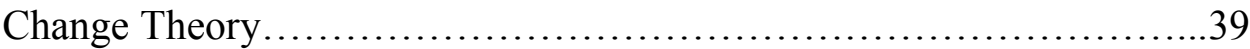

Standards Forming the Curriculum of the Preparation Program.............41

Content Knowledge..................................................44

Pedagogical Content Knowledge......................................48

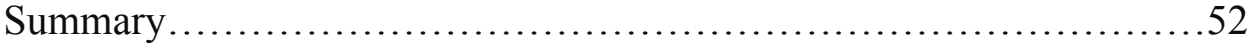

4. CONTRIBUTION TO PRACTICE.......................................54

Practitioner Presentation Document..................................56

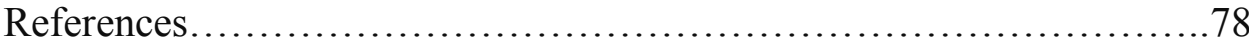

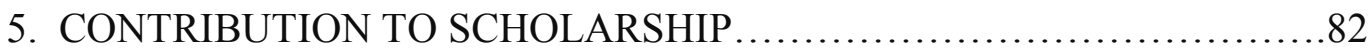

Submission-Ready Journal Article.................................. 84

References..................................................... 127

6. SCHOLARLY PRACTITIONER REFLECTION.........................135

Influenced as an Educational Leader...................................135

Leadership and Change....................................135

Leadership as a Process.....................................136

Leadership Strengths......................................136

Leadership Development Areas................................137

Influenced as Scholar............................................... 138

Content and Context for Learning..............................138

Learning Reflection......................................138

Learning Leader...........................................139

Facilitation of Change .....................................140

Conclusion..........................................................

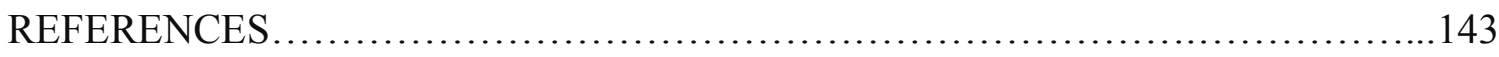

APPENDIX

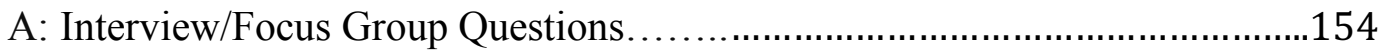

B: Recruitment/Script Letter..............................................156

C: Follow up Phone Call Protocol........................................... 157

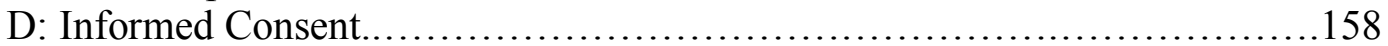

E: Alpha University Organizational Chart................................. 160

F: Beta University Organizational Chart................................. 161

G: National Council of Teachers of Mathematics Council for the

Accreditation of Educator Preparation Standard ......................162

H: Association of Mathematics Teacher Educators Standards for Well-

Prepared Beginning Teachers of Mathematics...........................164 
I: State Educator Evaluation System Quality Indicators of the Academic Standard......................................................... 165

J: National Council of Teachers of Mathematics Council for the Accreditation of Educator Preparation Mathematics Content for Secondary..... 167

K: State Department of Elementary and Secondary Education Certification

Requirements for Secondary Education (9-12)......................171

L: Alpha University Mathematics Education Requirements...................173

M: Beta University Teacher Education in Mathematics Requirements..........174

N: IRB Approval.................................................... 175

O: Permission to Conduct Research (Alpha) ..............................177

P: Permission to Conduct Research (Beta) ....................................178

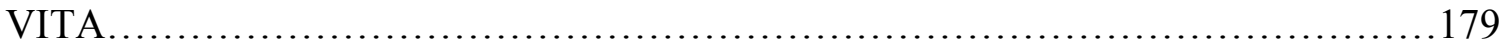




\section{LIST OF FIGURES}

Figure

Page

1. Illustration of the Conceptual Underpinning and forces used to guide the study 


\title{
ANALYSIS OF CONTENT AND PEDAGOGICAL CONTENT KNOWLEDGE IN SECONDARY MATHEMATICS TEACHERS' PREPARATION PROGRAMS: PERCEPTIONS OF NOVICE TEACHERS, COOPERATING TEACHERS, AND UNIVERSITY PROFESSORS
}

\author{
Angela K. Dorsey \\ Dr. Carole Edmonds, Dissertation Supervisor
}

ABSTRACT

Previous research focused on characteristics of effective teachers, teacher recruitment or new pathways to teaching (Ball \& Forzani, 2009; Ronfeldt et. al., 2014). However, there is a gap in the research regarding the best path to prepare secondary math teachers. Universities create a customized path of preparation based on their beliefs within the scope of a set of standards given by organizations such as the National Council for Teachers of Mathematics or National Council for Accreditation of Teacher Education. Further research supports the necessity for both content and pedagogical knowledge (Ball, 2000; Graham \& Fennell, 2001; NCATE, 2010; Thames \& Ball, 2010). Therefore, the purpose of this qualitative case study pursues to increase the research by uncovering perceptions of secondary math teacher preparation with the standards, content knowledge, and content pedagogical knowledge. The study included two universities' programs to gain awareness as to the interpretations of novice teachers, cooperating teachers, and University professors of the pre-service training program used to prepare future secondary mathematics educators. The findings suggest: while only the Mathematics Education Professor at both Universities were the only study participants to have a vast knowledge of the standards it did not seem to impede on the overall preparation of the novice teacher. Novice and Cooperating 
teachers lacked the vision for the purpose and value of upper level math classes required for the degree. Both Novice and Cooperating Teachers wanted an increase in opportunities for real-world content pedagogical situations along with differentiation, coteaching, and Special Education. Novice teachers acknowledged the need for relationships with University professors and peers in their path toward preparation. Lastly, Mathematics Education Professors stated value in making connections between courses and research to high school math. Furthermore, the finding suggest for teacher preparation program: to prepare secondary math teachers for the current culture of mathematics education, content and pedagogical courses should not be separated and a push to increase program enrollment should be a priority.

Keywords: Teacher Preparation, Change Theory, Secondary Mathematics Teacher Preparation Standards, Content Knowledge, Pedagogical Content Knowledge 


\section{SECTION ONE}

\section{INTRODUCTION}

Even though preparation for effective teachers is an implied goal, there are conflicting views between the different processes to achieve that goal (Lasley, Sidentop, \& Yinger, 2006). Also, research is lacking on what characteristics are needed for an effective teacher preparation program (Ronfeldt et al., 2014). Variations and indecision still resides on the academic components of the program standards for teacher preparation (Whitford \& Villaume, 2014) and since the scope of a teacher's role to be effective has widened and deepened, "preservice teacher education, up to this point, has been ineffective in making an initial contribution to the start of the teacher's career" (Fullan, 1996, p. 498). Therefore, would the different programs of two different universities both prepare their teachers to effectively educate students?

In 2010, the National Academy of Sciences conveyed the pursuit of preparing effective teachers for educating all students. An effective teacher has content knowledge, knowledge in the practice of teaching and knowledge of student learning and learning environment (NCATE, 2010). Research summarized by the National Council for Accreditation of Teacher Education (2010) indicated a direct relationship between teacher preparation and student achievement. Therefore, a strong teacher preparation impacts the effectiveness of the teachers and increases teachers' efficacy (Podolsky, Kini, Bishop \& Darling-Hammond, 2016; Ronfeldt, Schwartz, \& Jacob, 2014) and keeps teachers in the profession (Ronfeldt et al., 2014; Scherer, 2012).

Witford and Villaume (2014) reviewed the history of reform efforts of teacher preparation from the mid-1900's of an "approved program" determined by the faculty, to 
the adoption of the National Council for Accreditation of Teacher Education (NCATE, 2001) standards. Although, "the history of educational reform and innovation is replete with good ideas or policies that fail to get implemented or that are successful in one situation, but not in another" (Fullan, Cuttress \& Kilcher, 2005, p. 54). In 2006, Levine stated, "today, the teacher education curriculum is a confusing patchwork" (p. 26). NCATE (2010) concluded about 700 United States teacher preparation programs align with the NCATE standards and progress has been made within the last 30 years. More progress is essential, especially with the inclusion of pedagogical approaches (NCATE, 2010).

Does our educational system run like clockwork to prepare our teachers to educate our students? Does it work like a mechanical clock?

Mechanical clocks tell time using two important parts: a mainspring and a pendulum. Instead of a mainspring, some mechanical clocks have weights that pull the gears at the right pace. As the mainspring unwinds, its energy turns gears, which cause the hands to move. The pendulum keeps time and ensures that the gears move at the right pace: second by second. (National Watch and Clock Museum, 2016, "How Does It Work," para. 2).

In the teacher preparation system, what makes up the mainspring, or weights, and pendulum and are they working together to ensure the correct pacing and time? The purpose of these national standards is to improve teacher education through collaboration with each State Department of Education and the institutions to assure the quality of teacher education programs (NCATE, 2010). These standards are the pendulum of a mechanical clock and are needed as an important part to certify consistency in effectively preparing secondary content teachers. The content and education courses within the degree certification act as the mainspring. These courses are 
also an important part for pre-service teachers to know their content and how to teach it. Similarly, instead of the mainspring, some clocks use weights and in comparison, universities have various ways of developing their education preparation programs. In the end, whether using mainsprings or weights, clocks need to keep the same time, as well as universities need to equally prepare teachers to be effective.

\section{Statement of the Problem}

\section{Problem of Practice}

Teachers significantly influence the curriculum and strategies needed for students to learn (Cochran-Smith \& Villegas, 2015). Therefore, consideration needs to be given to whether former ways of teaching mathematics is being perpetuated by not changing the mathematics teacher preparation programs to teach math (Ball, Thames, \& Phelps, 2008). Although prior to the implementation of the Common Core State Standards Initiative, Ball and Forzani (2009) claim the demands for preparing $21^{\text {st }}$ century youth emphasize "...collaborative work, integrated and problem-based curricula, and higher expectations for students" (p. 497). Thus, it is important for pre-service mathematics teacher programs to evolve with reforms such as the Common Core State Standards Initiative. However, are universities' secondary mathematics teacher preparation program evolving with the times and preparing teachers for this latest reform of expectations?

Since the launch of Sputnik in 1957, "motivation for teacher preparation" in the United States shifted to mathematics as a defense against a deficit in the technology race (Graham, Li, \& Buck, 2000). Mathematics education reform has been a topic of discussion for many years. It has continued to pose challenges for those involved in 
mathematics education in the United States (Peressini, Borko, Romagnano, Knuth, \& Willis, 2004; Zoest \& Bohl, 2005). Though, "most initiatives, however, have focused on teacher recruitment and retention and on developing new pathways to teaching" (Ball \& Forzani, 2009, p. 497). However, the Common Core State Standards Initiative (2009) had provided a spark to keep the discussion burning. The Common Core State Standards (CCSS) was a collaborative effort between local, state, and national organizations and institutions striving for effective mathematics education (APLU, 2011). They provided K-12 with a set of clear and consistent standards to ensure all students had competitive skills for college or the workplace (Core Standards, nd.). Therefore, teachers could collaborate around shared expectations for what mathematics students need to know and how they should know it. One shift of the CCSS for mathematics focuses on increased rigor in teaching mathematics by changing from merely concentrating on procedural skills and fluency to combining procedure with conceptual understanding (Core Standards, 2012, 2016). However, as this shift in math education has forced current math teachers to consider reforming their teaching practices, have secondary mathematics teacher preparation programs changed as well?

\section{Existing Gap}

A gap exists in the view of the best approach to prepare effective teachers and what characteristics make a teacher effective (Levine, 2006, Ronfeldt et. al., 2014). A review of literature supports the need for both content and pedagogical knowledge for teacher preparation (Ball, 2000; Graham \& Fennell, 2001; NCATE, 2010; Thames \& Ball, 2010) along with consistent set of standards (NCATE, 2010, NCTM-CAEP, 2012). This lack of per swayable research continues to allow various universities to choose the 
path of preparation for their students toward unclear expectations of effective.

Researching current teacher preparation programs in regards to perceptions of preparedness could provide specific components necessary to ensure novice teachers are prepared to educate students for their future.

\section{Purpose of the Study}

The researcher's purpose was to investigate novice teachers', university mathematics education professors', and cooperating teachers' perceptions of the secondary math education preparation programs from two Midwest state universities.

The focus of how to teach math has been debated from mastery of basic skills to encouraging more of a conceptual understanding of the math (National Research Council, 2010). Therefore, has secondary math teacher education preparation evolved with reform or remain stagnant in perpetuating the familiar way of teaching math? Since research is limited concerning novice teacher's, university professors', and cooperating teacher's perceptions of their preparation program, this study seeks "to uncover and interpret" (Merriam \& Tisdell, 2016, p. 25) how these groups characterize these preparation programs. The study considered the current state teacher preparation standards, math content required for teaching secondary math, and the inclusion of pedagogical content knowledge within the programs at two universities within the same state and region.

\section{Research Questions}

This study is guided by the overarching research question, "How do secondary math teacher education programs at two Midwest universities prepare beginning math teachers for the classroom?" Consequently, sub questions derived from the research question include the following: 
1. What are novice math teachers', cooperating teachers', and university professors' perceptions of the 9-12 mathematics teacher preparation standards at each university?

2. What are novice math teachers', cooperating teachers', and university professors' perceptions of the mathematics content in the 9-12 mathematics teacher preparation program at each university?

3. What are novice math teachers', cooperating teachers', and university professors' perceptions of the pedagogical content knowledge in the 9-12 mathematics teacher preparation program at each university?

4. What are the novice teachers', cooperating teachers', and university professors' perceptions of preparedness for teaching mathematics?

5. *How is Annual Performance Review data for mathematics teacher preparation used within each University? (*Note: Subquestion \#5 is for University Professors only.)

\section{Conceptual Framework}

Education has been in a continuous cycle of reform (Cuban, 1990). The process of change is complex (Shen, 2008), it is "inevitably, empirically, and theoretically nonlinear" (Fullan, 1996, p. 496). Shen (2008) synthesized various definitions of change and summarized it as "a process of improving your practice" (p. 73). Not only has education been in constant reform, so has the process of change itself. Goodson (2001) explains the different phases of educational change since 1970. Phase one focused on internal change in education initiated and defined by teachers from within the school (Goodson, 2001). Phase two concentrated on the external relations of change initiated 
from outside the school or organization, such as state or national curriculum or guidelines in a top-down approach (Goodson, 2001). Lastly, phase three focused on consolidating internal, external, and personal change. Consideration of the personal level of educational change involved "the personal beliefs and missions that individuals bring to the change process" (Goodson, 2001, p. 45). Corbo, Reinholz, Dancy, Deetz, and Finkelstein (2016) viewed this interdependence of these processes through an institutional perspective.

As an institution, three pillars can define education, at a conceptual level: regulative, normative, and cognitive (Hanson, 2001). Professional standards direct sets of prescribed actions for teachers and administrators through rules both formal and informal that mold the regulative pillar (Hanson, 2001). The normative pillar focuses on the how teachers should teach, "values and norms about how educators should pursue valued ends through legitimate means" (Hanson, 2001, p. 646). Lastly, how people view and interpret their world gives meaning to them and shapes the cognitive pillar (Hanson, 2001). The internal, external, and personal routes of change and the three pillars of an institution are interrelated and reinforce each other.

\section{Internal Process of Change}

Through the 1960s and 1970s, internal change was the focus for change theory (Goodson, 2001). The process of internal change is concentrated where teacher groups "played central roles in initiating and promoting educational change" (Goodson, 2001, p. 48). Internal change is from education groups motivated in the quest of educational change through ideas or activities (Goodson, 2001; Hanson, 2001). Similarly, Hanson (2001) frames this model as the normative pillar, values and norms, of the conceptual 
level of an institution. Corbo et al., (2016) defines the change in the normative pillar, beliefs, value, and norms, through a cultural perspective. Therefore, change involves reculturing (Fullan, 2002). Lasting change includes wrestling with new beliefs of what people in the organization value and how they collaborate to achieve the goal (Fullan, 2002; Fullan, Cuttress, \& Kilcher, 2005). Education is a complex system (Corbo et al., 2016) of internal and external forces and because the inclination of this system is fragmented. This at time poses a challenge to change, causing the internal and external forces to not align (Fullan, 2002). External interest groups altered the focus on internal change during the 1980s and 1990s (Goodson, 2001).

\section{External Process of Change}

External change patterns considered the interests of government agencies and corporate groups in shaping educational change (Goodson, 2001). Rather than initiating change, "internal change agents now find themselves responding to changes" (Goodson, 2001, p. 48). Similarly, Corbo et al., (2016) views this key feature as the evolutionary perspective; which is associated with the concept of "first order" change. First order change is correcting deficiencies in what an organization already does, such as policies and procedures, but retaining existing goals and structures (Corbo et al., 2016; Waks, 2007). Similarly, Hanson (2001) explains this model as the regulative pillar of the conceptual level of an institution. The regulative pillar involves, for example, professional standards or policies to rule the actions of teachers and administrators (Hanson, 2001). Policies have a purpose as a necessary stimulus, but only achieving superficial compliance (Fullan, 1996). Goodson (2001) states, "external direction and definition of large-scale reform does not ensure internally implemented and sustained 
improvement" (p. 49). Internal change agents are no longer committed to educational change; they become opponents of external educational change and "the result of these ruptures between external and internal forces may be an educational change process that is riven with conflict and dysfunctionality on an epic scale" (Goodson, 2001, p. 48). Therefore, change involves redefining resistance (Fullan, 2002) or problems (Fullan, 1996). The process of finding the solution to the problems is when breakthroughs occur (Fullan, 1996). However, the cycles between internal and external forces initiating change have alternated without the concern of teachers' personal viewpoints until the end of the 1990s (Goodson, 2001).

\section{Personal Process of Change}

Personal viewpoints of change involve each person's story of purpose (Goodson, 2001). Goodson (2001) explains, "Change most often begins with a transformation of people's personal perceptions and projects and flows outwards into the social and institutional domain" (p. 56-57). Institutionally, Hanson (2001) views this as the cognitive pillar which gives teachers meaning and serves as a screen for understanding their environment. Teachers choose the projects and teaching strategies based on their unique set of students and subjects (Hanson, 2001). Similarly, Corbo et al. (2016) refers to this as the social cognition perspective of change; which is related with the concept of "second order" change (Corbo et al, 2016). Second order change challenges reconstructing organizational structures to resolve differences in organizational beliefs and actions (Corbo et al., 2016; Waks, 2007). As individuals define new viewpoints or incorporate new practices, the social aspect allows for coalitions to be formed (Goodson, 2001). These coalitions could build capacity (Fullan, 1996) and change culture (Fullan, 
2002) by changing the cultural perspective (Hanson, 2001) then expand into internal change (Goodson, 2001).

In summary, "change and reform must be seen as going both ways in relation to school and context, both into and out from the school" (Goodson, 2001, p. 59). Therefore, schools cannot only collaborate internally towards change; they must have connections to the external entities (Fullan, 1996). Each process of change: internal, external, and personal, comes with their own challenges and issues. An issue with internal change forces, the normative pillar, is "confronting existing memories of schools and school practices" (Goodson, 2001, p. 58-59) where school groups can protect the status quo as opposed to innovative changes (Hanson, 2001). Whereas, a caution for the external force, the regulative pillar, is one of Fullan's (1996) lessons for understanding the change process, which pertains to not mandating such things as skills, attitudes, or beliefs, but to let them happen at the ground level or the possibility of change will break down. However, personal process of change may not be the change needed for the institution (Goodson, 2001). Collectively, an interdependence of internal, external, and personal change is needed to transform actions from figurative to substantive toward educational change (Goodson, 2001). Recommended standards, mathematical content knowledge and pedagogical content knowledge are forces of change for secondary mathematics teacher preparation.

Preparation Program Standards. Traditionally, secondary mathematics teacher preparation programs have focused on well-preparing initial teachers with a solid foundation in mathematics content (Graham \& Fennell, 2001; Graham et al., 2000), albeit not sufficient any longer. Therefore, recommendations for secondary mathematics 
teacher preparation programs prior to the beginning of the $21^{\text {st }}$ century expanded expectations for secondary mathematics teachers to incorporate knowing students as learners, mathematical pedagogy, along with mathematics content (Graham et al., 2000; Graham \& Fennel, 2001; NCTM 2000). Beginning with the Mathematical Education of Teachers (CBMS, 2001) and National Council of Teachers of Mathematics-Council for the Accreditation of Educator Preparation (NCTM-CAEP, 2003) and continuing with both their updates in 2012, significant external changes have been made in teacher education (CBMS, 2017).

Content knowledge. Research validates mathematical content knowledge is necessary for teaching mathematics (Graham \& Fennell, 2001; NCTM-CAEP, 2012; Thames \& Ball, 2010) especially for creating effective lessons and helping students learn (Ball, 2000; Wilburne \& Long, 2010). The culture of preparing secondary mathematics teachers has focused on a major in mathematics (Evans, 2011; Graham et al., 2000; Schmidt, Burroughs, Cogan, \& Houang, 2016). This philosophy, in part, is still promoted through NCTM-CAEP Mathematics Content for Secondary (2012), however, is also challenged by the lack of understanding prospective teachers have for the task of teaching (Thames \& Ball, 2010). Attention is given to analyzing the types of math content mathematics teachers need to teach math and for students to learn math (Ball \& Bass, 2000; Ball \& Forzani, 2009; Thames \& Ball, 2010). Internal change begins with a change formation from an educational group about new directions or demands (Goodson, 2001).

Pedagogical content knowledge. Pedagogical content knowledge is a specific type of mathematical knowledge, knowledge to be able to represent the content that is 
relevant to teaching (Ball et al., 2008; NCTM-CAEP, 2012; Shulman, 1986). However, more research is necessary to define the exact content knowledge and the amount of pedagogical knowledge (Ball et al., 2008, Hill, Rowan, \& Ball, 2005). Pedagogical content knowledge is essential for teacher's flexible use of strategies to represent mathematics for student learning (Ball et al., 2008). Although, current mathematics courses for mathematics teachers do not include this type of learning (Ball et al., 2008). Methods and mathematics courses are isolated into different departments at the university level (Graham et al., 2000). Therefore, leaving the teacher to merge the gap between content and connected pedagogy (Ball, 2000). Allowing teachers to make their own resolutions about pedagogy (Goodson, 2001). However, these personal decisions and activities can flow outward into the internal and external levels for change (Goodson, 2001; Hanson, 2001).

\section{Design of the Study}

This study is developed to provide two Midwest United States universities with insights about the successes and challenges of their secondary math teacher preparation programs. However, ultimately the results can enhance the conversation about change in education preparation by understanding the experiences of secondary math teachers involved in the universities' teacher preparation programs. As Patton stated (2015), "it aims to critique existing conditions and through that critique bring about change" (p. 692).

Through a social constructivist philosophy, the researcher will be doing qualitative research to "understand how people interpret their experiences, how they construct their worlds, and what meaning they attribute to their experiences" (Merriam \& 
Tisdell, 2016, p. 6). Social constructivists beliefs are formed through human interactions and are based upon on the participants' views of the understanding the situation (Creswell, 2014). The qualitative research used will be a case study, an "in-depth description and analysis of a bounded system" (Merriam \& Tisdell, 2016, p. 37). Case studies are considered bounded provided the number of participants or the time frame of the study is limited (Merriam \& Tisdell, 2016).

\section{Setting}

Alpha and Beta Universities (pseudonyms) are state-funded, four-year universities located in the Midwest. Both universities offer various undergraduate and graduate programs with similar total student enrollment. Alpha University prides itself as providing experience for the profession whereas Beta University boasts its instruction is based on practice. Alpha University offers a Secondary Mathematics Education degree whereas Beta University offers a Mathematics degree with a Certification for Secondary Education. The number of students who have declared majors in mathematics with education at Beta University range from three to eight students per semester with an average of two graduating each year (Beta University, 2016). Alpha University has an enrollment and graduation average of four each year (Alpha University, 2016).

\section{Participants}

Secondary math teacher preparation programs have various participants regardless of the institution being examined. For the purpose of this study, participants include graduate teachers from the two Midwest Universities who have been teaching mathematics with one to six years teaching experience, their cooperating teachers and university professors of math education from each university. To engage participants 
and gain insight into understanding and discovering successes and challenges of secondary mathematics teacher preparation and increase validity, the researcher will use purposeful, random sampling (Creswell, 2014; Merriam \& Tisdell, 2016; Seidman, 2012).

\section{Data Collection}

The researcher will use diverse qualitative research methods; interviews, focus groups, and artifacts. These methods will assist the researcher to "uncover meaning, develop understanding and discover insights relevant to the research problem" (Merriam $\&$ Tisdell, 2016, p. 106). The overarching focus of the study is perceptions of secondary math teacher preparation programs; therefore, interviews of novice teachers, cooperating teachers and university professors will be used to understand "the lived experience ... and the meaning they make of that experience" (Seidman, 2013, p. 9). Interviews will be face-to-face, by email, or by phone. Focus groups of cooperating teachers and university professors are another way to discover perceptions and the rational about issues (Krueger $\&$ Casey, 2015). Other qualitative research data such as the state standards for teacher preparation; the state standards for secondary math certification, and both universities programs of study for secondary math education will be used as artifacts. Artifacts provide a stable and objective document (Merriam \& Tisdell, 2016). These qualitative research methods of interviews, focus groups, and artifacts will provide a triangulation of data for analysis for increasing credibility and internal validity (Merriam \& Tisdell, 2016).

Interviews. Seidman (2013) encourages interviewing as a form of inquiry for data collection. The researcher was interested in the stories of individual novice teachers. 
Therefore, open-ended, guided questions (Appendix A) were used to understand the experiences. Novice teacher participants from both institutions will be identified through communication and collaboration with both universities' Institutional Research Departments or Mathematics Departments. Initial contact will be made through an email or letter (Appendix B). The email and letter explained the researcher's study, its purpose, and a request for a 30-minute interview. If needed, the researcher used a follow-up phone call protocol (Appendix C) to further explain the study and secured an interview. Then, a confirmation email will be sent to determine a location convenient for the interviewee and to inform them the interview will be recorded therefore requesting consent by the attached form (Appendix D). Interviewing, "affirms the importance of the individual without denigrating the possibility of community and collaboration" (Seidman, 2013, p. 13). Interviews will be conducted until saturation or new insights are not reached (Creswell, 2014). The interaction of the interviewer and the researcher may have biases or predispositions that could affect the data collected (Meriam \& Tisdell, 2016). However, to ensure internal validity, member check will be used (Meriam \& Tisdell, 2016).

Focus Groups. Hennink (2014) explained, “during the group discussion participants share their views, hear the views of others, and perhaps refine their own views in light of what they have heard" (as cited by Merriam \& Tisdell, 2016, p. 114). Therefore, using focus groups will provide insight or understanding the researcher would not have had using only one-on-one interviews. Focus groups will be used as opposed to individual interviews when possible to allow collaboration and communication. Krueger and Casey (2015) recommend purposeful, random sampling in order to select members 
from prospective participants. Initial emails (Appendix B) were sent explaining the researcher's study, its purpose, and a request for a 30-minute focus group. If needed, the researcher used a follow-up phone call protocol (Appendix C) to further explain the study and secured participation in the focus group. Subsequent emails confirmed a convenient date and location for all participants. The researcher should note, it is important for the researcher to listen for understanding and ask questions for clarification not to take the discussion on a tangent (Lawrence \& Paige, 2016).

Artifacts. Documents and artifacts provide insights pertaining to the research question (Merriam \& Tisdell, 2016). Therefore, the researcher gathered various documentary materials through the state's website and from each university's mathematics departments and websites. However, Merriam \& Tisdell (2016) caution, "documents generally are not produced for research purposes" (p. 181) and the researcher used these as a primary data sources to help build the categories of the qualitative study.

\section{Data Analysis}

The researcher's purpose was to "collect and analyze multiple forms of data in a systematic way" (Merriam \& Tisdell, 2016, p. 52). Therefore, the researcher reviewed documents and transcriptions of the data from the interviews and focus groups and began analyzing it by marking possible category code titles in the right margins. The researcher then determined which data "might be relevant to the study" (Merriam \& Tisdell, 2016, p. 229) as part of the process of open coding (Creswell, 2016; Merriam \& Tisdell, 2016). The researcher will plan backwards according to Creswell (2016). The sub-questions of the research question were written on large pieces of paper. Data from artifacts, interviews and focus group transcripts will be organized under its suited question. An 
analysis of the information for each question determined the themes. This open coding process showed how "multiple sources of data helps build the codes, and in turn, the evidence for the theme[s]" (Creswell, 2016, p. 157).

\section{Limitations, Delimitations, and Assumptions}

\section{Limitations}

Since this is a qualitative case study reliability and validity are a concern based on the different assumptions and perceptions of the participants (Merriam \& Tisdell, 2016). Also, the study is specific to the two universities and therefore is limited on its transferability to other secondary mathematics teacher preparations programs. Another limitation is not all novice or cooperating teachers are considered to be highly qualified therefore altering their perceptions of reality in regards to their preparation or guidance, respectively. An added limitation is the probability most participants will be between the ages of 21- 25 and Caucasian because of the demographic of the population in this

Midwest area. The novice teachers in the study are students from the teacher preparation programs whom secured a teaching position, therefore creating a limitation. University professors and cooperating teachers in the study could present a limitation by adjusting their responses to guard their reputations.

\section{Delimitations}

Delimitation included using only novice teachers with one to six years experience from two specific Midwest universities. Therefore, the sample space of the researcher's participants is fixed. Also, delimitation was the variation in perceptions of novice and cooperating teachers based on teaching in an urban versus rural school. Interviews were kept to a 30-minute maximum and data about novice teachers' perceptions of their 
personal secondary learning was omitted from the study. Another delimitation was the researcher's perceptions of secondary math teacher preparation coupled with the experiences as a veteran teacher and the recent changes in math instruction.

\section{Assumptions}

Merriam and Tisdell (2016) caution assumptions in qualitative research to be multi-dimensional and ever changing perceptions of reality. The researcher's assumption in choosing novice teachers with one to six years teaching experience restricted this assumption. Novice teachers, cooperating teachers, and university professors knew they were being studied. An assumption is their honest responses based on the confidentiality of collecting the data.

\section{Definition of Key Terms}

Cooperating teacher. Fully certified teachers with at least three years of classroom teaching experience. They serve as mentors, role models, and evaluators to the pre-service teacher.

High quality (well-prepared) math teacher. Having a solid foundation in math along with knowing how students learn mathematics and knowing mathematical pedagogy (Graham, et al., 2000).

Mathematical content knowledge. Know substantial mathematics and know it well to reason and communicate (CBMS, 2012, Graham \& Fennell, 2001).

Novice teacher. A novice teacher, for the purpose of this study, is a teacher who has taught one to three years.

Pedagogy. Knowledge formed through experiences of how students learn (Graham \& Fennell, 2001). 
Pedagogical content knowledge. The combination of mathematical knowledge, knowledge of how students learn math and knowledge of the learner (Ball \& Bass, 2000).

Secondary math education. For the purpose of this study, secondary math education is specific to certification for teaching math in grades nine through twelve.

Teacher preparation program. Courses, standards and experiences university students are required to complete for teacher certification (Graham, et al., 2000).

Teacher preparation standards. Describe the knowledge and skills of a wellprepared teacher (AMTE, 2017).

\section{Significance of the Study}

\section{Practice}

The world of education has changed from teachers' knowledge of what to teach to teachers' knowledge of how students learn (Levine, 2006). The National Research Council (2010) indicates little and varying evidence of how best to prepare teachers. By understanding the preparedness of novice teachers from secondary math education programs, educational leaders will be able to consider adjustments to math and education courses and curricula in their programs needed for teachers to be equipped to educate all students. Additionally, this research will add to the literature on math education and teacher preparation at the secondary level.

\section{Scholarship}

This research will offer insight into the successes and struggles of both universities' secondary math teacher preparation programs to determine what adjustments or overhaul needs to be completed. In turn, this research opens the collaborative door between Alpha and Beta Universities secondary math preparation programs to develop a 
culture of learning with common strategies for improvement (Fullan et al., 2005). Thus, supplying high quality secondary math teachers to the Midwest.

\section{Summary}

Education reform is attempted in fragments and is not likely to change anything (Fullan, 1996). Based on the history, the process of change is an evolving model. Compounding the problem of the shifts in mathematics education and education in general is the directions from which change is forced. Change can come from internal forces of culture, external forces such as new standards, or personal forces of teacher's perceptions (Goodson, 2001). Qualitatively researching Alpha and Beta University’s secondary math teacher preparation programs, through interviews, focus groups, and artifacts, provided an understanding of the alignment between the change forces and process in teacher preparedness for the classroom. Thus, providing insight into adjustments, if any, of the standards, and/or courses needed for these programs. Even a mechanical clock needs maintenance to keep the gears moving smoothly. 


\section{SECTION TWO}

\section{PRACTIONER SETTING FOR THE STUDY}

The researcher's setting for this study consisted of two universities, Alpha and Beta, in the Midwest United States. Teacher education was a main strand in the development and improvement of each university. In this section, the researcher provides a history of each organization, the similarities and differences in the universities' organizational and leadership analysis. Lastly, implications for research in this setting are offered.

\section{History of the Organizations}

\section{Alpha University}

Teacher education was the foundation of Alpha University since its inception in the 1800's as a non-state funded college. By 1905, Alpha University was a state funded Normal School. "In the state of Missouri, a Normal School was where the teachers were developed (Alpha professor, personal communication, fall 2017)." High academic standards for teacher training in accordance with the state standards were designed and implemented by the first president. Students of Alpha Normal School, at this time, were uncertified teachers in rural areas who were seeking certification along with standardization of student education. In 1906, a laboratory school was developed providing an environment for students to learn and participate in best practice instruction.

From 1913 to 1921, under the leadership of Alpha's fourth president, focus on teacher education continued to grow as recognition as a Standard College was acknowledged in June 1916. In 1917, the Secondary Department of Alpha Normal School was part of the Academic Department. The Secondary Department, also, known 
as the Alpha Normal High School, gave students who had completed the Alpha Normal School training an opportunity to continue their work in a laboratory high school. This allowed practice teaching in their major subject, monitored by the subject matter experts and the high school supervisor, which categorized them as specialists. The Alpha Normal School became a four-year undergraduate institution, Alpha State Teacher's College by 1919. Shortly thereafter students graduated with the first Bachelor of Science in education degrees. Growth ensued beyond population and buildings, but also through improving the school's standards. As a Teacher's College, the American Association of Teachers placed Alpha State Teacher's College among the top institutions in the United States. By the spring of 1921, the school was empowered to sanction Bachelor of Arts degrees as well.

Through the 1930's and 1940's, the institution developed further. The education department believed teaching was an art and a science. In 1942, the laboratory school had its own building housing grades nursery through high school. The laboratory school was the central focus of the college dedicated to the education of teachers in both content and pedagogical strategies through observation, participation, and direct teaching practices under the supervision of the classroom teacher and course department supervisor.

Mathematics Department. As the college evolved following World War II, the student population expanded and spurred changes at the college. The seventh president renamed Alpha State Teacher's College to Alpha State College in 1949; training other professionals beside teachers. Therefore, expanding the mathematics department. The mathematics department believed of the importance of math in everyday life and offered 
courses in practical mathematics, advanced courses, and elementary courses for students to complete either a major or minor in the field. Courses in methods of teaching mathematics were offered along with courses in education for teachers to specialize in various fields of teaching such as senior high school. Based on the 1950 course catalog, the mathematics department at Alpha State College included courses for an undergraduate study along with math courses for teaching secondary and elementary mathematics. Graduate classes were first offered in the summer of 1955. The inclusion of other fields caused rapid growth and the emergence of the mathematics building. The mathematics department continued to offer programs for a major in mathematics toward degrees of Bachelor of Arts and Bachelor of Sciences. The 1960 course catalog indicated a Bachelor of Science in Secondary Education was also offered, including certification to teach in the Midwest State, with an understanding teachers should be masters of the subject they teach. As the mathematics department grew, its philosophy evolved to include for any degree was providing university students with an awareness and appreciation of the power of mathematics and an understanding of the connections of mathematics to other areas. In the classroom, instructors of the mathematics department were interested in the learning, discussing, and discovering of mathematics. The mathematics department continued to grow, by 2002, undergraduate minors were included. By 2012, the philosophy of the department included educating students to be competitive in the job market. As recent as the 2017 course catalog, instruction included activities similar to those in the work force.

Education Department. As the Teacher's School expanded into a State College, the inclusion of degrees outside of education restructured education to a department. 
Based on the 1950 course catalog, teacher preparation courses required observation of student and the supervising teacher, gradual participation and finally directed teaching. After 1960, the education department changed its structure and eliminated the high school level of the laboratory school. Education courses began in a student's third year of an education degree indicated by the suggested program of study in the 1960 course catalog. Direct teaching for secondary degrees was completed off campus instead of at the laboratory school during the first semester of the fourth year. The Bachelor of Science in Education for the secondary level included five semester hours of teaching at the secondary level with at least half of those hours done in the major subject. The National Council for Accreditation of Teacher Education (NCATE) accredited Alpha State College since 1954. As noted in the 1955 course catalog, Alpha State Teacher's College was a member of the American Association of Colleges for Teacher Education and the American Council on Education. Alpha State College became Alpha University in 1972. By 1979, Master of Science in Secondary Education and Master of Arts in Teaching were offered. The secondary education preparation program at Alpha University maintained consistency through the 1980's and was noted for excellence in teacher education based on the use of assessment data to improve K-12 student learning outcomes in 2006. In 2017 a redesign of the teacher preparation program incorporated education modules as early as the freshman year increasing exposure to pedagogy. However, a semester of direct teaching in the fourth year remains consistent.

\section{Beta University}

Teacher education was a focus of the local school district in which Beta University was formed, about 45 miles from Alpha University. In 1904, a one-year 
Teacher Training Program was established for high school graduates. The training program was offered as an extension of the high school courses and curriculum. Concentration for the program was on pedagogy and elementary classroom exposure. Once a participant successfully completed the program and assisted teachers in the city's elementary school for two years, also referred to as normal schools, they could fulfill a regular teaching position. Although a professional program, it did not require or include work in a college or university. Shortly, thereafter, the discussion between offering a two-year normal school or a junior college surfaced based on emphasis from universities within this Midwest state to upgrade the quality of work.

The local school district's Board of Education discontinued the normal school and organized Beta Junior College as a liberal arts college in the summer of 1915 as an integral part of the public-school system. It was the second organized Junior College in the state. It was under the guidance of the local Superintendent of Schools and Board of Education, however, directly led by the principal and staff of the local high school of the building in which it was housed until 1925 when it was moved to its own building. Beta Junior College's purpose was a two-year program of basic courses of curricula in literature, science, mathematics, social studies, some electives, and education courses. Although not acknowledged by the Midwest state until 1927, the standards and curriculum were equivalent to the first and second-year of a four-year university. North Central Association of Colleges first accredited Beta Junior College in 1923. By 1922, there were 59 alumni dispersed in various career paths, however, 19 were enrolled in a college or university and 22 were teaching. Some of them had degrees while others completed their teaching degrees through summer work after teaching through the winter. 
During the next 40 years, Beta Junior College continued to satisfy its original purpose and expectations. Through depression and wars, stability prevailed and plans for growth emerged. The effects of the war changed the array of American education in coursework and population. Beta Junior College focused more attention to vocational training and semi-professional education. Based on the 1944 course catalog, vocational courses such as automotive mechanics and welding were offered along with courses for nurses from nearby hospitals and accredited teacher-training courses. The population of Beta Junior College began to grow by including students over the age of 21 and by 1954 had included the first black teachers to attend Junior College. Beta Junior College continued to evolve as an individual institution including adding sports, activities, and clubs.

By the spring of 1969, Beta Junior College became Beta College, a combination of the existing junior college supported by the local school district combined with the third and fourth years, which were state funded. This granted the option of baccalaureate degrees. Enrollment increased drastically and the curriculum reflected three main programs liberal arts, vocational, and teacher education. Elementary education and secondary education programs were part of the education and psychology department. The goal for students becoming teachers was to know and apply knowledge of the student and beliefs of learning. In the fall of 1969, Beta College moved to a new location consisting of three buildings: Classroom-Administration building, Learning Resource Center, and the Science and Mathematics building. During the next five years, other buildings such as Fine Arts, Physical Education, Student Union, and dormitories were added. 
By the fall of 1973, the hybrid Beta College had merged into a full four-year institution and named Beta State College, but was not fully state funded until 1977. One of the main goals for the 1974 academic year was to achieve accreditation from NCATE for teacher-education programs, which was accomplished by October of that year. By 1983, large portions of students were part of the teacher educations programs and Beta State College. The latest transformation for Beta State College came in 2005 when it became Beta State University. The education department continues the three-phase program to prepare its teachers and is still accredited by NCATE and approved by the state's Department of Elementary and Secondary Education (DESE).

Mathematics Department. As a junior college, mathematics courses offered was college algebra through calculus III and differential equations. As the junior college evolved into Beta College, the mathematics department expanded immensely to also include courses such as matrix theory, topics in geometry, statistics, vector analysis, probability, and complex variables. Based on the 1973 course catalog, the content expectation for secondary mathematics teachers included a sound knowledge of the content. Beta State College's Mathematics Department prided itself on providing mathematics students with the latest methods and resources to prepare its graduates for their intended career. The mathematics department offered courses such as methods in teaching mathematics in order to prepare its students to teach secondary math. In 1975 and 1983, the Mathematics Department at Beta State College served as the host for the state sections of the Mathematical Association of America. The mathematics department continues the expectation of deep content knowledge for teaching at the secondary level 
by requiring a Bachelor of Science Degree in Mathematics in conjunction with the education department's sequence of courses.

Education Department. Beta State College offered one-year certifications, associate degrees, and bachelor's degrees in various fields with or without certification in education. Through the years, as these certificates and degrees evolved and were modified based on enrollment and changing times, the Department of Education remained consistent. The education program consisted of a three-phase in-school model. Phase one would occur in the student's sophomore year with a limited experience with pupils and teachers. Phase two would occur in the junior year experiencing classroom activities and techniques. Lastly, phase three would occur in the senior year and include a comprehensive teaching experience. Beta State College was the first institution to use this method, which has since been widely adopted, by other institutions. The program also ignited the state's teacher-certification requirements to include pre-student teacher experiences.

\section{Organizational Analysis}

\section{Structural Frame}

According to Bolman and Deal (2013), the structural frame is the design of how an organization assigns roles, interactions, and the coordination of its operation, similar to Manning's (2013) explanation of labor organizations. Both Alpha and Beta Universities have similar structures by differentiations. Differentiation includes the distribution of tasks, organized by units of various characteristics, such as product, place, or process (Bolman \& Deal, 2013). Both Universities differentiate by the product of degree and the process of standards or courses necessary to meet the degree's 
requirements. However, integration, how to coordinate group efforts, is handled differently at each university. Integration is executed two ways: vertically and laterally (Bolman \& Deal, 2013). Vertical coordination is a top-down method of decisions, communication, and coordination (Bolman \& Deal, 2013). Lateral coordination, “...formal and informal meeting, task forces, coordinating roles..." (Bolman \& Deal, 2013, p. 54). Past deans of the Schools of Education at Alpha University have set a culture of collaboration and communication with the various schools in the College of Arts and Sciences (Alpha professor, personal communication, 2017). This culture has encouraged informal instructional collaboration and changes by the mathematics teachers (Alpha professor, personal communication, 2017). Whereas, the department chairs at Beta University meet formally and informally for student, curriculum, and implementation needs (Beta professor, personal communication, 2017). Therefore, the "...structural frame both enhances and constrains what an organization can accomplish" (Bolman \& Deal, 2013, p. 47).

\section{Alpha University}

Stemming from a Normal School beginning, the president of the school oversaw the teacher preparation program. As the school evolved as a state teaching school, state college, and university, so did its organizational structure. Even as a university, restructuring is a component of progress and budget balancing. By 1955, the Education Department was noted to be included within the College of Education. According to the 1996-1998 catalog revealed the College of Education changed to the College of Education and Human Services. However, the current restructure indicates the College of Education and Human Services has now become the School of Education. Meanwhile, 
since 1972, the Mathematics Department has remained within the College of Arts and Sciences.

The organizational charts from 2011 through 2015 show the provost's leadership council including both the Dean of College of Arts and Sciences and the Dean of the College of Education and Human Services. Therefore, providing the opportunity for Education and Mathematics to have a seat at the same table. However, the newest structure places the vice provost as the head of the various schools within the university, including the School of Education, and the Associate Provost of Undergraduate Studies and Dean, College of Arts and Sciences as the head of the various academic departments, including the Mathematics Department. They are two of the five members of the Associate Provost Council. Therefore, the seats at the table are representative of the Education and Mathematics Departments.

In 2016, Alpha University established a reorganization of its organization chart and academic affairs leadership. One of the driving forces behind the reorganization was their dedication to profession-based learning. This new structure was focused on integrating learning experiences through liberal and disciplinary studies. Another force was the addition of the vice provost to focus on student learning to help reach strategic goals. The current structure under the president consists of a provost, vice provost, associate provosts, deans, directors, and department chairs (Appendix E). However, this new structure separated the governing positions of the School of Education and the Department of Mathematics and Statistics. 


\section{Beta University}

Founded as part of the local school district, Beta University began under the direction of the district school board. Similarly, to Alpha University, Beta's structure has changed through the years following the progression of a junior college, state college, and university. In 1968, the Department of Education for Secondary and Elementary was imbedded in the Division of Education and Psychology. Meanwhile, the Department of Physics and Math was part of the Division of Liberal Arts and Sciences. By 1979, Education was part of the Education and Applied Sciences. Mathematical Sciences was within Liberal Arts and Sciences. Since 2010, the department is still known as the Department of Education inside the College of Professional Studies. Mathematical Sciences was renamed Computer Science, Math \& Physics and remained in the College of Liberal Arts and Sciences.

In 1968, the organizational chart shows the Education and Mathematic Departments under different divisions being led by directors under the Dean of Academic Affairs. However, in 1979, each department was led by their own dean under the guidance of the Vice President for Academic Affairs. Little adjustments in the overall structure continued. In 2009, Education and Mathematics Departments remained in different colleges each having their own dean. Each dean was part of the leadership team under the Provost and Vice President for Academic Affairs, who at this time in the structure had an Associate Vice President of Academic Affairs.

Presently, under the University President there is a provost, various vice presidents, associate provosts, deans, and chairs (Appendix F). In 2016, Beta University organizational chart and leadership of academic affairs went through another slight 
adjustment. The Associate Vice President of Academic Affairs was removed. However, this did not change the overall structure under the Provost and Vice-President for Academic Affairs. Direct reports still include the Dean of the College of Liberal Arts and Sciences and the Dean College of Professional Studies. Each of the departments within the colleges has their own department chair as part of the leadership team for each dean.

\section{Leadership Analysis}

A large number of studies have been conducted during the last 50 years to define a great leader (George, Sims, McLean, \& Mayer, 2007). Northouse (2016) and Helland and Winston (2005) define leadership as a process. Not only does leadership include what an effective leader does, it is an interactive process including the relationship component between leader and follower and what followers do in response to the leader's personality and actions (Helland \& Winston, 2005). Northouse (2016) claims leadership is a complex process to achieve a common goal. Secondary Mathematics Education degrees require the mathematics and education departments to work together toward a common goal to prepare and certify their pre-service teachers.

\section{Alpha University}

The leadership structure at Alpha University supports Northouse's (2016) pathgoal theory, which focuses on the process of collaborative work between education and mathematics professors toward profession-based learning of the common goal to develop prepared math teachers. "Path-goal theory provides direction about how leaders can help followers to accomplish their work in a satisfactory manner" (Northouse, 2016, p. 121). The leadership styles of this theory fluctuate between directive, supportive, participative, and achievement oriented based on the needs of the followers (Northouse, 2016). Alpha 
University's leadership through the Provost, Deans, and Department chairs uses directive leadership by ensuring the expectations and standards of the degree are met. Supportive and participating leadership is seen through the collaboration of the Deans, Department chairs, and teachers to develop and implement a competency based cross-departmental curriculum as opposed to course driven. Alpha University's leadership focuses on the achievement needs of their students by analyzing CAEP data, collaborate about its impact, and implement program adjustments. Lastly, teachers of the mathematics department have been challenged to incorporate discovery lessons in their courses displaying achievement-oriented leadership by "establishing a high standard of excellence for followers and seeks continuous improvement" (Northouse, 2016, p. 118).

\section{Beta University}

The leadership structure at Beta University includes both leader and manager. Kotter (2011) defined leadership as setting direction, aligning people, and providing motivation to cope with change. Yet Kotter (2011) defined management as planning and budgeting, organizing and staffing, and controlling and solving problems to bring order and predictability to a situation. Both systems are necessary for a successful organization (Kotter, 2011). The mathematics department chair provides leadership as a servant leader by acknowledging, investing, and cherishing the strengths of both mathematics and education colleagues without degrading others. A servant leader is defined as a person who chooses to serve first while acknowledging their desire to lead and focusing on the overall organization's purpose; they also remain attentive to and empower and develop their followers' capabilities (Northouse, 2016). Servant leadership also includes bringing equality to all stakeholders and "downplays competition in the organization and promotes 
egalitarianism" (Northouse, 2016, p. 239). The education department chair provides the management through the skills approach by using knowledge of the standards and expectations of the degree and the ability to choreograph the various components needed for the certification of teachers. Assessment data for Beta University is analyzed monthly for areas of weakness so that data drives program decisions. Northouse (2016) described that knowledge and abilities are skills needed for effective leadership. Also, the "leader's effectiveness depends on the leader's ability to solve complex organizational problems" (Northouse, 2016, p. 43).

\section{Transformative Leadership}

Goleman (2011) believes a great leader is distinguished from a good one by possessing emotional intelligence, "the ability to work with others and effectiveness in leading change" (p. 2). Therefore, an opportunity for change in secondary mathematics teacher preparation requires transformational leadership. Transformational leaders see the need for change; have and communicate the vision, and possess personal and problem-solving skills to implement change (Northouse, 2016). Transformational leaders inspire and help followers "to get them to transcend their own self-interests for the sake of others" (Northouse, 2016, p. 175). Transformational leadership provides a risk-free culture, which empowers employees to discuss and try new ideas (Northouse, 2016). The current leadership structure at both universities would require the deans and department chairs of the prospective departments to provide this type of leadership in order for the professors to feel inclined to change. 


\section{Implications for Research in the Practitioner Setting}

Researching current models of secondary math teacher preparation programs' incorporation of current standards, content, and pedagogical courses through qualitative research could provide the professors and/or leaders of the programs the insight and motivation to adjust or change the components of the program to meet the needs of novice teachers in a changing educational system. An adjustment or change in the program could result in an organizational structure change also. Since the mathematics and education departments are in two different colleges within the university, a restructure may be needed to provide the opportunity for collaboration and ingenuity in creating an updated program for the preparation of novice teachers. Also, since the universities are close in proximity, the organizational structure between them could change. Opening up collaboration between the universities to provide high-quality secondary mathematics teachers for the area. All participants in the program need to reflect upon its components and how they are implemented, not only to meet accreditation guidelines through their own standards and expectations, but to also keep up with the educational system's standards and expectations in which these teachers will be employed.

\section{Summary}

Although there is a longer standing history of teacher preparation at Alpha University, both university's education and mathematics departments have evolved and have offered secondary mathematics teacher preparation programs for a prolonged period. Through the progression from either a Normal school or a Junior College and all the reorganizations, the organizational structure of both universities is similar in leaving 
the mathematics and education departments segregated except for the leadership teams of the deans. Leadership and philosophy is where the two universities diverge. The various leadership types are necessary for accomplishing different outcomes. However, if the outcome is to change as education changes then transformational leadership may need to be considered. 


\section{SECTION THREE}

\section{SCHOLARLY REVIEW}

The United States is enduring a major shift from past generations of teachers (Levine, 2006). The focus as an industrial society was on achieving common processes whereas shifting to an informational society moves the focus to common outcomes (Cochran-Smith \& Villegas, 2015). This change "brought attention to the quality of education systems, and in particular to teachers" (Cochran-Smith \& Villegas, 2015, p. 9). Podolsky et. al. (2016) draw attention to the need for more teachers. Due to teacher shortages and new teachers not staying in the profession, student achievement and school improvement is under minded (Podolsky et. al., 2016). Meanwhile, Lasley et. al. (2006) focuses on the need for the preparation of high-quality teachers. Our teacher education programs are challenged to do both. Although, Scherer's (2012) interview with Linda Darling-Hammond quoted her saying, "we know that teachers who are fully prepared stay in teaching at much higher rates than those who lack key elements of preparation" (p. 18).

\section{Pedagogical Preparation}

Effective and high quality teacher preparation is important (Levine, 2006). NCATE (2010) defines effective teachers as those who understand the content knowledge and can apply strategies for student learning. Cochran-Smith and Villegase (2015) highlight the changing concept of teacher education from what teachers need to know to how do students learn. Shulman (1986) emphasized the need for teacher's to know the demands of their subject and engage in consistent practices. Teachers are no longer just transferring content; teachers are expected to engage students in problem- 
solving activities (Cochran-Smith \& Villegas, 2015). Therefore, "professional judgment and instructional decisions made on pedagogical grounds (Cochran-Smith \& Villegas, 2015, p. 10). Boyd et al. (2009) found that improving pedagogical preparation can be a part of teacher preparation. Both Hill et al. (2005) and Boyd et al. (2009) suggest increasing the coursework about methods of instruction would predict teacher effectiveness.

\section{Mathematics Preparation}

Since 1957, following the launch of Sputnik, the United States has focused attention and resources for improving mathematics education at all levels (Graham, Li, \& Buck, 2000). This led to an increased number of college-level mathematics courses required for all levels of mathematics teacher preparation (Graham et al., 2000). Graham et al., (2000) concludes, “The recommendations of the post-Sputnik era reflect a commitment to deep and broad content knowledge for mathematics teachers" (p. 8). However, there was a lack of attention given to pedagogical content knowledge (Graham et al., 2000). Graham \& Fennell (2001) focused on the potential to change mathematics teacher preparation programs to include not only content knowledge, but also pedagogical content knowledge based on the mathematics education community's agreement for the need of different types of knowledge. However, "Reaching consensus on the types of knowledge that research suggests are central to effective teaching is only the first step in determining what type of experiences should be included in effective mathematics teacher preparation programs" (Graham \& Fennell, 2001, p. 322).

While various studies have been conducted about mathematics teacher preparation most of the research thus far has focused on other aspects of secondary 
mathematics teacher preparation programs such as self-efficacy and hard work (Mostofo \& Zambo, 2015; Wasserman \& Ham, 2013) or research done by current university methods professors (Mostofo \& Zambo, 2015; Schmidt, Burroughs, Cogan, Houang, 2016). Limited research has been done on secondary mathematics teacher preparation from an outside researcher (Drake \& Heath, 2011; Merriam \& Tisdell, 2016) or considering perspectives from others involved in teacher preparation such as university mathematics education professors.

\section{Literature Review}

This literature review focuses the conceptual framework of change and three components of this topic: the standards forming the curriculum of the teacher preparation programs, the content knowledge, and pedagogical content knowledge needed to prepare secondary mathematics teachers. In the following sections the researcher will briefly discuss contrasting points of view of the literature in these areas, indicate any relevant gaps in each area that influences the research questions in this study, and connect each area to the conceptual framework of change.

\section{Change Theory}

Change was the conceptual framework for this study, educational change occurs in order to realign the institutions environment with current practices (Hanson, 2001). Hence, changes in practices and cultures are required to improve education (Corbo, Reinholz, Dancy, Deetz, \& Finkelstein, 2016). Personal change gives meaning to the teacher's work and allows for individual teacher transformation through projects and personal works (Hanson, 2001; Goodson, 2001). Therefore, change in practice and beliefs, second order change, can come from an individual's impact on an organization to 
change its thinking (Corbo et al., 2016; Goodson, 2001; Waks, 2007). Thus, changing the thinking of an organization resulting in a cultural change of beliefs and values (Corbo et al., 2016). However, change cannot only be going out of the schools, but also into the schools (Goodson, 2001). External forces, first order change, are necessary to rule actions of teachers and serve as a stimulus for change for policies and procedures (Corbo et al., 2016; Fullan, 1996; Hanson, 2001; Waks, 2007;).

Figure 1 Change Framework

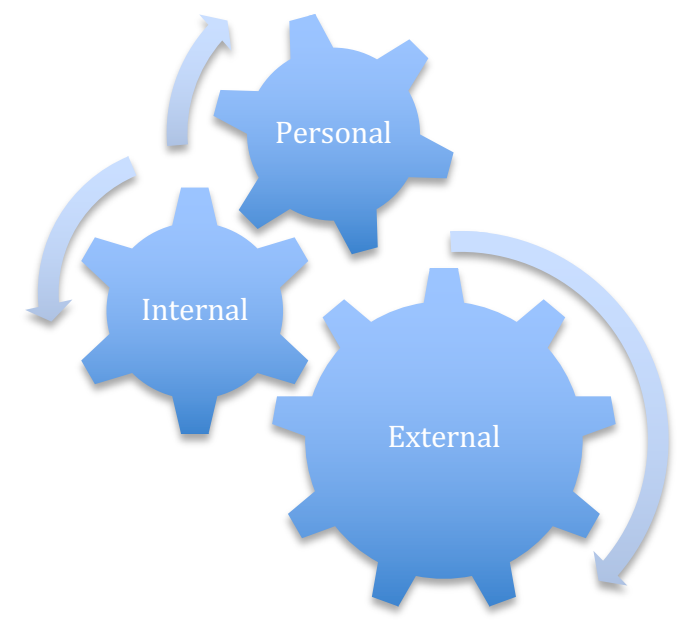

Figure 1. The three gears represent each force working for change. The gears themselves show the collaboration and cohesiveness needed to make change happen.

Educational change may be initiated by internal forces, such as educational groups, or from external forces, such as government agencies, or personal forces (Goodson, 2001). However, schools must have connections to external entities as well as internal collaboration (Fullan, 1996). Also, internal and external forces alone without the consideration of personal change in one's belief will hinder change (Goodson, 2001). Researchers Fullan (1996) and Waks (2007) urges the change process to not be linear, but more a complex process. Therefore, an interdependence of all three forces is necessary for change to be substantive (Goodson, 2001). These gears of change provide a 
framework for analyzing secondary mathematics teacher preparation programs in regards to standards, content knowledge, and pedagogical content knowledge.

\section{Standards Forming the Curriculum of the Preparation Program}

The history of secondary math teacher preparation programs begins in the 1800's as mathematics degree graduates lacking preparation in methods of teaching were assigned whatever subjects to teach (Graham, Li, \& Buck, 2000). By the early 1920's, high school mathematics teacher preparation included some courses of mathematics teaching through the school of education (Swafford, 1995). By the late 1950's, recommendations of mathematics concepts or courses along with a few mathematicsteaching experiences were produced by the National Council of Teachers of Mathematics (NCTM) and the Mathematical Association of America (MAA) (Graham et al., 2000). Following the launch of Sputnik in 1957, recommendations reflected "a commitment to deep and broad content knowledge for mathematics teachers" (Graham et al., 2000, p. 8). These proposals were the norm for mathematics teacher preparation until the early 1980's (Graham et al., 2000). A change in mathematics education was required to adjust to the increased access to information and technology (Graham et al., 2000). Math content and procedures were no longer sufficient (Graham et al., 2000). This prompted recommendations from NCTM's Agenda for Action (1980) in which one key component was for schools to make problem solving a focus for mathematics with similar advice given for teacher preparation (Graham et al., 2000). The guidance emphasized, "priority should be given to involving students in meaningful problem-solving activities...that teachers should use a diverse set of instructional strategies" (Graham et al., 2000, p. 8).

Grahman et at., (2000) explained the MAA, in 1991, acknowledged mathematical content 
knowledge as a foundation for mathematics teaching preparation, however, it should also include an education in mathematical pedagogy.

National Teacher Preparation Standards. In 2001, the Conference Board for Mathematical Sciences (CBMS) provided an opportunity for various national organizations to collaborate, prioritizing math education for teachers, and produced the document Mathematical Education of Teachers (MET) to improve mathematics education for teachers (CBMS, 2017). Recommendations of MET were updated in 2012, known as MET II, which included proficiency in math content and math knowledge for teaching (American Mathematical Society, 2012). Concurrently, NCTM's Council for the Accreditation of Educator Preparation (CAEP) updated the accreditation standards for math teacher preparation program reviews (Appendix G) for colleges and universities (NCTM-CAEP, 2012). Subsequently, the Association of Mathematics Teacher Educators (AMTE), based in part from MET II and NCTM-CAEP, recently released the Standards for Preparing Teachers of Mathematics (2017). The Standards for Preparing Teachers of Mathematics (2017) provides a national vision for the beginning preparation of math teachers. These standards are to guide improvement, influence policy, and promote dialogue and action for preparation of teachers of mathematics (AMTE, 2017).

The Standards for Preparing Teachers of Mathematics (2017) offered the standards (Appendix $\mathrm{H}$ ) to guide what beginning teachers of mathematics should know and be able to do to be well prepared. The four standards were (a) knowledge of mathematics for teaching, (b) pedagogical knowledge and practices for teaching mathematics, (c) students as learners of mathematics, and (d) social contexts of 
mathematics teaching and learning (AMTE, 2017). Each standard is then broken down into three to six indicators to provide further description of the standards (AMTE, 2017).

State Teacher Preparation Standards. In 2006, the state Department of Elementary and Secondary Education (DESE) provided the State Standards for Teacher Education Programs (SSTEP) as a benchmark for teacher preparation (DESE, 2006). However, the SSTEP were reorganized as the State Standards for the Preparation of Educators (SSPE) and effective in March of 2013 with full implementation expected by spring of 2017 (DESE, 2017). Within the SSPE, the first of the six program standards involve academic learning, such as general, content and pedagogical, of the beginning teacher (DESE. 2013a). Further explanation of this standard is identified in the State Educator Evaluation System (SEES), which identifies teacher growth (DESE, 2013b). The academic standard of the SSPE is broken down into five quality indicators in the SEES. The five indicators are 1) content knowledge and academic language, 2) student engagement in subject matter, 3) disciplinary research and inquiry methodologies, 4) interdisciplinary instruction and 5) diverse social and cultural perspectives (DESE, 2013b). For this particular review of literature, focus was given to the first and third standards (Appendix I), which focused on the mathematical content knowledge and pedagogical content knowledge.

These standards from organizations outside of teacher preparation programs served as a direction for well-prepared mathematics teachers, thus representing the regulative pillar (Hanson, 2001), evolutionary perspective (Corbo et al., 2016) or part of the external forces (Goodson, 2001) of the change conceptual framework. Furthermore, updating of the MET and NCTM-CAEP was first order change (Waks, 2007) by 
enhancing the existing documents while leaving the structure of mathematics teacher preparation unchanged. Thus, creating an environmental shift, "when one or more of the many organizations in an educational system's organizational field modifies some aspect of an expectation" (Hanson, 2001, p. 654). Environmental shifts are one force in the external environment that can bring about incremental change (Hanson, 2001).

\section{Content Knowledge}

Content knowledge as defined by NCTM-CAEP Standards (2012) is the ability to "demonstrate and apply knowledge of major math concepts, algorithms, procedures, connections, and applications within and among mathematical content domains" (p. 1). The point of teaching mathematics requires a deep mathematical knowledge and skill through rigorous mathematical courses for secondary mathematics teacher preparation is not debatable (Graham \& Fennell, 2001; Latterall, 2008; Schmidt et al., 2016; Thames \& Ball, 2010; Wasserman, 2013; Zuya, 2017). Mathematics teachers must know content and make use of it to help all students learn (Ball, 2000; Ball et al., 2008; Ball \& Forzani, 2009). So, "when teaches are comfortable with the content they are teaching they become more confident with designing effective lessons and teaching the content" (Wilburne \& Long, 2010, p. 3). Ball (2000) claims the ability to listen to students thinking and create learning experiences requires understanding the subject matter. Schmidt et al., (2016) claims a connection between a math teacher's perception of preparedness with the courses taken and what the teacher studied in their preparation program. Hill, Rowan, and Ball (2005) claimed teachers through subject matter majors or certifications to be considered highly qualified demonstrate competency in mathematics. Although, few studies have been conducted to determine the specific 
content knowledge that matter (Ball, et al., 2008). Also, Evans' (2011) findings contradict the need for mathematical content knowledge provided a teacher has high levels of teacher efficacy and positive attitudes toward mathematics.

Since the mid-1900's, four-year degree programs for prospective secondary math teachers included a core of mathematics courses (Graham \& Fennell, 2001). Researchers, such as Evans (2011) and Schmidt et al., (2016) indicted today's programs do not significantly differ from the former programs by expecting high school mathematics teachers have a major in mathematics or equivalent. Graham et al., (2000) concurs, "for prospective high school mathematics teachers, the completion of a full major in mathematics, or its equivalent, is typical" (p. 321). Whittington (2002) claimed high school math teachers were well prepared based on courses taken in college. NCTMCAEP Mathematics Content for Secondary (2012) includes guidelines for courses and competencies for secondary mathematics teachers (Appendix $\mathrm{J}$ ) in the following domains: Number and Quantity, Algebra, Geometry, Trigonometry, Statistics, Probability, Calculus, and Discrete Mathematics. Coursework is important in these content areas to provide teachers with a firm grasp of important content areas to help them guide their students' explorations and investigations (Whittington, 2002). However, researchers claim the subject matter of prospective secondary mathematics teachers is deficient in depth and understanding even though they have a major in mathematics (Bryan, 1999; Graham \& Fennell, 2001). Thames and Ball (2010) concur by indicating, "conventional content knowledge is insufficient for skillfully handling the mathematical tasks of teaching” (p. 221). However, researchers have not determined 
"how knowing math affects instruction" (Hill et al., 2005, p. 401) or supported the link between 'teachers' content knowledge to their students' learning” (Ball, 2000, p. 243).

Specialized Content Knowledge. Researchers refuted the need and use of math for mathematics educators is different from that of pure mathematicians or others (Ball \& Bass, 2000; Bryan 1999; Thames \& Ball, 2010). Since, “we realized that the capacity to see mathematical ideas from another's perspective and to understand what another person is doing involves mathematical reasoning and skill not needed for research mathematics" (Thames \& Ball, 2010, p. 222). The teachers' ability to learn, understand, think, and do is not sufficient, they must be able to enable others to do all these to help them learn (Ball \& Forzani, 2009). Knowing how to respond to students' thinking requires mathematics knowledge and conceptual understanding not typically taught in mathematics courses (Ball, 2000; Bryan 1999; Ma, 1999; Thames \& Ball, 2010; Wilburne \& Long, 2010). Ball et al., (2008) decided the demands of teaching will doubtfully be satisfied by just knowing more advanced math. Thames and Ball (2010) claimed, "effective teaching involves significant, specialized mathematical knowledge and skill” (p. 226). This specialized content knowledge is considered mathematical knowledge, not pedagogy (Hill et al., 2005). Although, most research has mainly focused on mathematical content knowledge for elementary teachers (Evans, 2011; Ma, 1999; Thames \& Ball, 2010) recent studies focused on mathematical content knowledge for prospective secondary teachers (Alvey, Hudson, Newton, \& Males, 2016; Zuya, 2017). The recommendation from the American Mathematical Society (2012) Conference Board of Mathematical Sciences required at least three courses from an advanced perspective that focused on secondary content. 
State and Universities' Content Knowledge. Based on the SSPE (2013b), a pre-service teacher must show evidence of a comprehensive knowledge of the curriculum. Quality indicator one of standard one of the SEES (2013a) expects a teacher to have mastery of the subject. In 2008, DESE revised the certification requirements for secondary education (Appendix K). Content knowledge, known as the subject matter knowledge, for secondary teachers required minimum total of 30 subject matter hours with 20 hours comprised of eight hours of Calculus and Analytical Geometry, three hours of Algebraic Structure, three hours of Geometry, three hours of Computer Science, and four from similar elective courses. The remaining course is a minimum of 10 hours from at least three areas of mathematics such as History of Mathematics, Structure of the Real Number System, Number Theory, Probability and Statistics, and Linear Algebra.

Both Alpha and Beta Universities require the secondary mathematics teacher preparation candidates to earn more than the required 30 hours from DESE. Alpha University's content requirements (Appendix L) include a total of 46 hours with a set 21 hours as a common foundation. Between the set 21 hours and the remaining 25 hours all components of DESE's 30 hours for subject matter for teachers are incorporated. Alpha University students are expected to take a course, Connections to Teaching Mathematics, geared toward specialized content knowledge. Meanwhile, Beta University requires 45 hours of content courses (Appendix M). Beta University also has a set 21 hours of specific mathematics requirements, although the courses themselves differ from the required 21 hours of mathematics courses at Alpha. The remaining 24 hours at Beta University are elective mathematics hours comprising the 45 total, however, a computerprogramming course is not listed. Nonetheless, both universities offer extensive 
mathematics content courses covering the domains recommended by the NCTM-CAEP Mathematics Content for Secondary (2012).

The undisputed need for content knowledge through the culture of traditional mathematics courses needed for secondary math teacher preparation within the mathematics community demonstrations the normative pillar (Hanson, 2001), cultural perspective (Corbo et al, 2016), or part of the internal forces (Goodson, 2001) of the change conceptual framework. Hanson (2001) identifies how educational groups using routines or accepted norms based on past analyses become a force for stability however they "can also be dynamic in pursuit of educational change" (p. 652). Internal educational experts initiate, promote, and define change within an external framework (Hanson, 2001). Therefore, the mathematics community's search for the types of mathematics course or degrees needed for secondary mathematics teachers brings about a type of second order change transforming familiar ways and is necessary in the change process (Waks, 2007).

\section{Pedagogical Content Knowledge}

In 1986, Shulman initiated pedagogical content knowledge (Graham \& Fennell, 2001). Shulman (1986) defined pedagogical content knowledge (PCK) as a dimension beyond content knowledge to content knowledge needed for teaching, such as an understanding of the difficulty of certain topics, representations of knowledge, and preconceptions of students. Similarly, Ball (2000) concurs with the need for content and pedagogical knowledge along with knowledge of the learner and of learning. NCTMCAEP Standards (2012) defined content pedagogy to include knowledge and interrelations of mathematics curriculum standards and use of multiple instructional 
strategies, such as technological tools, discourse, and real-world application. Ball et al., (2008) attributes the value of PCK as "a way to bridge between the academic world of disciplinary knowledge and the practice world of teaching" (p. 398). However, lacking in the definition of PCK is a balance, which in some cases is lopsided, between content knowledge and pedagogical knowledge needed for teaching to support student learning (Ball et al., 2008). Additionally, Hill et al., (2005) encouraged further analysis in "what knowledgeable teachers do in classrooms" (p. 401).

Mathematical Knowledge for Teaching. Knowledge for mathematical teaching is multidimensional, it requires more than understanding and doing mathematics (Ball et al., 2008; Ball \& Forzani, 2009). There is a necessity for mathematical understanding of the subject's curriculum to plan and instruct the math required to teach and insightful ways of representing mathematics to be understandable to students (Ball et al., 2008). Also, teachers need knowledge of strategies to reorganize misconceptions for the learners' understanding of mathematics (Shulman, 1986). Ball et al., (2008) stated being able to pinpoint the reason behind a mathematical error requires skillful teaching. Therefore, "effective pedagogy, practical tools, technology, and the ability to contextualize teaching are incredibly important" (Wasserman, 2013, p. 17). However, the lack of pedagogical content knowledge in mathematics courses for mathematics teachers inhibits teachers' ability on how to structure lessons to incorporate mathematical reasoning and limits their insight necessary to teaching math (Ball et al., 2008).

Mathematics teaching requires an amalgam of content knowledge and pedagogical content knowledge (Grahman \& Fennell, 2001; NCTM 2000; Shulman, 1986; Thames \& Ball, 2010). Shulman (1986) anticipated this mixture of content and 
process to take hold in teacher education programs. However, most institutions segregate content courses in mathematics departments from methods courses in education departments (Graham et al., 2000). Thus, teacher education is disjointed, fragmenting teaching by this gap between theory and practice (Ball, 2000). Therefore, "the challenge for teacher education is to forge this close relationship between the prospective teachers' deep understanding of mathematics, the mathematics instructional needs of children, and appropriate strategies for teaching" (Graham \& Fennell, 2001). Otherwise, the individual teacher is left to integrate mathematics knowledge and pedagogy in their teaching (Ball, 2000). Even though some teacher education programs require mathematics content and related pedagogy, definite requirements are not established to ensure they are appropriate and sufficient for the grade level to be taught (Graham \& Fennell, 2001). Although, Graham and Fennell (2001) acknowledge models expecting prospective teachers to make connections between different areas of mathematics, such as geometry and algebra, are being explored. Further connections are needed between degree seeking and school mathematics (Graham \& Fennell, 2001). Also, Latterell (2008) claims at some undergraduate institutions content course in mathematics are aligning to mathematics methods courses.

State and Universities' Pedagogical Content Knowledge. Pedagogical knowledge is also a component of SSPE (2013b). Having a strong content knowledge is necessary, but a pre-service teacher must also have the ability to teach so students can learn mathematics. Quality indicator three of standard one of the SEES (2013a), challenges teachers for continued research and use of various methodologies of teaching for student learning. The 2008 revised certification requirements for secondary education 
by DESE (Appendix K), indicates a minimum of eight hours of secondary methods and techniques. A portion of these hours includes Instructional Strategies for Secondary Teachers and Curriculum, Methods, and Techniques in the subject area specialty and additionally ten hours of clinical and field experiences.

Alpha University offers two three credit hour courses toward the pedagogical experiences for their pre-service teachers, Methods in Teaching with Technology and Methods in Secondary School Mathematics (Appendix L). Beta University offers one three credit hour methods course, Mathematics Teaching: Methods and Materials (Appendix M). Both universities require participation and experience in teaching mathematics in collaboration with secondary schools. The combination of courses for methods and techniques of teaching mathematics and teaching experiences encompasses the pedagogy definition from NCTM-CAEP Standards (2012).

The various definitions of pedagogical content knowledge are so broad it incorporates any combination of teacher knowledge, experience, and views (Ball et al., 2008). Therefore, representing the cognitive pillar (Hanson, 2001), social perspective (Corbo et al, 2016), or part of the personal forces (Goodson, 2001) of the change conceptual framework. Part of the change and reform movement is the importance of teachers' personal beliefs (Goodson, 2001). Spillane (2014) posed that pedagogical practices in the classroom are at the hands of teacher practice and belief. So, changing the teacher's work will lead to changing education (Goodson, 2001). Also, teaching strategies are based on personal judgment and classroom experiences (Hanson, 2001). A transformation of personal views and activities ignites change (Goodson, 2001). Corbo et al., (2016) claims the social cognition perspective "accounts for the complicated nature of 
human beings in the change process and the critical role of individual knowledge" (p. 010113-5). Also, "what individuals learn feed the collective knowledge base. Thus, knowledge is acquired and exchanged between the individual, group, and organizational levels" (Hanson, 2001, p. 658). Graham and Fennell (2001) claimed in order for this type of teacher learning to adapt, the structure of university programs need to change. This calls for interrelations between various departments at the universities representing second order change efforts (Corbo et al., 2016).

\section{Summary}

Ball and Forzani (2009) emphasize, "we need a reliable system that can begin with ordinary people willing to learn the practice of teaching and actually equip them to do the work effectively" (p. 498). Secondary mathematics teacher preparation programs are guided by external standards in which they are being certified. NCTM (2000) along with researchers (Graham et al., 2000; Graham \& Fennell, 2001) supported the need for mathematics content and mathematical content pedagogy. Teacher educators of mathematics must ensure pre-service teachers are competent with the math knowledge to teach math (Wilbourne \& Long, 2010). Internally, mathematics content knowledge is unanimously supported by research (Graham \& Fennell, 2001; Thames \& Ball, 2010), but the exact type of content is still being investigated (Ball \& Bass, 2000; Ball \& Forzani, 2009; Thames \& Ball, 2010). Pedagogical content knowledge is generally defined as a connection between the knowledge of math and the art of teaching it (Ball et al., 2008). This is left to teachers to determine (Ball, 2000) as part of their personal perspective or activity (Goodson, 2001). Similar to mathematics content knowledge, further research is necessary to pinpoint the specific amount to be taught (Ball et al., 
2008; Hill et al., 2005) and how universities should structure their departments (Graham et al., 2000) for pedagogical content knowledge. The relevance of this review is for policy makers and teacher educators in secondary teacher preparation by knowing which areas novice teachers need the most support to fine-tune their skills through experience and practice (Ball \& Forzani, 2009; Graham \& Fennell, 2001) by increasing "teacher quality through better preparation" (Evans, 2011, p. 26). 


\section{SECTION FOUR}

\section{CONTRIBUTION TO PRACTICE}

\section{Dissemination of Practitioner Contribution}

Dissemination for practitioner contribution is a presentation session at the Missouri Association of Colleges for Teacher Education (MACTE). MACTE is a state affiliate of the American Association of Colleges for Teacher Educations. The conference is in the Lake of the Ozarks, Missouri in October 2018. These presentations are 50 minutes in length.

\section{Type of Document}

Presenters develop a PowerPoint that provide a brief overview of their work and facilitate discussion with participants. The proposal should include a connection to one of the conference strands, objectives of the presentation, session description, opportunities of interactive participation and findings. The proposal is due approximately one month before the conference date.

\section{Rationale for this Contribution Type}

The primary goal of the Missouri Association of Colleges for Teacher Education is, based on evidence and professional consensus, to provide clear statements about educator preparation in areas such as standards and curriculum. Also, to strengthen and improve educator preparation programs for high quality learning for every child in Missouri.

\section{Outline of Proposed Contents}

Objectives:

Design of the Study: 
Research Questions:

Results:

Conclusions:

Implications:

References: 


\section{Practitioner Document}

ANALYSIS OF CONTENT AND PEDAGOGICAL CONTENT KNOWLEDGE IN SECONDARY MATHEMATICS TEACHERS' PREPARATION PROGRAMS: PERCEPTIONS OF NOVICE TEACHERS, COOPERATING TEACHERS, AND UNIVERSITY PROFESSORS

Power Point for Presentation

Missouri Association of Colleges for Teacher Education Conference in

Lake of the Ozarks, Missouri

October 2018

By Angela Dorsey 


\title{
ANALYSIS OF CONTENT AND PEDIGOGICAL CONTENT KNOWLEDGE IN SECONDARY MATHEMATICS TEACHERS' PREPARATION PROGRAMS: PERCEPTIONS OF NOVICE TEACHERS, COOPERATING TEACHERS, AND UNIVERSITY PROFESSORS
}

\author{
Angela K. Dorsey, \\ K-12 Curriculum Advisor, \\ St, Joseph School District
}

MACTE-Fall 2018

\section{Statement of the Problem}

$\checkmark$ Are universities' secondary mathematics teacher preparation program evolving with the times and preparing teachers for this latest reform of expectations?

$\checkmark$ Shift in math education has forced current math teachers to consider reforming their teaching practices, have secondary mathematics teacher preparation programs changed as well?

Notes: Teachers significantly influence the curriculum and strategies needed for students to learn (Cochran-Smith \& Villegas, 2015). Therefore, consideration needs to be given to whether former ways of teaching mathematics is being perpetuated by not changing the mathematics teacher preparation programs to teach math (Ball, Thames, \& Phelps, 2008). One shift of the CCSS for mathematics focuses on increased rigor in teaching mathematics by changing from merely concentrating on procedural skills and fluency to combining procedure with conceptual understanding (Core Standards. 2012. 2016). 


\section{Objectives}

- Provide qualitative case study research relative to two Universities Secondary Mathematics Teacher Preparation Programs.

- Provide an opportunity for discussion and dialogue focused on the path of Secondary Mathematics Teacher Preparation Programs.

\section{Purpose}

The researcher's purpose was to investigate novice teachers', university mathematics education professors', and cooperating teachers' perceptions of the secondary math education preparation programs from two Midwest state universities.

Notes: The focus of how to teach math has been debated from mastery of basic skills to encouraging more of a conceptual understanding of the math (National Research Council, 2010). Therefore, has secondary math teacher education preparation evolved with reform or remained stagnant in perpetuating the familiar way of teaching math? Since research is limited concerning novice teacher's, university professors', and cooperating teacher's perceptions of their preparation program, this study seeks "to uncover and interpret" (Merriam \& Tisdell, 2016, p. 25) how these groups characterize these preparation programs. The study considered the current state teacher preparation standards, math content required for teaching secondary math, and the inclusion of pedagogical content knowledge within the programs at two universities within the same state and region. 


\section{Conceptual Framework: Change Theory}

Change Framework

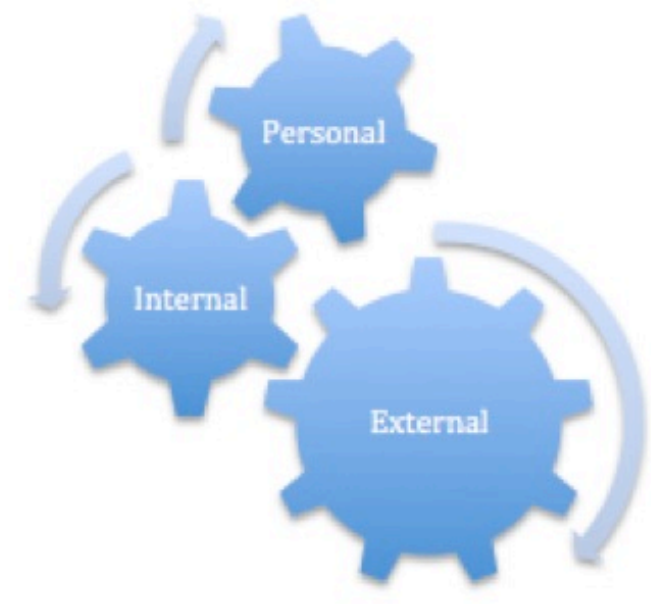

The three gears represent each force working for change.

The gears themselves show the collaboration and cohesiveness needed to make change happen.

Notes: The conceptual underpinning for this study is change theory as introduced in the early work of Goodson (2001) and Hanson (2001). In addition to Goodson's and Hanson's research, the change theory underpinning has continued to be examined by Fullan 2002 and Corbo (2016).

\section{Overarching Research Question}

This study is guided by the overarching research question, "How do secondary math teacher education programs at two Midwest universities prepare beginning math teachers for the classroom?" 


\section{Sub questions guiding the research}

- What are novice math teachers', cooperating teachers', and university professors' perceptions of the 9-12 mathematics teacher preparation standards at each university?

- What are novice math teachers', cooperating teachers', and university professors' perceptions of the mathematics content in the 9-12 mathematics teacher preparation program at each university?

- What are novice math teachers', cooperating teachers', and university professors' perceptions of the pedagogical content knowledge in the 9-12 mathematics teacher preparation program at each university?

- What are the novice teachers', cooperating teachers', and university professors' perceptions of preparedness for teaching mathematics?

- *How is Annual Performance Review data for mathematics teacher preparation used within each University? ( ${ }^{*}$ Note: Subquestion \#5 is for University Professors only.)

Notes: Sub questions provided guidelines for the researcher's inquiry during the interviews and focus group (Creswell, 2014).

\section{Design of the Study}

\section{- Setting}

\section{- Alpha and Beta Univeristies}

Notes: SETTING - Alpha and Beta Universities (pseudonyms) are state-funded, four-year universities located in the Midwest. Both universities offer various undergraduate and graduate programs with similar total student enrollment. Alpha University prides itself as providing experience for the profession whereas Beta University boasts its instruction is based on practice. Both universities offer Mathematics Education degrees. The number of students who have declared majors in mathematics with education at Beta University range from three to eight students per semester with an average of two graduating each year (Beta University, 2016). Alpha University has an enrollment and graduation average of four each year (Alpha University, 2016). 


\section{Design of the Study}

\section{- Participants:}

- Novice Teachers (BS in mathematics

or mathematics education with 1-6

years teaching experience)

- University Math Education Professors

- Cooperating Teachers

Notes: PARTICIPANTS - To engage participants and gain insight into understanding and discovering successes and challenges of secondary mathematics teacher preparation and increase validity, the researcher will use purposeful, non-random sampling (Creswell, 2014; Merriam \& Tisdell, 2016; Seidman, 2012).

\section{Design of the Study}

\section{- Data Collection:}

- Interviews

- Focus Groups

- Artifacts

Notes: DATA COLLECTION - These qualitative research methods of interviews, focus groups, and artifacts will provide a triangulation of data for analysis for increasing credibility and internal validity (Merriam \& Tisdell, 2016). However, to ensure internal validity, member check was used (Meriam \& Tisdell, 2016). 


\section{Data Analysis}

- The researcher determined which data "might be relevant to the study" (Merriam \& Tisdell, 2016, p. 229) as part of the process of open coding (Creswell, 2016; Merriam \& Tisdell, 2016).

- The researcher planned backwards according to Creswell (2016). The sub-questions of the research question were written on large pieces of paper. Data from artifacts, interviews and focus group transcripts will be organized under its suited question. An analysis of the information for each question determined the themes.

\section{Details of the Study}

- Limitation

- Delimitations

- Assumptions 


\section{Limitations}

- Two Universities - limited on transferability

- Highly Qualified - altered perceptions of preparedness

- Age and Ethnicity biases

- Novice teachers are employed - not considered people who did not stay in teaching

- Cooperating Teachers and University Professors guarded responses

\section{Delimitations}

- Sample space was restricted - Novice teachers 1-6 years experience from two specific Universities

- Varied perceptions based on school participation.

- Researcher's bias of being a current math teacher. 


\section{Assumptions}

- Merriam and Tisdell (2016) caution assumptions in qualitative research to be multi-dimensional and ever changing perceptions of reality. Therefore, to limit this assumption, novice teacher experience had bounds of one to six years.

- Expectation of honest response from all participants.

\section{Mathematics Teacher Preparation}

- Most of the research thus far has focused on other aspects of secondary mathematics teacher preparation programs such as self-efficacy and hard work (Mostofo \& Zambo, 2015; Wasserman \& Ham, 2013) or research done by current university methods professors (Mostofo \& Zambo, 2015; Schmidt, Burroughs, Cogan, Houang, 2016). Limited research has been done on secondary mathematics teacher preparation from an outside researcher (Drake \& Heath, 2011; Merriam \& Tisdell, 2016) or considering perspectives from others involved in teacher preparation such as university mathematics and mathematics education professors. 


\section{Scholarly Review - Standards}

- Recommendations for secondary mathematics teacher preparation programs prior to the beginning of the $21^{\text {st }}$ century expanded expectations for secondary mathematics teachers to incorporate knowing students as learners, mathematical pedagogy, along with mathematics content (Graham et al., 2000; Graham \& Fennel, 2001; NCTM 2000).

Notes: Beginning with the Mathematical Education of Teachers (CBMS, 2001) and National Council of Teachers of Mathematics-Council for the Accreditation of Educator Preparation (NCTM-CAEP, 2003) and continuing with both their updates in 2012, significant external changes have been made in teacher education (CBMS, 2017).

\section{Scholarly Review - Mathematics Content Knowledge}

- Research validates mathematical content knowledge is necessary for teaching mathematics (Graham \& Fennell, 2001; NCTM-CAEP, 2012; Thames \& Ball, 2010) especially for creating effective lessons and helping students learn (Ball, 2000; Wilburne \& Long, 2010).

Notes: The culture of preparing secondary mathematics teachers has focused on a major in mathematics (Evans, 2011; Graham et al., 2000; Schmidt et al., 2016). This philosophy, in part, is still promoted through NCTM-CAEP Mathematics Content for Secondary (2012), however, is also challenged by the lack of understanding prospective teachers have for the task of teaching (Thames \& Ball, 2010). Attention is given to analyzing the types of math content mathematics teachers need to teach math and for students to learn math (Ball \& Bass, 2000; Ball \& Forzani, 2009; Thames \& Ball, 2010). Internal change begins with a change formation from an educational group about new directions or demands (Goodson, 2001). 


\section{Scholarly Review - Pedagogical Content Knowledge}

- Pedagogical content knowledge is a specific type of mathematical knowledge, knowledge to be able to represent the content that is relevant to teaching (Ball et al., 2008; NCTM-CAEP, 2012; Shulman, 1986).

Notes: However, more research is necessary to define the exact content knowledge and the amount of pedagogical knowledge (Ball et al., 2008; Hill, Rowan, \& Ball, 2005). Methods and mathematics courses are isolated into different departments at the university level (Graham et al., 2000). Therefore, leaving the teacher to merge the gap between content and connected pedagogy (Ball, 2000). Allowing teachers to make their own resolutions about pedagogy (Goodson, 2001). However, these personal decisions and activities can flow outward into the internal and external levels for change (Goodson, 2001; Hanson, 2001).

\section{Key Findings}

- This study was implemented using twenty-two interviews of novice teachers, cooperating teachers, and mathematics education professors and a focus group of cooperating teachers held over a two-month period. The accounts were coded, analyzed, and triangulated with artifacts. The analysis revealed five themes related to the research question. These themes are: Knowledge of the Standards; Strong Content Knowledge; Foundation of Content Pedagogical Knowledge; Program Performance Review, and; Unexpected Outcomes: Relationships, Additional Experiences, and Connections. 


\section{Key Findings}

- Knowledge of the standards - while Mathematics Education Professors are well versed in the standards because courses are required to be aligned for accreditation and recognized as a teacher preparation course that knowledge is not disseminated to novice or cooperating teachers at either university.

- One novice teacher, participant F, from Alpha University stated, "I do remember what 'Alpha' required, but I do not know specifically what was required by the state."

- However, Participant I from Beta recalled, "I have seen them because I had to grade her on those standards, but I don't know them." Further reflection allowed Participant $\mathrm{J}$ from Beta to recall the community standard and felt it was difficult for a student teacher to do "in that short amount of time."

\section{Key Findings}

- Strong Content Knowledge - novice teachers, cooperating teachers, and math education professors at both universities overwhelmingly agreed there was evidence of strong content knowledge. However, novice teachers had a disconnection with the cooperating teachers and MEP with the purpose and value of the upper level courses for teaching high school.

- Participant B from Beta claimed, "Overall, I do think I had a good experience and a strong foundation in math."

- "I don't know how applicable everything that I went through and learned was to the courses that I'm now teaching," claimed Participant A (Beta).

- Participant Q (Alpha) stated, “They're going to be a lot more prepared to teach all math classes. (They will) see how content that they have in their upper courses, how that relates to middle or high school curriculum."

Notes:: This correlates to the artifacts SEES Standard 1.1 (Appendix I) and AMTE standard C-1 (Appendix H), which refers to a prepared teacher's math knowledge relative to the math they will teach. In contrast, Participant B (Beta) stated a value of the upper level course, "doing all the upper level stuff certainly builds that understanding of the content." This correlates to NCTMCAEP Standard 1 (Appendix G). 


\section{Key Findings}

- Foundation of Content Pedagogical Knowledge - Each category of participants agreed upon the indication of a strong content pedagogical foundation through the secondary mathematics teacher preparation programs at Alpha and Beta universities. Although, novice and cooperating teachers expressed the desires for increased pedagogical courses focusing on how students learn specific math concepts or method for specific math courses. Mathematics Education Professors at Alpha include technology and connections in their pedagogical courses. Meanwhile, Beta included real classroom experience.

Notes: Participant Q (Alpha) stated about the methods class, "They have their education classes and their math classes then they have these two...I try to bridge those two pieces together." This course aligns to the NCTM-NAEP Standards 4 and 5 on the use of technology for learning. "We're not using technology just to engage the students like in a fun way, but we're using it to teach something new," Participant Q (Alpha) stated about the technology course. "Well, when you put the connections to teaching math class, so that's a total of seven of math education hours" (Participant Q Alpha). This correlates to Alpha University Mathematics Education Requirements (Appendix L).

“So, I don't have enough pedagogical Math coursework. I feel like I let everybody in that I can, so I end up having people in who have not done any external experience out in schools to somebody who's already done their junior experience" (Participant M, Beta). However, students at Beta get more of a realworld experience in their one Methods course they do have in which Participant M (Beta) believes, "That was a great experience." 


\section{Key Findings}

- Foundation of Content Pedagogical Knowledge (cont.)

- "In both of those classes, they did a great job of focusing on the method of teaching secondary math....we talked about just different ways of teaching that same material and how different learners that we're going to have in our classroom" (Participant S, Alpha).

- "...There is not enough time spent on how to teach concepts, of what technique would work with this and what technique would work with this..."

- "I think that part is really valuable, not just knowing the math, but knowing what it means to teach it and, if you ask questions of students, what kind of answers should you be listening for."

Notes: A correlation was found with artifact SPTM Standard C2 (Appendix H).

\section{Key Findings}

- Foundation of Content Pedagogical Knowledge (cont.)

- Participant $Q$ (Alpha) stated about the methods class, "They have their education classes and their math classes then they have these two...I try to bridge those two pieces together." This course aligns to the NCTMNAEP Standards 4 and 5 on the use of technology for learning. "We're not using technology just to engage the students like in a fun way, but we're using it to teach something new," Participant Q (Alpha) stated about the technology course. "Well, when you put the connections to teaching math class, so that's a total of seven of math education hours" (Participant Q, Alpha). This correlates to Alpha University Mathematics Education Requirements (Appendix L).

"So, I don't have enough pedagogical Math coursework. I feel like I let everybody in that I can, so I end up having people in who have not done any external experience out in schools to somebody who's already done their junior experience" (Participant M, Beta). However, students at Beta get more of a real-world experience in their one Methods course they do have in which Participant M (Beta) believes, "That was a great experience." 


\section{Key Findings}

- Program Performance Review - Alpha has a system for an annual review, but Beta does not. However, both universities have an internal five-year cyclical review. Other areas, which instigate review, are externally when the state changes its guidelines or personally when professors want to discuss something different.

- "We have program outcomes, and we have certain classes that assess certain outcomes. Then we keep track of those through our Canvas, which is an online learning management system. At the end of the semester, if you teach a class that has one of the program outcomes, you put that in there and say did they meet that outcome or not. We can look at a student and see which outcomes have been met, or we can look at a program as a whole and say where are we doing well and what do we need to work on. We can also look at the 'State' Content Assessment” (Participant Q, Alpha).

- "We don't have enough people, so a lot of times, the data that we get is they can't tell anything because we have less than ten students who graduate and that doesn't help us" (Participant M, Beta).

Notes: This correlates to SSPE Program Standard 2, which refers to data to measure the performance of candidates and educator preparation programs.

\section{Key Findings}

\section{- Unexpected Outcomes}

- Relationships - Novice teachers from both universities recognized the importance of relationships with their mathematics education professor(s) in their secondary mathematics teacher preparation program.

\footnotetext{
- "...Being able to have a teacher who really knew the situation....and could help me a lot with that and always there to answer questions" (Participant C, Beta).

- Alpha's novice teacher also treasured the relationships they had with their colleagues. Participant G (Alpha) stated, "We were kind of a little cohort where we actually kind of worked together and helped each other."
}

Notes: This correlates to the SSPE Standard 1C, which refers to the need for relationships to foster learning. 


\section{Key Findings}

\section{- Unexpected Outcomes}

\section{- Additional Experiences}

- Alpha University novice teachers desired earlier and more realworld experiences within the secondary math teacher preparation program.

- "Find a way to get kids into a classroom before student teaching." (Participant U, Alpha)

- Novice teachers from Beta wanted more experience with other expectations of being a teacher.

- "More preparation on how to deal with different situations such as IEP's, 504's, those kinds of things" (Participant D, Beta).

Notes: These situations correlate to the SEES Standard 3.3.

\section{Key Findings}

\section{- Unexpected Outcomes}

- Additional Experiences (cont.) - Cooperating teachers from both Alpha and Beta universities desired more real-world experience with other expectations and various aspects of being a teacher.

- Participant W (Alpha) stated, "Students just need more exposure and more instruction on dealing with special education students." She continued, "I would say being able to differentiate a lesson either for more advanced students or for lower level students within a regular class setting."

- "I would say as far as the actual teaching aspect goes, more hours inside an actual classroom that you're going to teach and less in a lecture classroom would be what I would say would be ideal" (Participant N, Beta). 


\section{Key Findings}

\section{- Unexpected Outcomes}

- Connections - Mathematics education professors at both universities mentioned connections as part of their program.

- "I think our biggest focus is to help build connections so that they can hopefully build those connection with their students."

- , "One-on-one opportunities with faculty. We get to know each other very well. Other faculty members engage them in research-type activities....and they can see applications of that in the high school.... So, they are given opportunities to present their work to other people, which enhances their communication skills."

Notes: Building connections correlates to the course description artifact of the recently added connections course.

\section{Discussion}

- The overall perceptions of the research participants toward preparedness for teaching mathematics were positive and met the content and pedagogical criteria of the standards. This study aimed to collect perceptions from Novice Teachers, Cooperating Teachers, and Mathematics Education Professors about the components for secondary mathematics teacher preparation to provide insights into the successes and struggles of Alpha and Beta universities' secondary math teacher preparation programs to determine what adjustments or overhaul needs to be completed. In turn, this research opens the collaborative door between Alpha and Beta universities secondary math preparation programs to develop a culture of learning with common strategies for improvement (Fullan et al., 2005). Thus, supplying high quality secondary math teachers to the Midwest to meet the current high demand. 


\section{Discussion}

- The findings suggest (Standards):

- State Department of Secondary and Elementary Education (DESE) to make the standards easier to find on their website and the university professors provide these standards to the novice and cooperating teachers.

- Beta University increase collaboration between the Education and Mathematics Departments to incorporate program standards within the courses they have without creating more courses.

\section{Discussion}

- The findings suggest (Mathematics Content Knowledge):

- To include as part of the preparation program teacher candidate's tutoring for students in the lower lever college course through calculus I or having pre-service teachers volunteer at local high schools to assist math tutoring in classes.

- For both universities to consider reorganizing the required mathematics classes for secondary math teacher preparation, their purpose, and the number of hours required.

Note: Both Universities require at least 36 hours of mathematics coursework plus the education classes, which leaves no room for other coursework. Therefore, cross-referencing the course curriculum and the teacher preparation math standards could shed light on courses that can modify or merged to integrate content and pedagogy or eliminated to reduce the number of courses. 


\section{Discussion}

- The findings suggest (Pedagogical Content Knowledge):

- Both universities incorporate authentic ways for pre-service teachers to obtain real-world experiences or situations to meet this expectation.

- An option would be to collaborate with a local math teacher to obtain actual student work samples and have the pre-service teachers develop a lesson or strategy to move the student from their current knowledge to the lesson goal.

\section{Discussion}

\section{- The findings suggest (Program Performance Review):}

- Alpha incorporate a way in which qualitative data can be collected and analyzed as part of their program performance review.

- Beta University create and implement a way to gather specific data for their secondary mathematics teacher preparation program.

Note: One way would be to imbed the triangulation of feedback from novice teachers, cooperating teachers and University math education professors. 


\section{Discussion}

- The findings suggest (Unexpected Outcomes):

- Relationships - The culture of relationships be fostered and continued at both universities.

- Additional Experiences - Alpha University should re-evaluate their 30 hours of observation and Beta their participation I and II courses to include collaboration or co-teaching with teachers in the cooperating school to include focused learning in areas such as differentiation, IEPs, 504s, and classroom management.

Notes: Although, Beta does include authentic real-world experience in their participation courses, the scope of the experience needs to broaden to include various types of learners and situations.

\section{Discussion}

- The findings suggest (Unexpected Outcomes (cont.)):

- Connections - both universities not only teach how to reflect and make it a part of the pre-service teacher expectations, but also for the cooperating teacher to reflect upon the experience with the student teacher and the university.

Notes: Reflection was evident in both universities course descriptions of their methods courses. However, there was a disconnection with the higher education preparation courses since novice and cooperating teachers did not mention reflection in regards to being prepared to teach math. 


\section{Recommendations}

- The overarching question of this research was 'How do secondary math teacher education programs at two Midwest universities prepare beginning math teachers for the classroom?' Evidence supported Standards for Preparing Teachers of Mathematics from AMTE (2017), having a strong knowledge of mathematics and a foundation of pedagogical knowledge. Based on the perceptions of this studies participants, both universities, although the mathematics coursework varied, produced novice teachers with a strong content knowledge.

\section{Recommendations}

- Firstly, to prepare secondary math teachers for the current culture of mathematics education, content and pedagogical courses should not be separated. These courses are taught separately in the universities' programs, but as a secondary mathematics educator they are performed together. 


\section{Recommendations}

- Secondly, a push to increase program enrollment should be a priority. Two recommendations are given: 1) Alpha and Beta universities form a cohort and merge the best aspects of each of their secondary math teacher preparation programs and 2) work with legislatures, such as the State Board of Education or the Department of Elementary and Secondary Education, to change grade point average policy to encourage more pre-service teachers to stay in this career field.

Notes: "Legislators know what GPA means, and they understand GPA, but that doesn't mean that's the only thing that's valuable...They need a 3.0 in their math classes to be certified to teach math. If you get a C in calc I, you're swimming up stream.... think we're losing a lot of quality math teachers. I understand the goal is that you want them to understand math well, fine. But I don't know that a 3.0 means that they understand math well enough to teach it all the time, so I think we need our legislatures to learn that there are other metrics, not just GPA, that's important."

\section{Conclusion}

- Regardless of the use of pulleys or gears, the clock still keeps the same time. However, as time changes the culture and expectations of educational needs and desires, so too must the mechanics of secondary mathematics teacher preparation. Nevertheless, novice teachers of secondary mathematics need strong content and pedagogical knowledge. However, we now know these standards need to be embedded within the courses they take. Consequently, the external standards, the internal program design and the personal belief of math education professors all need to reflect this desire in order for this change to occur. 


\section{Acknowledgement}

- To my committee Co-Chairs, Dr. Edmonds and Dr. Wall, as well as committee members, Dr. Barnes-Gregory and Dr. Freeman, your knowledge, time, advice, and reassurance have been greatly appreciated. I feel honored to have your leadership and academic foundation for my future ventures. A special thank you to Dr. Edmonds for the perpetual time spent reading, reviewing, revising, reflecting, guiding, supporting, and encouraging my work. You have been the rock that kept my pace steady.

\section{References}

- Association of Mathematics Teacher Educators. (2017). Standards for preparing teachers of mathematics. Retrieved June 9, 2017 from https://amte.net/sites/default/files/ SPTM.pdf.

- Association of Public and Land-Grant Universities. (2011). The common core state standards and teacher preparation: The role of higher education. Retrieved on July 7, 2017 from http://www.aplu.org/projects-and-initiatives/stem-education/SMTI_Library/APLU-SMTI-Paper-2.

- Ball, D. L. (2000). Bridging practices intertwining content and pedagogy in teaching and learning to teach. Journal of Teacher Education, 51(3), 241-247. https://doi.org/ $10.1177 / 0022487100051003013$.

- Ball, D. L. \& Bass, H. (2000). Making believe: The collective construction of public mathematical knowledge in the elementary classroom. In D. C. Phillips (Ed.), Constructivism in education: Opinions and second opinions on controversial issues. Yearbook of the National Society for the Study of Education p. 193-224. Chicago: University of Chicago Press.

- Ball, D. L., \& Forzani, F. M. (2009). The work of teaching and the challenge for teacher education. Journal of Teacher Education, 60(5), 497-511. https://doi.org/10.1177/0022487109348479.

- Ball, D. L., Thames, M. H., \& Phelps, G. (2008). Content knowledge for teaching what makes it special? Journal of Teacher Education, 59(5), 389-407. https://doi.org/ 10.1177/0022487108324554.

- Cochran-Smith, M., \& Villegas, A. M. (2015). Framing teacher preparation research an overview of the field, part 1. Journal of Teacher Education, 66(1), 7-20. https://doi.org/10.1177/0022487114549072.

- Common Core State Standards Initiative. (2009). Development process. Retrieved July 6, 2017 from http://www.corestandards.org/about-the-standards/development-process/. 


\section{References}

- Conference Board of Mathematical Sciences. (2001). National summit on the mathematical education of teachers: Meeting the demand for high quality mathematics education in America. Retrieved June 3, 2017 from http://www.cbmsweb.org/archive//NationalSummit/summary_article.htm.

- Conference Board of Mathematical Sciences. (2017). The mathematical education of teachers. Retrieved June 3, 2017 from http://www.cbmsweb.org/the-mathematical-education-of-teachers/.

- Corbo, J. C., Reinholz, D. L., Dancy, M. H., Deetz, S., \& Finkelstein, N. (2016). Framework for transforming departmental culture to support educational innovation. Physical Review Physics Education Research, 12(1), 10113-1-10113-15.

- Core Standards. (n.d.). Frequently asked questions. Retrieved on July 7, 2017 from http:// www.corestandards.org/about-the-standards/frequently-asked-questions/.

- Core Standards (2012). Common core state standards. Retrieved on March 10, 2017 from http://www.corestandards.org/assets/CCSSI_Math\%20Standards.pdf.

- Core Standards (2016). Common core state standards key shifts in math. Retrieved on March 10, 2017 from http://www.corestandards.org/other-resources/key-shifts-in-mathematics/.

- Creswell, J. W. (2014). Research design: Quantitative, qualitative, and mixed methods approaches (4th ed.). Thousand Oaks, CA: Sage.

- Drake, P., \& Heath, L. (2011). Practitioner research at doctoral level developing coherent research methodologies. (First ed., pp. 46-58). London, New York: Routledge.

- Evans, B. R. (2011). Secondary mathematics teacher differences: Teacher quality and preparation in a new york city alternative certification program. Mathematics Educator, 20(2), 24-32.

\section{References}

- Fullan, M. (2002). The Change Leader. Educational Leadership, 59(8), 16-20.

- Fullan, M., Cuttress, C., \& Kilcher, A. (2005). Eight forces for leaders of change: Presence of the core concepts does not guarantee success, but their absence ensures failure. Journal of Staff Development, 26(4), 54-58.

- Goodson, I. F. (2001). Social histories of educational change. Journal of Educational Change, 2(1), 45-63. doi: 10.1023/A:1011508128957.

- Graham, K. J., \& Fennell, F. (2001). Principles and standards for school mathematics and teacher education: Preparing and empowering teachers. School Science and Mathematics, 101(6), 319-327. https://doi.org/10.1111/j.1949-8594.2001.tb17963.x.

- Graham, K. J., Li, Y., \& Buck, J. C., (2000). Characteristics of mathematics teacher preparation programs in the united states: An exploratory study. The Mathematics Educator, 5(1), 5-31.

- Hanson, M. (2001). Institutional theory and educational change. Educational Administration Quarterly, 37(5), 637-661. doi: 10.1177/00131610121969451.

- Hill, H. C., Rowan, B., \& Ball, D. L. (2005). Effects of teachers' mathematical knowledge for teaching on student achievement. American Educational Research Journal, 42(2), 371-406.

- Merriam, S. B., \& Tisdell, E. J. (2016). Qualitative research: A guide to design and implementation (4th ed.). San Francisco, CA: Joseey-Bass. 


\section{References}

- Mostofo, J., \& Zambo, R. (2015). Improving instruction in the mathematics methods classroom through action research. Educational Action Research, 23(4), 497-513. https://doi.org/10.1080/09650792.2015.1019903.

- National Council of Teachers of Mathematics. (2000). Principal and standards for school mathematics. Retrieved June 4, 2017 from http://www.nctm.org/Standards-and-Positions/Principles-and-Standards/Principles,-Standards,and-Expectations/.

- National Council of Teachers of Mathematics Council for the Accreditation of Educator Preparation. (2003). Standards for mathematics teacher preparation. Retrieved June 4, 2017 from http://www.nctm.org/Standards-and-Positions/CAEP-Standards/.

- National Council of Teachers of Mathematics Council for the Accreditation of Educator Preparation. (2012). Standards for mathematics teacher preparation. Retrieved June 4, 2017 from http://www.nctm.org/Standards-and-Positions/CAEP-Standards/.

- National Research Council. (2010). Preparing teachers: Buildingevidence for sound policy. Committee on the Study of Teacher Preparation Programs in the United States, Center for Education. Division of Behavioral and Social Sciences and Education. Washington, DC: The National Academies Press.

- Peressini, D., Borko, H., Romagnano, L., Knuth, E., \& Willis, C. (2004). A conceptual framework for learning to teach secondary mathematics: A situative perspective. Educational Studies in Mathematics, 56(1), 67-96.

- Schmidt, W. H., Burroughs, N. A., Cogan, L. S., \& Houang, R. T. (2016). The role of subject-matter content in teacher preparation: an international perspective for mathematics. Journal of Curriculum Studies, 0(0), 1-21 http://doi.org/10.1080/00220272.2016.1153153.

\section{References}

- Seidman, I. (2012). Interviewing as qualitative research: A guide for researchers in education and the social sciences (4th ed.). New York, NY: Teachers College Press.

- Shulman, L. S. (1986). Those Who Understand: Knowledge Growth in Teaching. Educational Researcher, 15(2), 4-14.

- Thames, M. H., \& Ball, D. L. (2010). What math knowledge does teaching require? Teaching Children Mathematics, 17(4), 220-229.

- Wasserman, N. H., \& Ham, E. (2013). Beginning teachers perspective on attributesfor teaching secondary mathematics: Reflections on teacher education. Mathematics Teacher Education and Development, 15(2), 23.

- Wilburne, J. M., \& Long, M. (2010). Secondary pre-service teachers' content knowledge for state assessments: Implications for mathematics education programs. Issues in the Undergraduate Mathematics Preparation of School Teachers, 1, 13.

- Zoest, L. R. V., \& Bohl, J. V. (2005). Mathematics teacher identity: A framework for understanding secondary school mathematics teachers' learning through practice. Teacher Development, 9(3), 315-345. https://doi.org/10.1080/1366453050020025. 


\section{Contact information}

- Dr. Angela K. Dorsey, K-12 Curriculum Advisor, St. Joseph School District

- Angela.dorsey@sjsd.k12.mo.us

- (816)262-7373 


\section{SECTION FIVE}

\section{CONTRIBUTION TO SCHOLARSHIP}

\section{Target Journal}

The target journal for publication is the Mathematics Teacher Educator, a biannual, peer reviewed journal for practitioners. This is the journal of the Association of Mathematics Teacher Educators published through the National Council of Teachers of Mathematics.

\section{Rationale for this Target}

The primary audience of the Mathematics Teacher Educators is practitioners in mathematics teacher education. This includes mathematics educators, mathematicians, teacher leaders, school district mathematics experts who contribute to the preparation and professional development of pre-K-12 pre-service and in-service teachers of mathematics. This journal is a practitioner journal dedicated to developing the knowledge base of mathematics teacher educators.

\section{Outline of Proposed Contents}

Based on Crespo's (2017) guided template, a 10-15 page article identifying a problem shared by Mathematics Teachers Educators. The article will also include: situating the problem in literature, description and argument for the innovation, details of the research on the innovation, evidence for claims, and new contribution to knowledge and practices of Mathematics Teacher Educators.

\section{Plan for Submission}

Who: Mathematics Teacher Educators

When: September, 2018 
How: Sandra Crespo, Editor

Mathematics Teacher Educators

National Council of Teachers of Mathematics

1906 Association Drive

Reston, VA 20191-1502

nctm@nctm.org 


\section{Submission-Ready Journal Article}

\section{ANALYSIS OF CONTENT AND PEDAGOGICAL CONTENT KNOWLEDGE IN SECONDARY MATHEMATICS TEACHERS' PREPARATION PROGRAMS: PERCEPTIONS OF NOVICE TEACHERS, COOPERATING TEACHERS, AND UNIVERSITY PROFESSORS}

Abstract: Previous research focused on characteristics of effective teachers, teacher recruitment or new pathways to teaching (Ball \& Forzani, 2009; Ronfeldt et. al., 2014). However, there is a gap in the research regarding the best path to prepare secondary math teachers. Universities create a customized path of preparation based on their beliefs within the scope of a set of standards given by organizations such as the National Council for Teachers of Mathematics or National Council for Accreditation of Teacher Education. Further research supports the necessity for both content and pedagogical knowledge (Ball, 2000; Graham \& Fennell, 2001; NCATE, 2010; Thames \& Ball, 2010). Therefore, the purpose of this qualitative case study pursues to increase the research by uncovering perceptions of secondary math teacher preparation with the standards, content knowledge, and content pedagogical knowledge. The study included two universities' programs to gain awareness as to the interpretations of novice teachers, cooperating teachers, and University professors of the pre-service training program used to prepare future secondary mathematics educators. The findings suggest: while only the Mathematics Education Professor at both Universities were the only study participants to have a vast knowledge of the standards it did not seem to impede on the overall preparation of the novice teacher. Novice and Cooperating teachers lacked the vision for the purpose and value of upper level math classes required for the degree. Both Novice and Cooperating Teachers wanted an increase in opportunities for real-world content pedagogical situations along with differentiation, coteaching, and Special Education. Novice teachers acknowledged the need for relationships with University professors and peers in their path toward preparation. Lastly, Mathematics Education Professors stated value in making connections between courses and research to high school math. Furthermore, the finding suggest for teacher preparation program: to prepare secondary math teachers for the current culture of mathematics education, content and pedagogical courses should not be separated and a push to increase program enrollment should be a priority.

Keywords: Teacher Preparation, Change Theory, Secondary Mathematics Teacher Preparation Standards, Content Knowledge, Pedagogical Content Knowledge

\section{Introduction}

Even though preparation for effective teachers is an implied goal, there are conflicting views between the different processes to achieve that goal (Lasley, Sidentop, \& Yinger, 2006). Variations and indecision still resides on the academic components of 
the program standards for teacher preparation (Whitford \& Villaume, 2014) and since the scope of a teacher's role to be effective has widened and deepened, "preservice teacher education, up to this point, has been ineffective in making an initial contribution to the start of the teacher's career" (Fullan, 1996, p. 498). Also, research is lacking on what characteristics are needed for an effective teacher preparation program (Ronfeldt et al., 2014). Therefore, would the different programs of two different universities both prepare their teachers to effectively educate students?

In 2010, the National Academy of Sciences conveyed the pursuit of preparing effective teachers for educating all students. An effective teacher has content knowledge, knowledge in the practice of teaching and knowledge of student learning and learning environment (NCATE, 2010). Research summarized by the National Council for Accreditation of Teacher Education (2010) indicated a direct relationship between teacher preparation and student achievement. Therefore, a strong teacher preparation impacts the effectiveness of the teachers, increases teachers' efficacy (Podolsky, Kini, Bishop \& Darling-Hammond, 2016; Ronfeldt, Schwartz, \& Jacob, 2014) and keeps teachers in the profession (Ronfeldt et al., 2014; Scherer, 2012).

Witford and Villaume (2014) reviewed the history of reform efforts of teacher preparation from the mid-1900's of an "approved program" determined by the faculty, to the adoption of the National Council for Accreditation of Teacher Education (NCATE, 2010) standards. Although, "the history of educational reform and innovation is replete with good ideas or policies that fail to get implemented or that are successful in one situation, but not in another" (Fullan, Cuttress \& Kilcher, 2005, p. 54). In 2006, Levine stated, "today, the teacher education curriculum is a confusing patchwork" (p. 26). 
NCATE (2010) concluded about 700 United States teacher preparation programs align with the NCATE standards and progress has been made within the last 30 years. More progress is essential, especially the inclusion of pedagogical approaches (NCATE, 2010).

Does our educational system run like clockwork to prepare our teachers to educate our students? Does it work like a mechanical clock?

Mechanical clocks tell time using two important parts: a mainspring and a pendulum. Instead of a mainspring, some mechanical clocks have weights that pull the gears at the right pace. As the mainspring unwinds, its energy turns gears, which cause the hands to move. The pendulum keeps time and ensures that the gears move at the right pace: second by second. (National Watch and Clock Museum, 2016, "How Does It Work," para. 2).

In the teacher preparation system, what makes up the mainspring, or weights, and pendulum and are they working together to ensure the correct pacing and time? The purpose of these national standards is to improve teacher education through collaboration with each State Department of Education and the institutions to assure the quality of teacher education programs (NCATE, 2010). These standards are the pendulum of a mechanical clock and are needed as an important part to certify consistency in effectively preparing secondary content teachers. The content and education courses within the degree certification act as the mainspring. These courses are also an important part for pre-service teachers to know their content and how to teach it. Similarly, instead of the mainspring, some clocks use weights and in comparison, universities have various ways of developing their education preparation programs. In the end, whether using mainsprings or weights, clocks need to keep the same time, as well as universities need to equally prepare teachers to be effective. 
Teachers significantly influence the curriculum and strategies needed for students to learn (Cochran-Smith \& Villegas, 2015). Therefore, consideration needs to be given to whether former ways of teaching mathematics is being perpetuated by not changing the mathematics teacher preparation programs to teach math (Ball, Thames, \& Phelps, 2008). Although prior to the implementation of the Common Core State Standards Initiative, Ball and Forzani (2009) claim the demands for preparing $21^{\text {st }}$ century youth emphasize “...collaborative work, integrated and problem-based curricula, and higher expectations for students" (p. 497). Thus, it is important for pre-service mathematics teacher programs to evolve with reforms such as the Common Core State Standards Initiative. However, are universities' secondary mathematics teacher preparation program evolving with the times and preparing teachers for this latest reform of expectations?

Since the launch of Sputnik in 1957, "motivation for teacher preparation" in the United States shifted to mathematics as a defense against a deficit in the technology race (Graham, Li, \& Buck, 2000). Mathematics education reform has been a topic of discussion for many years. It has continued to pose challenges for those involved in mathematics education in the United States (Peressini, Borko, Romagnano, Knuth, \& Willis, 2004; Zoest \& Bohl, 2005). Though, "most initiatives, however, have focused on teacher recruitment and retention and on developing new pathways to teaching" (Ball \& Forzani, 2009, p. 497). Furthermore, the Common Core State Standards Initiative (2009) had provided a spark to keep the discussion burning. The Common Core State Standards (CCSS) was a collaborative effort between local, state, and national organizations and institutions striving for effective mathematics education (APLU, 2011). They provided K-12 with a set of clear and consistent standards to ensure all students had competitive 
skills for college or the workplace (Core Standards, nd.). Therefore, teachers could collaborate around shared expectations for what mathematics students need to know and how they should know it. One shift of the CCSS for mathematics focused on increased rigor in teaching mathematics by changing from merely concentrating on procedural skills and fluency to combining procedure with conceptual understanding (Core Standards, 2012, 2016). However, as this shift in math education has forced current math teachers to consider reforming their teaching practices, have secondary mathematics teacher preparation programs changed as well?

\section{Standards Forming the Curriculum of the Preparation Program}

The history of secondary math teacher preparation programs begins in the 1800's as mathematics degree graduates lacking preparation in methods of teaching were assigned whatever subjects to teach (Graham, Li, \& Buck, 2000). By the early 1920's, high school mathematics teacher preparation included some courses of mathematics teaching through the school of education (Swafford, 1995). By the late 1950's, recommendations of mathematics concepts or courses along with a few mathematicsteaching experiences were produced by the National Council of Teachers of Mathematics (NCTM) and the Mathematical Association of America (MAA) (Graham et al., 2000). Following the launch of Sputnik in 1957, recommendations reflected "a commitment to deep and broad content knowledge for mathematics teachers" (Graham et al., 2000, p. 8). These proposals were the norm for mathematics teacher preparation until the early 1980's (Graham et al., 2000). A change in mathematics education was required to adjust to the increased access to information and technology (Graham et al., 2000). Math content and procedures were no longer sufficient (Graham et al., 2000). This prompted 
recommendations from NCTM's Agenda for Action (1980) in which one key component was for schools to make problem solving a focus for mathematics with similar advice given for teacher preparation (Graham et al., 2000). The guidance emphasized, "priority should be given to involving students in meaningful problem-solving activities...that teachers should use a diverse set of instructional strategies" (Graham et al., 2000, p. 8). Grahman et at., (2000) explained the MAA, in 1991, acknowledged mathematical content knowledge as a foundation for mathematics teaching preparation, however, it should also include an education in mathematical pedagogy.

National Teacher Preparation Standards. In 2001, the Conference Board for Mathematical Sciences (CBMS) provided an opportunity for various national organizations to collaborate, prioritizing math education for teachers, and produced the document Mathematical Education of Teachers (MET) to improve mathematics education for teachers (CBMS, 2017). Recommendations of MET were updated in 2012, known as MET II, which included proficiency in math content and math knowledge for teaching (American Mathematical Society, 2012). Concurrently, NCTM's Council for the Accreditation of Educator Preparation (CAEP) updated the accreditation standards for math teacher preparation program reviews (Appendix G) for colleges and universities (NCTM-CAEP, 2012). Subsequently, the Association of Mathematics Teacher Educators (AMTE), based in part from MET II and NCTM-CAEP, recently released the Standards for Preparing Teachers of Mathematics (2017). The Standards for Preparing Teachers of Mathematics (2017) provides a national vision for the beginning preparation of math teachers. These standards are to guide improvement, influence policy, and promote dialogue and action for preparation of teachers of mathematics (AMTE, 2017). 
The Standards for Preparing Teachers of Mathematics (2017) offered the standards (Appendix $\mathrm{H}$ ) to guide what beginning teachers of mathematics should know and be able to do to be well prepared. The four standards were (a) knowledge of mathematics for teaching, (b) pedagogical knowledge and practices for teaching mathematics, (c) students as learners of mathematics, and (d) social contexts of mathematics teaching and learning (AMTE, 2017). Each standard is then broken down into three to six indicators to provide further description of the standards (AMTE, 2017).

State Teacher Preparation Standards. In 2006, the state Department of Elementary and Secondary Education (DESE) provided the State Standards for Teacher Education Programs (SSTEP) as a benchmark for teacher preparation (DESE, 2006). However, the SSTEP were reorganized as the State Standards for the Preparation of Educators (SSPE) and effective in March of 2013 with full implementation expected by spring of 2017 (DESE, 2017). Within the SSPE, the first of the six program standards involve academic learning, such as general, content and pedagogical, of the beginning teacher (DESE. 2013a). Further explanation of this standard is identified in the State Educator Evaluation System (SEES), which identifies teacher growth (DESE, 2013b). The academic standard of the SSPE is broken down into five quality indicators in the SEES. The five indicators are 1) content knowledge and academic language, 2) student engagement in subject matter, 3) disciplinary research and inquiry methodologies, 4) interdisciplinary instruction and 5) diverse social and cultural perspectives (DESE, 2013b). For this particular review of literature, focus was given to the first and third standards (Appendix I), which focused on the mathematical content knowledge and pedagogical content knowledge. 
These standards from organizations outside of teacher preparation programs served as a direction for well-prepared mathematics teachers, thus representing the regulative pillar (Hanson, 2001), evolutionary perspective (Corbo et al., 2016) or part of the external forces (Goodson, 2001) of the change conceptual framework. Furthermore, updating of the MET and NCTM-CAEP was first order change (Waks, 2007) by enhancing the existing documents while leaving the structure of mathematics teacher preparation unchanged. Thus, creating an environmental shift, "when one or more of the many organizations in an educational system's organizational field modifies some aspect of an expectation" (Hanson, 2001, p. 654). Environmental shifts are one force in the external environment that can bring about incremental change (Hanson, 2001).

\section{Content Knowledge}

Content knowledge as defined by NCTM-CAEP Standards (2012) is the ability to "demonstrate and apply knowledge of major math concepts, algorithms, procedures, connections, and applications within and among mathematical content domains" (p. 1). The point of teaching mathematics requires a deep mathematical knowledge and skill through rigorous mathematical courses for secondary mathematics teacher preparation is not debatable (Graham \& Fennell, 2001; Latterall, 2008; Schmidt et al., 2016; Thames \& Ball, 2010; Wasserman, 2013; Zuya, 2017). Mathematics teachers must know content and make use of it to help all students learn (Ball, 2000; Ball et al., 2008; Ball \& Forzani, 2009). So, "when teaches are comfortable with the content they are teaching they become more confident with designing effective lessons and teaching the content" (Wilburne \& Long, 2010, p. 3). Ball (2000) claims the ability to listen to students thinking and create learning experiences requires understanding the subject matter. 
Schmidt et al., (2016) claims a connection between a math teacher's perception of preparedness with the courses taken and what the teacher studied in their preparation program. Hill, Rowan, and Ball (2005) claimed teachers through subject matter majors or certifications to be considered highly qualified demonstrate competency in mathematics. Although, few studies have been conducted to determine the specific content knowledge that matter (Ball, et al., 2008). Also, Evans' (2011) findings contradict the need for mathematical content knowledge provided a teacher has high levels of teacher efficacy and positive attitudes toward mathematics.

Since the mid-1900's, four-year degree programs for prospective secondary math teachers included a core of mathematics courses (Graham \& Fennell, 2001). Researchers, such as Evans (2011) and Schmidt et al., (2016) suggested today's programs do not significantly differ from the former programs by expecting high school mathematics teachers have a major in mathematics or equivalent. Graham et al., (2000) concurs, "for prospective high school mathematics teachers, the completion of a full major in mathematics, or its equivalent, is typical" (p. 321). Whittington (2002) claimed high school math teachers were well prepared based on courses taken in college. NCTMCAEP Mathematics Content for Secondary (2012) includes guidelines for courses and competencies for secondary mathematics teachers (Appendix J) in the following domains: Number and Quantity, Algebra, Geometry, Trigonometry, Statistics, Probability, Calculus, and Discrete Mathematics. Coursework is important in these content areas to provide teachers with a firm grasp of important content areas to help them guide their students' explorations and investigations (Whittington, 2002). However, researchers claim the subject matter of prospective secondary mathematics 
teachers is deficient in depth and understanding even though they have a major in mathematics (Bryan, 1999; Graham \& Fennell, 2001). Thames and Ball (2010) concur by indicating, "conventional content knowledge is insufficient for skillfully handling the mathematical tasks of teaching" (p. 221). However, researchers have not determined "how knowing math affects instruction" (Hill et al., 2005, p. 401) or supported the link between 'teachers' content knowledge to their students' learning” (Ball, 2000, p. 243).

Specialized Content Knowledge. Researchers refuted the need and use of math for mathematics educators is different from that of pure mathematicians or others (Ball \& Bass, 2000; Bryan 1999; Thames \& Ball, 2010). Since, "we realized that the capacity to see mathematical ideas from another's perspective and to understand what another person is doing involves mathematical reasoning and skill not needed for research mathematics" (Thames \& Ball, 2010, p. 222). The teachers' ability to learn, understand, think, and do is not sufficient, they must be able to enable others to do all these to help them learn (Ball \& Forzani, 2009). Knowing how to respond to students' thinking requires mathematics knowledge and conceptual understanding not typically taught in mathematics courses (Ball, 2000; Bryan 1999; Ma, 1999; Thames \& Ball, 2010; Wilburne \& Long, 2010). Ball et al., (2008) decided the demands of teaching will doubtfully be satisfied by just knowing more advanced math. Thames and Ball (2010) claimed, "effective teaching involves significant, specialized mathematical knowledge and skill” (p. 226). This specialized content knowledge is considered mathematical knowledge, not pedagogy (Hill et al., 2005). Although, most research has mainly focused on mathematical content knowledge for elementary teachers (Evans, 2011; Ma, 1999; Thames \& Ball, 2010) recent studies focused on mathematical content knowledge for prospective secondary 
teachers (Alvey, Hudson, Newton, \& Males, 2016; Zuya, 2017). The recommendation from the American Mathematical Society (2012) Conference Board of Mathematical Sciences required at least three courses from an advanced perspective that focused on secondary content.

State and Universities' Content Knowledge. Based on the SSPE (2013b), a pre-service teacher must show evidence of a comprehensive knowledge of the curriculum. Quality indicator one of standard one of the SEES (2013a) expects a teacher to have mastery of the subject. In 2008, DESE revised the certification requirements for secondary education (Appendix K). Content knowledge, known as the subject matter knowledge, for secondary teachers required minimum total of 30 subject matter hours with 20 hours comprised of eight hours of Calculus and Analytical Geometry, three hours of Algebraic Structure, three hours of Geometry, three hours of Computer Science, and four from similar elective courses. The remaining course is a minimum of 10 hours from at least three areas of mathematics such as History of Mathematics, Structure of the Real Number System, Number Theory, Probability and Statistics, and Linear Algebra.

Both Alpha and Beta Universities require the secondary mathematics teacher preparation candidates to earn more than the required 30 hours from DESE. Alpha University's content requirements (Appendix L) include a total of 46 hours with a set 21 hours as a common foundation. Between the set 21 hours and the remaining 25 hours all components of DESE's 30 hours for subject matter for teachers are incorporated. Alpha University students are expected to take a course, Connections to Teaching Mathematics, geared toward specialized content knowledge. Meanwhile, Beta University requires 45 hours of content courses (Appendix M). Beta University also has a set 21 hours of 
specific mathematics requirements, although the courses themselves differ from the required 21 hours of mathematics courses at Alpha. The remaining 24 hours at Beta University are elective mathematics hours comprising the 45 total, however, a computerprogramming course is not listed. Nonetheless, both universities offer extensive mathematics content courses covering the domains recommended by the NCTM-CAEP Mathematics Content for Secondary (2012).

The undisputed need for content knowledge through the culture of traditional mathematics courses needed for secondary math teacher preparation within the mathematics community demonstrations the normative pillar (Hanson, 2001), cultural perspective (Corbo et al, 2016), or part of the internal forces (Goodson, 2001) of the change conceptual framework. Hanson (2001) identifies how educational groups using routines or accepted norms based on past analyses become a force for stability however they "can also be dynamic in pursuit of educational change" (p. 652). Internal educational experts initiate, promote, and define change within an external framework (Hanson, 2001). Therefore, the mathematics community's search for the types of mathematics course or degrees needed for secondary mathematics teachers brings about a type of second order change transforming familiar ways and is necessary in the change process (Waks, 2007).

\section{Pedagogical Content Knowledge}

In 1986, Shulman introduced the concept of pedagogical content knowledge (Graham \& Fennell, 2001). Shulman (1986) defined pedagogical content knowledge (PCK) as a dimension beyond content knowledge to content knowledge needed for teaching, such as an understanding of the difficulty of certain topics, representations of 
knowledge, and preconceptions of students. Similarly, Ball (2000) concurs with the need for content and pedagogical knowledge along with knowledge of the learner and of learning. NCTM-CAEP Standards (2012) defined content pedagogy to include knowledge and interrelations of mathematics curriculum standards and use of multiple instructional strategies, such as technological tools, discourse, and real-world application. Ball et al., (2008) attributes the value of PCK as "a way to bridge between the academic world of disciplinary knowledge and the practice world of teaching" (p. 398). However, lacking in the definition of PCK is a balance, which in some cases is lopsided, between content knowledge and pedagogical knowledge needed for teaching to support student learning (Ball et al., 2008). Additionally, Hill et al., (2005) encouraged further analysis in "what knowledgeable teachers do in classrooms" (p. 401).

Mathematical Knowledge for Teaching. Knowledge for mathematical teaching is multidimensional, it requires more than understanding and doing mathematics (Ball et al., 2008; Ball \& Forzani, 2009). There is a necessity for mathematical understanding of the subject's curriculum to plan and instruct the math required to teach and insightful ways of representing mathematics to be understandable to students (Ball et al., 2008). Also, teachers need knowledge of strategies to reorganize misconceptions for the learners' understanding of mathematics (Shulman, 1986). Ball et al., (2008) stated being able to pinpoint the reason behind a mathematical error requires skillful teaching. Therefore, "effective pedagogy, practical tools, technology, and the ability to contextualize teaching are incredibly important" (Wasserman, 2013, p. 17). However, the lack of pedagogical content knowledge in mathematics courses for mathematics 
teachers inhibits teachers' ability on how to structure lessons to incorporate mathematical reasoning and limits their insight necessary to teaching math (Ball et al., 2008). Mathematics teaching requires an amalgam of content knowledge and pedagogical content knowledge (Grahman \& Fennell, 2001; NCTM 2000; Shulman, 1986; Thames \& Ball, 2010). Shulman (1986) anticipated this mixture of content and process to take hold in teacher education programs. However, most institutions segregate content courses in mathematics departments from methods courses in education departments (Graham et al., 2000). Thus, teacher education is disjointed, fragmenting teaching by this gap between theory and practice (Ball, 2000). Therefore, "the challenge for teacher education is to forge this close relationship between the prospective teachers' deep understanding of mathematics, the mathematics instructional needs of children, and appropriate strategies for teaching" (Graham \& Fennell, 2001). Otherwise, the individual teacher is left to integrate mathematics knowledge and pedagogy in their teaching (Ball, 2000). Even though some teacher education programs require mathematics content and related pedagogy, definite requirements are not established to ensure they are appropriate and sufficient for the grade level to be taught (Graham \& Fennell, 2001). Although, Graham and Fennell (2001) acknowledge models expecting prospective teachers to make connections between different areas of mathematics, such as geometry and algebra, are being explored. Further connections are needed between degree seeking and school mathematics (Graham \& Fennell, 2001). Also, Latterell (2008) claims at some undergraduate institutions' content course in mathematics are aligning to mathematics methods courses. 


\section{State and Universities' Pedagogical Content Knowledge. Pedagogical}

knowledge is also a component of the SSPE, which is the State Standards for Preparation of Educators (2013b). Having a strong content knowledge is necessary, but a pre-service teacher must also have the ability to teach so students can learn mathematics. Quality indicator three of standard one of the SEES (2013a), challenges teachers for continued research and use of various methodologies of teaching for student learning. The 2008 revised certification requirements for secondary education by DESE (Appendix K), indicates a minimum of eight hours of secondary methods and techniques. A portion of these hours includes Instructional Strategies for Secondary Teachers and Curriculum, Methods, and Techniques in the subject area specialty and additionally ten hours of clinical and field experiences.

Alpha University offers two three credit hour courses toward the pedagogical experiences for their pre-service teachers, Methods in Teaching with Technology and Methods in Secondary School Mathematics (Appendix L). Beta University offers one three credit hour methods course, Mathematics Teaching: Methods and Materials (Appendix M). Both universities require participation and experience in teaching mathematics in collaboration with secondary schools. The combination of courses for methods and techniques of teaching mathematics and teaching experiences encompasses the pedagogy definition from NCTM-CAEP Standards (2012).

The various definitions of pedagogical content knowledge are so broad they incorporate any combination of teacher knowledge, experience, and views (Ball et al., 2008). Therefore, representing the cognitive pillar (Hanson, 2001), social perspective (Corbo et al, 2016), or part of the personal forces (Goodson, 2001) of the change 
conceptual framework. Part of the change and reform movement is the importance of teachers' personal beliefs (Goodson, 2001). Spillane (2014) posed that pedagogical practices in the classroom are at the hands of teacher practice and belief. So, changing the teacher's work will lead to changing education (Goodson, 2001). Also, teaching strategies are based on personal judgment and classroom experiences (Hanson, 2001). A transformation of personal views and activities ignites change (Goodson, 2001). Corbo et al., (2016) claims the social cognition perspective "accounts for the complicated nature of human beings in the change process and the critical role of individual knowledge" ( $\mathrm{p}$. 010113-5). Also, "what individuals learn feed the collective knowledge base. Thus, knowledge is acquired and exchanged between the individual, group, and organizational levels" (Hanson, 2001, p. 658). Graham and Fennell (2001) claimed in order for this type of teacher learning to adapt, the structure of university programs need to change. This calls for interrelations between various departments at the universities representing second order change efforts (Corbo et al., 2016).

\section{Change Theory}

Change was the conceptual framework for this study, educational change occurs in order to realign the institutions environment with current practices (Hanson, 2001). Hence, changes in practices and cultures are required to improve education (Corbo, Reinholz, Dancy, Deetz, \& Finkelstein, 2016). Personal change gives meaning to the teacher's work and allows for individual teacher transformation through projects and personal works (Hanson, 2001; Goodson, 2001). Therefore, change in practice and beliefs, second order change, can come from an individual's impact on an organization to change its thinking (Corbo et al., 2016; Goodson, 2001; Waks, 2007). Thus, changing 
the thinking of an organization resulting in a cultural change of beliefs and values (Corbo et al., 2016). However, change cannot only be going out of the schools, but also into the schools (Goodson, 2001). External forces, first order change, are necessary to rule actions of teachers and serve as a stimulus for change for policies and procedures (Corbo et al., 2016; Fullan, 1996; Hanson, 2001; Waks, 2007;).

Figure 1 Change Framework

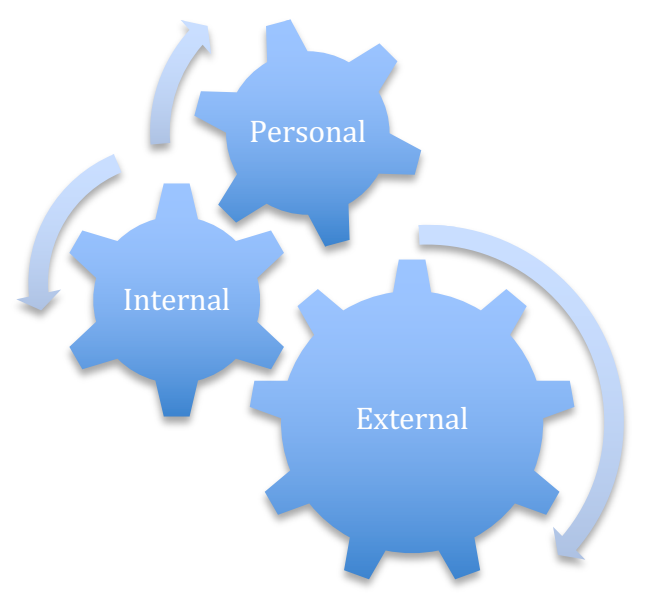

Figure 1. The three gears represent each force working for change. The gears themselves show the collaboration and cohesiveness needed to make change happen.

Educational change may be initiated by internal forces, such as educational groups, or from external forces, such as government agencies, or personal forces (Goodson, 2001). However, schools must have connections to external entities as well as internal collaboration (Fullan, 1996). Also, internal and external forces alone without the consideration of personal change in one's belief will hinder change (Goodson, 2001). Researchers Fullan (1996) and Waks (2007) urges the change process to not be linear, but more a complex process. Therefore, an interdependence of all three forces is necessary for change to be substantive (Goodson, 2001). These gears of change provide a 
framework for analyzing secondary mathematics teacher preparation programs in regards to standards, content knowledge, and pedagogical content knowledge.

\section{Purpose of the Study and Research Questions}

The researcher's purpose was to investigate novice teachers', university mathematics education professors', and cooperating teachers' perceptions of the secondary math education preparation programs from two Midwest state universities. The focus of how to teach math has been debated from mastery of basic skills to encouraging more of a conceptual understanding of the math (National Research Council, 2010). Therefore, has secondary math teacher education preparation evolved with reform or remain stagnant in perpetuating the familiar way of teaching math? Since research is limited concerning novice teacher's, university professors', and cooperating teacher's perceptions of their preparation program, this study sought "to uncover and interpret" (Merriam \& Tisdell, 2016, p. 25) how these groups characterized these preparation programs. The study considered the current state teacher preparation standards, math content required for teaching secondary math, and the inclusion of pedagogical content knowledge within the programs at two universities within the same state and region.

This study was guided by the overarching research question, "How do secondary math teacher education programs at two Midwest universities prepare beginning math teachers for the classroom?" Consequently, sub questions derived from the research question included the following:

1. What are novice math teachers', cooperating teachers', and university professors' perceptions of the implementation of the 9-12 mathematics teacher preparation standards at each university? 
2. What are novice math teachers', cooperating teachers', and university professors' perceptions of the content in the 9-12 mathematics teacher preparation program at each university?

3. What are novice math teachers', cooperating teachers', and university professors' perceptions of the pedagogical content knowledge in the 9-12 mathematics teacher preparation program at each university?

4. What are the novice teachers', cooperating teachers', and university professors' perceptions of preparedness for teaching mathematics?

5. *How is Annual Performance Review data for mathematics teacher preparation used within each University? (*Note: Subquestion \#5 is for University Professors only.)

\section{Design of the Study}

This study was developed to provide two Midwest United States universities with insights about the successes and challenges of their secondary math teacher preparation programs. However, ultimately the results enhanced the conversation about change in education preparation by understanding the experiences of secondary math teachers involved in the universities' teacher preparation programs. This study "aims to critique existing conditions and through that critique bring about change" (Patton, 2015, p. 692).

Through a social constructivist philosophy, the researcher conducted qualitative research to "understand how people interpret their experiences, how they construct their worlds, and what meaning they attribute to their experiences" (Merriam \& Tisdell, 2016, p. 6). Social constructivists beliefs are formed through human interactions and are based upon on the participants' views of the understanding the situation (Creswell, 2014). The 
qualitative research used was a case study, an "in-depth description and analysis of a bounded system" (Merriam \& Tisdell, 2016, p. 37). Case studies are considered bounded provided the number of participants or the time frame of the study is limited (Merriam \& Tisdell, 2016).

\section{Setting}

Alpha and Beta Universities (pseudonyms) are partially state-funded, four-year universities located in the Midwest. Both universities offer various undergraduate and graduate programs with similar total student enrollment. Alpha University prides itself as providing experience for the profession whereas Beta University boasts its instruction is based on practice. Alpha University offers a Secondary Mathematics Education degree whereas Beta University offers a Mathematics degree with a Certification for Secondary Education. The number of students who have declared majors in mathematics with education at Beta University range from three to eight students per semester with an average of two graduating each year (Beta University, 2016). Alpha University has an enrollment and graduation average of four each year (Alpha University, 2016).

\section{Participants}

Secondary math teacher preparation programs have various participants regardless of the institution being examined. For the purpose of this study, participants included graduate teachers from the two Midwest Universities who have been teaching mathematics with one to six years teaching experience, their cooperating teachers and university professors of math education from each university. To engage participants and gain insight into understanding and discovering successes and challenges of secondary mathematics teacher preparation and increase validity, the researcher used 
purposeful, non-random sampling (Creswell, 2014; Merriam \& Tisdell, 2016; Seidman, 2012).

\section{Data Collection}

The researcher used diverse qualitative research methods; interviews, focus groups, and artifacts. These methods assisted the researcher to "uncover meaning, develop understanding and discover insights relevant to the research problem" (Merriam \& Tisdell, 2016, p. 106). The overarching focus of the study was perceptions of secondary math teacher preparation programs; therefore, interviews of novice teachers, cooperating teachers and university professors will be used to understand "the lived experience ... and the meaning they make of that experience" (Seidman, 2013, p. 9). Interviews will be face-to-face, by email, or by phone. Focus groups of cooperating teachers and university professors are another way to discover perceptions and the rational about issues (Krueger \& Casey, 2015). Other qualitative research data such as the state standards for teacher preparation; the state standards for secondary math certification, and both universities programs of study for secondary math education were used as artifacts. Artifacts provide a stable and objective document (Merriam \& Tisdell, 2016). These qualitative research methods of interviews, focus groups, and artifacts provided a triangulation of data for analysis for increasing credibility and internal validity (Merriam \& Tisdell, 2016).

Interviews. Seidman (2013) encourages interviewing as a form of inquiry for data collection. The researcher was interested in the stories of individual novice teachers. Therefore, open-ended, guided questions (Appendix A) were used to understand the experiences. Novice teacher participants from both institutions were identified through 
communication and collaboration with both universities' Institutional Research Departments or Mathematics Departments. Initial contact was made through an email or letter (Appendix B). The email and letter explained the researcher's study, its purpose, and requested a 30-minute interview. If needed, the researcher used a follow-up phone call protocol (Appendix C) to further explain the study and secure an interview. Then, a confirmation email was sent to determine a location convenient for the interviewee and informed them the interview will be recorded therefore requesting consent by the attached form (Appendix D). Interviewing, "affirms the importance of the individual without denigrating the possibility of community and collaboration" (Seidman, 2013, p. 13). Interviews were conducted until saturation or new insights are not reached (Creswell, 2014). The interaction of the interviewer and the researcher may have had biases or predispositions that could have affected the data collected (Meriam \& Tisdell, 2016). However, to ensure internal validity, member check was used (Meriam \& Tisdell, 2016).

Focus Groups. Hennink (2014) explained, "during the group discussion participants share their views, hear the views of others, and perhaps refine their own views in light of what they have heard" (as cited by Merriam \& Tisdell, 2016, p. 114). Therefore, using focus groups will provide insight or understanding the researcher would not have had using only one-on-one interviews. Focus groups will be used as opposed to individual interviews when possible to allow collaboration and communication. Krueger and Casey (2015) recommend purposeful, random sampling in order to select members from prospective participants. Initial emails (Appendix B) were sent explaining the researcher's study, its purpose, and a request for a 30-minute focus group. If needed, the 
researcher used a follow-up phone call protocol (Appendix C) to further explain the study and secure participation in the focus group. Subsequent emails confirmed a convenient date and location for all participants. The researcher noted, it is important for the researcher to listen for understanding and ask questions for clarification not to take the discussion on a tangent (Lawrence \& Paige, 2016).

Artifacts. Documents and artifacts provided insights pertaining to the research question (Merriam \& Tisdell, 2016). For the purpose of this study, the researcher used documents and artifacts from each University: four year plan of courses for Secondary Mathematics program, major declaration forms, course syllabi from methods courses. The following State documents and artifacts were also used: DESE's Educator Preparation form for mathematics (grades 9-12), Standards for the Preparation of Educators, and Educator Evaluation System Standards. However, Merriam \& Tisdell (2016) caution, “documents generally are not produced for research purposes” (p. 181) and the researcher used these as a primary data sources to help build the categories of the qualitative study.

\section{Data Analysis}

The researcher's purpose was to "collect and analyze multiple forms of data in a systematic way" (Merriam \& Tisdell, 2016, p. 52). Therefore, the researcher reviewed documents and transcriptions of the data from the interviews and focus groups and began analyzing it by marking possible category code titles in the right margins. The researcher then determined which data "might be relevant to the study" (Merriam \& Tisdell, 2016, p. 229) as part of the process of open coding (Creswell, 2016; Merriam \& Tisdell, 2016). The researcher planned backwards according to Creswell (2016). The sub-questions of 
the research question were written on large pieces of paper. Data from artifacts, interviews and focus group transcripts were organized under its suited question. An analysis of the information for each question determined the themes. This open coding process showed how "multiple sources of data helps build the codes, and in turn, the evidence for the theme[s]" (Creswell, 2016, p. 157).

\section{Findings}

This study was implemented using twenty-two interviews of novice teachers, cooperating teachers, and mathematics education professors and a focus group of cooperating teachers held over a two-month period. The accounts were coded, analyzed, and triangulated with artifacts. The analysis revealed five themes related to the research question. These themes are: Knowledge of the Standards; Strong Content Knowledge; Foundation of Content Pedagogical Knowledge; Program Performance Review, and; Unexpected Outcomes: Relationships, Additional Experiences, and Connections.

\section{Knowledge of the Standards}

Novice teachers. Ten out of twelve Bachelor of Science in Mathematics or Mathematics Education teachers with one to six years of teaching experience from both universities had little to no knowledge of the standards, however, they were aware standards existed mainly in the context of the degree requirements at their institutions. One novice teacher, participant F, from Alpha University stated, "I do remember what 'Alpha' required, but I do not know specifically what was required by the state." Participant G from Alpha and Participant $\mathrm{C}$ from Beta both recalled the standards requiring "a class related to teaching." Participant E from Beta University indicated, 
"Student growth needed to be connected to learning objectives" which correlates to SSPE standard 4 for candidates "to become practitioners they must connect to student growth."

Cooperating teachers. Similarly, the cooperating teachers for both universities had little knowledge of the standards. Participant H from Alpha stated, "Even when I had a student teacher, I don't recall anyone saying, 'hey, here is what you should expect from your student teacher." However, Participant I from Beta recalled, "I have seen them because I had to grade her on those standards, but I don't know them." Further reflection allowed Participant $\mathrm{J}$ from Beta to recall the community standard and felt it was difficult for a student teacher to do "in that short amount of time." Participant K from Beta concurred, since student teachers "don't have that many opportunities."

Mathematics education professors. Contrary to the novice and cooperating teachers, Mathematics Education Professors (MEP) have an in-depth, working knowledge of the standards. A MEP from Alpha University focused on the use of the State Educator Evaluation System (SEES) in regards to the "use of these standards to observe students doing microteaching" and the "consistency from the pre-service teacher preparation to the in-service teacher evaluation" which correlates to the course syllabus for Alpha's methods course and to Appendix I, a quality indicator of the SEES. Beta's MEP focused on their program standards expectations based on the state's additional requirements, "now their professional sequence is 36 hours, when I started it was $27 \ldots$. Education will create new courses rather than take a look at the ones they have and maybe they can tweak." This is reflected in Appendix M, Beta University Teacher Education in Mathematics Requirements. 
In summary, while MEP are well versed in the standards because courses are required to be aligned for accreditation and recognized as a teacher preparation course that knowledge is not disseminated to novice or cooperating teachers at either university.

\section{Strong Content Knowledge}

Novice teachers. Novice Teachers from both universities felt they had strong content knowledge. Participant N from Alpha acknowledged, "it (math courses) was pretty rigorous and really expanded my knowledge of the math.” Meanwhile, Participant B from Beta claimed, "Overall, I do think I had a good experience and a strong foundation in math." However, they questioned the quantity and the need for the upper level math courses and did not feel they prepared them for the courses they would be teaching. Participant C (Beta) noted, "I think that it definitely was above and beyond what I think I probably use most of the time.” Participant F (Alpha) stated, "I just don't know that it (upper level courses) is necessarily needed." "I don't know how applicable everything that I went through and learned was to the courses that I'm now teaching," claimed Participant A (Beta). This correlates to the artifacts SEES Standard 1.1 (Appendix I) and AMTE standard C-1 (Appendix H), which refers to a prepared teacher's math knowledge relative to the math they will teach. In contrast, Participant B (Beta) stated a value of the upper level course, "doing all the upper level stuff certainly builds that understanding of the content." This correlates to NCTM-CAEP Standard 1 (Appendix G).

Cooperating teachers. At both universities, cooperating teachers interviewed felt their student teachers had strong content knowledge and valued the need for upper level math courses. Participant J (Beta) claimed, "Content wise, she (the novice teacher) was 
very strong." Alpha's Participant $\mathrm{O}$ in referring to the value of upper level math courses acknowledged, "you truly know and love the intricacies of math and understanding of how all the different concepts in math play on each other." Participant T (Alpha) countered by saying, "You learn the higher math, but it doesn't teach you how to teach the concepts that you will be teaching in middle and secondary classrooms." Therefore, the cooperating teachers did not feel their student teachers were prepared to break down information for the courses they will be teaching. As noted by Participant J (Beta), "it wasn't her strong suit, getting kids to understand concepts that she was trying to teach." The SEES Standard 1.1 (Appendix I) and the AMTE Standard C-1 (Appendix H) both refer to a prepared teacher having an understanding of their curriculum.

Mathematics education professors. Similarly, MEP at both universities believed their pre-service teachers had strong content knowledge and valued the need for upper level math classes as well. Participant M (Beta) noted, "The positive is the math." Participant Q (Alpha) stated, “They're going to be a lot more prepared to teach all math classes. (They will) see how content that they have in their upper courses, how that relates to middle or high school curriculum.” Although, Participant Q (Alpha) questioned the purpose and structure of the math content required, "Why do we require all these courses if, obviously, when you're testing (Math Competency Exam) it's over the earlier stuff that's closer to what they'll be teaching?" This correlates to the Methods course syllabus for Alpha and the requirements for passing the test. Additionally, Participant M (Beta) discussed how the math course program could have variations of math courses for secondary mathematics teacher preparation programs. "Every math program that follows 
the guideline could look very different from each other" (Participant Q, Beta). This compares to the State Certification Requirements for Secondary Education (Appendix K).

In summary, novice teachers, cooperating teachers, and math education professors at both universities overwhelmingly agreed there was evidence of strong content knowledge. However, novice teachers had a disconnection with the cooperating teachers and MEP with the purpose and value of the upper level courses for teaching high school.

\section{Foundation of Content Pedagogical Knowledge}

Novice teachers. Novice teachers from both universities expressed a positive and strong foundation for pedagogical content knowledge within their secondary mathematics teacher preparation program. "In both of those classes, they did a great job of focusing on the method of teaching secondary math...we talked about just different ways of teaching that same material and how different learners that we're going to have in our classroom" (Participant S, Alpha). A similar comment from a Beta novice teacher, "I thought it went really well. We had a really small class, but it was very involved and very thorough" (Participant C). Novice teachers from Alpha contributed their experience was based upon the particular professor for these courses. "My professor was really good and I thought she did a great job of supporting us, but also critiquing us and then helping us learn ways to get better" (Participant N, Alpha). Novice teachers from Beta focused on the real class experience of teaching.

"We came to Cedar High School (pseudonym), at one point, and taught a lesson in somebody's classroom, and we each kind of got to take one. And that, to me, was the best part of it. It was hands-on, real experience, and to me any kind of real experience in teaching preparation is the good stuff' (Participant A, Beta). 
A correlation was found with artifact SPTM Standard C2 (Appendix H). However, novice teachers at both universities also believed they needed more content pedagogical classes pertaining to how secondary students learn math and specifically ones geared toward high school math. As noted in the following comments: “...some of the classes I would rather spent the time having a lot more methods courses than taking Calc four and above. It would have been nice to have an Algebra I methods course and a Geometry methods course and an Algebra II methods course" (Participant F, Alpha). "The one thing that didn't feel covered was algebra techniques for teaching Algebra..." (Participant E, Beta).

Cooperating teachers. The views of the cooperating teachers from both universities were similar to those of the novice teachers. The student teachers they worked with had some foundation of the content pedagogy behind teaching math. Similarly, they felt more pedagogical strategies were needed on how to help students learn certain concepts or grade level topics and real experiences with different learners. One cooperating teacher from Beta in regards to a gap in content pedagogy relayed, “...I think some type of review of some lower level type math courses..." (Participant I). Participant T (Alpha) claimed, “...There is not enough time spent on how to teach concepts, of what technique would work with this and what technique would work with this..." She continued, "I'm not sure they actually get the ability to instruct students at different levels, to see how to deal with those thought processes students have." However, a syllabus from one of Alpha's methods courses indicates the catalog description: "A study of teaching procedures and current literature useful in teaching secondary school mathematics." Conversely, Participant T (Alpha) also indicated 
pedagogy is a learned craft over time that occurs with experience. "I don't think there's enough time spent with teaching them and they do learn it when you get out into the classroom because you have to."

Mathematics education professors. MEPs at Alpha and Beta universities both conveyed the need for a strong foundation in content pedagogical strategies. As stated by Participant Q (Alpha), "I think that part is really valuable, not just knowing the math, but knowing what it means to teach it and, if you ask questions of students, what kind of answers should you be listening for." Alpha University has integrated some state standards in other classes to free up hours for content pedagogy. Alpha offers two courses geared toward content pedagogy, one for math methods and one on the use of technology. Participant Q (Alpha) stated about the methods class, "They have their education classes and their math classes then they have these two...I try to bridge those two pieces together." "We're not using technology just to engage the students like in a fun way, but we're using it to teach something new," Participant Q (Alpha) stated about the technology course. This course aligns to the NCTM-NAEP Standards 4 and 5 on the use of technology for learning.

Within the last two years, another course has been added for connections between higher math courses and high school math courses. "Well, when you put the connections to teaching math class, so that's a total of seven of math education hours" (Participant Q, Alpha). This correlates to Alpha University Mathematics Education Requirements (Appendix L). Beta University faces challenges of low program enrollment to increase content pedagogical courses. Low program enrollment causes the methods courses to be a hybrid of preparation levels for teaching. "So, I don't have enough pedagogical Math 
coursework. I feel like I let everybody in that I can, so I end up having people in who have not done any external experience out in schools to somebody who's already done their junior experience" (Participant M, Beta). However, students at Beta get more of a real-world experience in their one Methods course they do have in which Participant M (Beta) believes, "That was a great experience."

In summary, each category of participants agreed upon the indication of a strong content pedagogical foundation through the secondary mathematics teacher preparation programs at Alpha and Beta universities. Although, novice and cooperating teachers expressed the desires for increased pedagogical courses focusing on how students learn specific math concepts or method for specific math courses. Mathematics Education Professors at Alpha include technology and connections in their pedagogical courses. Meanwhile, Beta included real classroom experience.

\section{Program Performance Review}

Only Mathematics Education Professors at both universities were asked about their Annual Performance Review feedback data and its implications on changes to the program. As part of their annual review, Alpha University uses quantitative feedback for course outcomes and content assessment.

"We have program outcomes, and we have certain classes that assess certain outcomes. Then we keep track of those through our Canvas, which is an online learning management system. At the end of the semester, if you teach a class that has one of the program outcomes, you put that in there and say did they meet that outcome or not. We can look at a student and see which outcomes have been met, or we can look at a program as a whole and say where are we doing well and what 
do we need to work on. We can also look at the 'State' Content Assessment" (Participant Q, Alpha).

This correlates to SSPE Program Standard 2, which refers to data to measure the performance of candidates and educator preparation programs. Beta University's Chair of the Education Department shares data through its Educational Leadership Team; however, Secondary Math Teacher Preparation has a lack of program specific data based on low program enrollment. "We don't have enough people, so a lot of times, the data that we get is they can't tell anything because we have less than ten students who graduate and that doesn't help us" (Participant M, Beta).

In summary, Alpha has a system for an annual review, but Beta does not. However, both universities have an internal five-year cyclical review. Other areas, which instigate review, are externally when the state changes its guidelines or personally when professors want to discuss something different.

\section{Unexpected Outcomes}

Relationships. Novice teachers from both universities recognized the importance of relationships with their mathematics education professor(s) in their secondary mathematics teacher preparation program. "I still contact Dr. Smith and Dr. Jones (pseudonyms)...they are so personable, and I feel comfortable contacting them with any type of question I have about teaching” (Participant S, Alpha). “...Being able to have a teacher who really knew the situation... and could help me a lot with that and always there to answer questions" (Participant C, Beta). Alpha's novice teacher also treasured the relationships they had with their colleagues. Participant G (Alpha) stated, "We were kind of a little cohort where we actually kind of worked together and helped each other." 
This correlates to the SSPE Standard 1C, which refers to the need for relationships to foster learning.

\section{Additional experiences.}

Novice teachers. Alpha University novice teachers desired earlier and more realworld experiences within the secondary math teacher preparation program. Participant U (Alpha) desired more from the observation prior to student teaching. "Find a way to get kids into a classroom before student teaching." Another desire from both universities was for more experiences,

"Maybe more of having us teach a lesson to the kids that we want to actually teach when we get out in the field. Because sometimes when I was teaching my peers a lesson, they already know the content...it's different teaching your peers a lesson than it is teaching high school kids..." (Participant S, Alpha).

Participant B (Beta) made a similar comment. More experiences relate to the SSPE Standard 3. Artifacts from Alpha University indicate simulated real-world experiences whereas the novice teachers are referring to authentic experiences. Novice teachers from Beta wanted more experience with other expectations of being a teacher. "More preparation on how to deal with different situations such as IEP's, 504's, those kinds of things" (Participant D, Beta). These situations correlate to the SEES Standard 3.3.

Cooperating teachers. Cooperating teachers from both Alpha and Beta universities desired more real-world experience with other expectations and various aspects of being a teacher. Cooperating teachers associated with Alpha University wanted real world experiences with other expectations such as co-teaching, Special Education, and differentiation for their student teachers. Participant O (Alpha) wanted to 
see a push for co-teaching, "But possibly seeing a little bit of that would help with coteaching, co-planning, and it would help the student teacher learn some of the ins and outs of teaching." Whereas, Participant W (Alpha) stated, "Students just need more exposure and more instruction on dealing with special education students." She continued, "I would say being able to differentiate a lesson either for more advanced students or for lower level students within a regular class setting.” Meanwhile, cooperating teachers associated with Beta University wanted real-world experiences with various aspects of being a teacher such as various class size cultures, various classroom situations, and the day-to-day procedures of a teacher. "I would say as far as the actual teaching aspect goes, more hours inside an actual classroom that you're going to teach and less in a lecture classroom would be what I would say would be ideal" (Participant N, Beta). Participant I (Beta) referring to taking attendance, grading papers, etc. noted, “...They weren't prepared for the day-to-day operation of teaching that goes beyond the lesson." Lastly, a couple cooperating teachers from both universities mentioned the lack and necessity of strategies for classroom management. "No one really teaches you how to do the discipline and how to keep control of the class...that's just something they learn on the job" (Participant H, Alpha). "Probably just more of how to handle difficult students, or the kids that want to sleep. How to engage everybody in the class?" (Participant P, Beta). Engagement of students aligns to the SEES Standard 1.2.

Connections. Mathematics education professors at both universities mentioned connections as part of their program. Alpha University strives to help their students build conceptual understanding. "Our focus is to teach math conceptually, that we want our future teachers to be able to teach math conceptually" (Participant Q, Alpha). However, 
the math classes at Alpha are not all conceptually taught. Participant G mentioned, “They (math classes) were mainly lecture and ask questions if you don't understand it." Also, they focus on making connections between upper and lower math courses. "I think our biggest focus is to help build connections so that they can hopefully build those connection with their students." Building connections correlates to the course description artifact of the recently added connections course. Beta University focuses making personal connections and connections between research and classroom practice. Participant M (Beta) stated, “One-on-one opportunities with faculty. We get to know each other very well. Other faculty members engage them in research-type activities... and they can see applications of that in the high school... So, they are given opportunities to present their work to other people, which enhances their communication skills."

In summary, relationships, additional experiences such as co-teaching, special education, differentiation and day-to-day teacher procedures, along with connections are other aspects to be considered as part of a teacher preparation program based on the feedback of novice and cooperating teachers and mathematics education professors at Alpha and Beta Universities.

\section{Discussion}

Through the collection and analysis of artifacts, interviews, and focus groups responses from novice teachers, cooperating teachers, and mathematics education professors, the qualitative results revealed both Alpha and Beta universities prepare their secondary mathematics education students similarly with some variations. The overall perceptions of the research participants toward preparedness for teaching mathematics 
were positive and met the content and pedagogical criteria of the standards. While only the Mathematics Education Professors at both universities were the only study participants to have a vast knowledge of the standards it did not seem to impede on the overall preparation of the novice teacher. However, insight from this qualitative study sheds light on other components visible or lacking in the programs. Novice and Cooperating teachers lacked the vision for the purpose and value of upper level math classes required for the degree. Both Novice and Cooperating Teachers wanted an increase in opportunities for real-world content pedagogical situations along with differentiation, co-teaching, and Special Education. Novice teachers acknowledged the need for relationships with university professors and peers in their path toward preparation. Lastly, Mathematics Education Professors stated value in making connections between courses and research to high school math.

\section{Limitations}

Since this is a qualitative case study reliability and validity are a concern based on the different assumptions and perceptions of the participants (Merriam \& Tisdell, 2016). Also, the study is specific to the two universities and therefore is limited on its transferability to other secondary mathematics teacher preparations programs. Another limitation is not all novice or cooperating teachers are considered to be highly qualified, therefore altering their perceptions of reality in regards to their preparation or guidance, respectively. An added limitation is the probability most participants will be between the ages of 21-25 and Caucasian because of the demographic of the population in this Midwest area. The novice teachers in the study are students from the teacher preparation programs whom secured a teaching position, therefore creating a limitation. University 
professors and cooperating teachers in the study could present a limitation by adjusting their responses to guard their reputations.

\section{Implications for Practitioners}

This study aimed to collect perceptions from Novice Teachers, Cooperating Teachers, and Mathematics Education Professors about the components for secondary mathematics teacher preparation to provide insights into the successes and struggles of Alpha and Beta universities' secondary math teacher preparation programs to determine what adjustments or overhaul needs to be completed. In turn, this research opens the collaborative door between Alpha and Beta universities secondary math preparation programs to develop a culture of learning with common strategies for improvement (Fullan et al., 2005). Thus, supplying high quality secondary math teachers to the Midwest to meet the current high demand.

\section{Preparation Program Standards}

Ideally, Novice and Cooperating teachers would also have a working knowledge of the standards for teacher preparation. Two factors in assisting this possibility is for the State Department of Secondary and Elementary Education (DESE) to make the standards easier to find on their website and the university professors provide the information to the novice and cooperating teachers. Knowing the standards would allow novice teachers to know and understand the expectations ahead of them in preparing for their career. It would also allow the cooperating teachers parameters to help steer and support their student teacher during their practicum experience. Specifically, it is recommended that Beta University increase collaboration between the Education and Mathematics 
Departments to incorporate program standards within the courses they have without creating more courses.

\section{Mathematical Content Knowledge}

Teachers are more confident with designing and teaching effective lessons when they know the content (Wilbourne \& Long, 2010). However, even though the State requires a minimum of 30 mathematics credit hours for secondary mathematics teacher preparation, novice and cooperating teachers believed there is a necessity within those 30 hours to experience the level of math taught in high school. Therefore, a recommendation would be to include as part of the preparation program teacher candidate tutoring for students in lower lever college course through calculus I or having preservice teachers volunteer at local high schools to assist math tutoring in classes. At a structural level, it is recommended for both universities to consider reorganizing the required mathematics classes for secondary math teacher preparation. Allowing the number of hours to be reduced and their purpose to combine content and pedagogy.

\section{Pedagogical Content Knowledge}

Pedagogical content knowledge is essential for teacher's flexible use of strategies to represent mathematics for student learning (Ball et al., 2008). Although, both universities at least met the minimal guidelines for methods and techniques of teaching math, the desire for more was observed. Particularly geared toward specific concepts or content. It is recommended that both universities incorporate authentic ways for preservice teachers to obtain real-world experiences or situations to meet this expectation. An option would be to collaborate with a local math teacher to obtain actual student work 
samples and have the pre-service teachers develop a lesson or strategy to move the student from their current knowledge to the lesson goal.

\section{Program Performance Review}

The use of assessment systems is a challenge for teacher education programs to not only create, but use as a way to measure quality by assessing outcomes and other measures (Reusser, Butler, Symonds, Vetter, \& Wall, 2007). This is true for both universities. Although Alpha does have a system in place to analyze quantitative data, some of the picture is missing by not including qualitative data. Therefore, it is recommended Alpha incorporate a way in which qualitative data can be collected and analyzed as part of their program performance review. One way would be to use the finding of this study or imbed the triangulation of feedback from novice teachers, cooperating teachers and University math education professors. It is suggested that Beta University create and implement a way to gather specific data for their secondary mathematics teacher preparation program. A beginning step would be to collaborate with the assessment review personnel at Alpha.

\section{Unexpected Outcomes}

Relationships. Relationships are a part of teaching and learning at any level. Therefore, it is recommended the culture of relationships be fostered and continued at both universities.

Additional experiences. As stated in the SSPE, the clinical experience of the teacher preparation should include "varied and extensive opportunities." Also, the levels and types of learners teachers are challenged to educate are vast within one classroom of 30 students. Neither university provides this type of experience. Therefore, it is 
advocated for both universities to include in the clinical part of their programs ways to encompass differentiation. As reflected in the SSPE Standard C, the SEES Standard 2.1, and the NCTM-CAEP Standard 3C, differentiation is a key part of teacher preparation and evaluation. Alpha University should re-evaluate their 30 hours of observation and Beta their participation I and II courses to include collaboration with teachers in the cooperating schools or co-teaching to include focused learning in areas such as differentiation, IEPs, 504s, and classroom management. Although, Beta does include authentic real-world experience in their participation courses, the scope of the experience needs to broaden to include various types of learners and situations.

Connections. Connections were a goal of both universities. Alpha focused on the connection between upper level and high school math courses. This was expressed by the novice and cooperating teachers as a need. Beta focused on the connections between research and high school courses. These are valuable connections, which help novice teachers in their preparation of the content and pedagogy. However, one connection only surfaced in artifacts and that was reflection. Reflection was evident in both universities course descriptions of their methods courses. However, novice and cooperating teachers did not bring up any connection with reflection and being prepared to teach math. Therefore, it is recommended that both universities not only teach how to reflect and make it a part of the pre-service teacher expectations, but also for the cooperating teacher to reflect upon the experience with the student teacher and the university professors. 


\section{Recommendations}

The overarching question of this research was 'How do secondary math teacher education programs at two Midwest universities prepare beginning math teachers for the classroom?' External factors such as State Standards, internal factors such as the Universities' unique programs and personal factors such as the relationships within each University's programs have influenced change. Evidence supported Standards for Preparing Teachers of Mathematics from AMTE (2017), having a strong knowledge of mathematics and a foundation of pedagogical knowledge. Based on the perceptions of the participants in this study, both universities, although the mathematics coursework varied, produced novice teachers with a strong content knowledge. Also, both universities, using different goals and expectations, produced novice teachers with a foundation of content pedagogical strategies to build upon. Although, Latterell (2008), stated "mathematics content courses are coming into alignment with mathematics method courses, at least in some undergraduate institutions" (p. 2). The following is a recommended change.

- Firstly, to prepare secondary math teachers for the current culture of mathematics education, content and pedagogical courses should not be separated. These courses are taught separately in the universities' programs, but as a secondary mathematics educator they are performed together.

Also, low program enrollment was a concern for both Alpha and Beta. Participant Q (Alpha) claimed,

"Legislators know what GPA means, and they understand GPA, but that doesn't mean that's the only thing that's valuable... They need a 3.0 in their math classes 
to be certified to teach math. If you get a $\mathrm{C}$ in calc $\mathrm{I}$, you're swimming up stream....I think we're losing a lot of quality math teachers. I understand the goal is that you want them to understand math well, fine. But I don't know that a 3.0 means that they understand math well enough to teach it all the time, so I think we need our legislatures to learn that there are other metrics, not just GPA, that's important."

This restricts the flexibility in number and frequency of courses the universities can offer and the amount of collaboration possible between professors and students.

- Secondly, a push to increase program enrollment should be a priority. Two recommendations are given: 1) Alpha and Beta universities form a cohort and merge the best aspects of each of their secondary math teacher preparation programs and 2) work with legislatures, such as the State Board of Education or the Department of Elementary and Secondary Education, to change grade point average policy to encourage more preservice teachers to stay in this career field.

In conclusion, the world of education has changed from teachers' knowledge of what to teach to teachers' knowledge of how students learn (Levine, 2006). The National Research Council (2010) indicates little and varying evidence of how best to prepare teachers. Regardless of the use of pulleys or gears, the clock still keeps the same time. However, as time changes the culture and expectations of educational needs and desires, so too must the mechanics of secondary mathematics teacher preparation. Nevertheless, novice teachers of secondary mathematics need strong content and pedagogical knowledge. However, we now know these standards need to be imbedded within the 
courses they take. Consequently, the external standards, the internal program design and the personal belief of math education professors all need to reflect this desire in order for this change to occur. Additionally, this research will add to the literature on math education and teacher preparation at the secondary level that can be shared with other universities and teacher preparation program. 


\section{References}

Alvey, C., Hudson, R. A., Newton, J., \& Males, L. M. (2016). Secondary pre-service teachers' algebraic reasoning about linear equation solving. Issues in the Undergraduate Mathematics Preparation of School Teachers, 1, 16. Retrieved from http://proxy.mul.missouri.edu/login?url=http://search.proquest.com/docview $/ 1871581930 ?$ accountid $=14576$

American Mathematical Society. (2012). The mathematical education of teachers II. v17, Providence, Rhode Island.

Association of Mathematics Teacher Educators. (2017). Standards for preparing teachers of mathematics. Retrieved June 9, 2017 from https://amte.net/sites/default/files/ SPTM.pdf

Association of Public and Land-Grant Universities. (2011). The common core state standards and teacher preparation: The role of higher education. Retrieved on July 7, 2017 from http:/www.aplu.org/projects-and-initiatives/stem-education/ SMTI_Library/APLU-SMTI-Paper-2

Ball, D. L. (2000). Bridging practices intertwining content and pedagogy in teaching and learning to teach. Journal of Teacher Education, 51(3), 241-247. https://doi.org/ $10.1177 / 0022487100051003013$

Ball, D. L. \& Bass, H. (2000). Making believe: The collective construction of public mathematical knowledge in the elementary classroom. In D. C. Phillips (Ed.), Constructivism in education: Opinions and second opinions on controversial issues. Yearbook of the National Society for the Study of Education p. 193-224. Chicago: University of Chicago Press. 
Ball, D. L., \& Forzani, F. M. (2009). The work of teaching and the challenge for teacher education. Journal of Teacher Education, 60(5), 497-511.

https://doi.org/10.1177/0022487109348479

Ball, D. L., Thames, M. H., \& Phelps, G. (2008). Content knowledge for teaching what makes it special? Journal of Teacher Education, 59(5), 389-407. https://doi.org/ $10.1177 / 0022487108324554$

Bryan, T. J. (1999). The conceptual knowledge and pre-service secondary mathematics teachers: How well do they know the subject matter they will teach? Issue in the Undergraduate Preparation of School Teachers. In University of Michigan (pp. $10-21)$.

Cochran-Smith, M., \& Villegas, A. M. (2015). Framing teacher preparation research an overview of the field, part 1. Journal of Teacher Education, 66(1), 7-20. https://doi.org/10.1177/0022487114549072

Common Core State Standards Initiative. (2009). Development process. Retrieved July 6, 2017 from http://www.corestandards.org/about-the-standards/developmentprocess/

Conference Board of Mathematical Sciences. (2017). The mathematical education of teachers. Retrieved June 3, 2017 from http://www.cbmsweb.org/themathematical-education-of-teachers/

Corbo, J. C., Reinholz, D. L., Dancy, M. H., Deetz, S., \& Finkelstein, N. (2016). Framework for transforming departmental culture to support educational innovation. Physical Review Physics Education Research, 12(1), 10113-1-1011315. 
Core Standards. (n.d.). Frequently asked questions. Retrieved on July 7, 2017 from http://www.corestandards.org/about-the-standards/frequently-asked-questions/

Core Standards (2012). Common core state standards. Retrieved on March 10, 2017 from http://www.corestandards.org/assets/CCSSI_Math\%20Standards.pdf

Core Standards (2016). Common core state standards key shifts in math.

Retrieved on March 10, 2017 from http://www.corestandards.org/otherresources/key-shifts-in-mathematics/

Creswell, J. W. (2014). Research design: Quantitative, qualitative, and mixed methods approaches $\left(4^{\text {th }}\right.$ ed.). Thousand Oaks, CA: Sage.

Department of Elementary and Secondary Education. (2013a). Missouri educator evaluation system. Retrieved December 29, 2017 from https://dese.mo.gov/ sites/default/files/00-TeacherEvaluation-CompleteDoc.pdf

Department of Elementary and Secondary Education. (2013b). Missouri standards for the preparation of educators. Retrieved December 29, 2017 from https://dese.mo.gov /sites/default/files/MoSPEStandards.pdf

Department of Elementary and Secondary Education. (2017). Educator preparation. Retrieved December 29, 2017 from https://dese.mo.gov/educatorquality/educator-preparation/mo-standards-preparation-educators

Evans, B. R. (2011). Secondary mathematics teacher differences: Teacher quality and preparation in a new york city alternative certification program. Mathematics Educator, 20(2), 24-32.

Fullan, M. (1996). Professional culture and educational change. School Psychology Review, 25(4), 496-500. 
Fullan, M., Cuttress, C., \& Kilcher, A. (2005). Eight forces for leaders of change: Presence of the core concepts does not guarantee success, but their absence ensures failure. Journal of Staff Development, 26(4), 54-58.

Goodson, I. F. (2001). Social histories of educational change. Journal of Educational Change, 2(1), 45-63. doi: 10.1023/A:1011508128957

Graham, K. J., \& Fennell, F. (2001). Principles and standards for school mathematics and teacher education: Preparing and empowering teachers. School Science and Mathematics, 101(6), 319-327. https://doi.org/10.1111/j.19498594.2001.tb17963.x

Graham, K. J., Li, Y., \& Buck, J. C., (2000). Characteristics of mathematics teacher preparation programs in the united states: An exploratory study. The Mathematics Educator, 5(1), 5-31.

Hanson, M. (2001). Institutional theory and educational change. Educational Administration Quarterly, 37(5), 637-661. doi: 10.1177/00131610121969451

Hill, H. C., Rowan, B., \& Ball, D. L. (2005). Effects of teachers' mathematical knowledge for teaching on student achievement. American Educational Research Journal, 42(2), 371-406.

Krueger, R. A., \& Casey, M. A. (2009). Focus groups: A practical guide for applied research (5th ed.). Thousand Oaks, CA: Sage.

Lasley, T. J., Siedentop, D. \& Yinger, R. (2006). A systematic approach to enhancing teacher quality: the Ohio model. Journal of Teacher Education, 57, 13-21.

Latterell, C. M. (2008). A snapshot of ten pre-service secondary mathematics teachers. Issues in the Undergraduate Mathematics Preparation of School Teachers, 1, 13. 
Lawrence, R. L., \& Paige, D. S. (2016). What our ancestors knew: Teaching and learning through storytelling. New Directions for Adult and Continuing Education, 2016(149), 63-72. doi: 10.1002/ace.20177

Levine, A. (2006). Educating school teachers. New York: The Education Schools Project.

Ma, L. (1999). Knowing and teaching elementary mathematics: Teachers understanding of fundamental mathematics in China and the United States. Mahwah, NJ: Lawrence Erlbaum.

Merriam, S. B., \& Tisdell, E. J. (2016). Qualitative research: A guide to design and implementation (4th ed.). San Francisco, CA: Joseey-Bass.

National Council for Accreditation of Teacher Education. (2010). What makes a teacher effective. Retrieved June 5, 2017, from http://www.ncate.org/Public/ResearchReports/TeacherPreparationResearch/What MakesaTeacherEffective/tabid/361/Default.aspx

National Council of Teachers of Mathematics. (2000). Principal and standards for school mathematics. Retrieved June 4, 2017 from http://www.nctm.org/Standards-andPositions/Principles-and-Standards/Principles,-Standards,-and-Expectations/

National Council of Teachers of Mathematics Council for the Accreditation of Educator Preparation. (2012). Standards for mathematics teacher preparation. Retrieved June 4, 2017 from http://www.nctm.org/Standards-and-Positions/CAEPStandards/ 
National Research Council. (2010). Preparing teachers: Building evidence for sound policy. Committee on the Study of Teacher Preparation Programs in the United States, Center for Education. Division of Behavioral and Social Sciences and Education. Washington, DC: The National Academies Press. National Watch and Clock Museum. (2016). How does it work? Retrieved on June 20, 2017 from https://nawcc.org/index.php/just-for-kids/about-time/how-does-it-work

Patton, M. Q. (2015). Qualitative research \& evaluation methods: Integrating theory and practice (4th ed.). St. Paul, MI: Sage Publications.

Peressini, D., Borko, H., Romagnano, L., Knuth, E., \& Willis, C. (2004). A conceptual framework for learning to teach secondary mathematics: A situative perspective. Educational Studies in Mathematics, 56(1), 67-96.

Podolsky, A., Kini, T., Bishop, J., \& Darling-Hammond, L. (2016). Solving the teacher shortage: How to attract and retain excellent educators. Palo Alto, CA: Learning Policy Institute. Retrieved from https://learningpolicyinstitute.org/ product/solving-teacher-shortage

Ronfeldt, M., Schwartz, N., \& Jacob, B., (2014). Does pre-service preparation matter? Examining an old question in new ways. Teachers College Record, 116(10). Retrieved from http://search.proquest.com.proxy.mul.missouri.edu/eric/ docview/1651856494/FB83F21B4DD0446DPQ/23

Reusser, J., Butler, L., Symonds, M., Vetter, R., \& Wall, T., (2007). An assessment system for teacher education program quality improvement. International Journal of Educational Management, 21(2), 105-113. 
Scherer, M. (2012). The challenges of supporting new teachers: A conversation with Linda Darling-Hammond. Educational Leadership, 69(8), 18-23.

Schmidt, W. H., Burroughs, N. A., Cogan, L. S., \& Houang, R. T. (2016). The role of subject-matter content in teacher preparation: an international perspective for mathematics. Journal of Curriculum Studies, O(0), 1-21 http://doi.org/10.1080/ 00220272.2016 .1153153

Seidman, I. (2012). Interviewing as qualitative research: A guide for researchers in education and the social sciences (4th ed.). New York, NY: Teachers College Press.

Shulman, L. S. (1986). Those Who Understand: Knowledge Growth in Teaching. Educational Researcher, 15(2), 4-14.

Spillane, J. P. (2012). The more things change, the more things stay the same? Education and Urban Society, 44(2), 123-127.

Swafford, J. O. (1995). Teacher preparation. In I. M. Carl (Ed). Prospects for School Mathematics (p. 157-174). Reston, VA: The National Council for Teachers of Mathematics.

Thames, M. H., \& Ball, D. L. (2010). What math knowledge does teaching require? Teaching Children Mathematics, 17(4), 220-229.

Waks, L. J. (2007). The concept of fundamental educational change. Educational Theory, 57(3), 277-295. doi: 10.1111/j.1741-5446.2007.00257.x

Wasserman, N. H., \& Ham, E. (2013). Beginning teachers perspective on attributes for teaching secondary mathematics: Reflections on teacher education. Mathematics Teacher Education and Development, 15(2), 23. 
Whitford, B. L., \& Villaume, S. K. (2014). Clinical teacher preparation: A retrospective. Peabody Journal of Education, 89(4), 423-435.

Whittington, D. (2002). 2000 National survey of science and mathematics education:

Status of high school mathematics teaching. Horizon Research Inc.

Wilburne, J. M., \& Long, M. (2010). Secondary pre-service teachers' content knowledge for state assessments: Implications for mathematics education programs. Issues in the Undergraduate Mathematics Preparation of School Teachers, 1, 13.

Zuya, H. (2017). Prospective teachers' conceptual and procedural knowledge in mathematics: The case of algebra (PDF Download Available). (n.d.). https://doi.org/http://dx.doi.org/10.12691/education-5-3-12 


\section{SECTION SIX}

\section{SCHOLARLY PRACTITIONER REFLECTION}

The purpose of this section is to reflect upon how the dissertation process has influenced my practice as an educational leader and as a scholar. Reflection is an active process. To partake in true reflection, one must take action whether it be "noticing, recognizing, realizing, investigating, [or] pondering" (Chalikandy, 2014, p. 126). The doctoral courses provided me with a broad scope of knowledge in the areas of leadership, organizations, policy analysis, adult learning and the dissertation process. However, the process of writing the dissertation helped make connections of that learning to my growth in regards to my practice as a leader and as a scholar.

\section{Dissertation Influencing Practice as an Educational Leader}

\section{Leadership and Change}

Kotter (2011) defined leadership as setting direction, aligning people, and providing motivation to cope with change. A large number of studies have been conducted during the last 50 years to define a great leader (George, Sims, McLean, \& Mayer, 2007). However, Goleman (2011) believes a great leader is distinguished from a good one by possessing emotional intelligence, "the ability to work with others and effectiveness in leading change" (p. 2). The conceptual framework of my dissertation was change theory. The in-depth research on change has strengthened my abilities as a leader by knowing the components required for change to happen. My school district has done some restructuring with our curriculum coordinators. We have changed from 16 content specific, part-time curriculum coordinators to five, full-time, generalist curriculum advisors. I have taken the position of one of the five. This is a big change in 
theory and practice for the teachers in our district. Although the change is internal, it will take time to change the culture and personal beliefs of the teachers affected by this change.

\section{Leadership as a Process}

Researchers (Helland \& Winston, 2005; Northouse, 2016) define leadership as a process. Not only does leadership include what an effective leader does, it is an interactive process including the relationship component between leader and follower and what followers do in response to the leader's personality and action (Helland \& Winston, 2005). Completing this dissertation was also an interactive process. I realized through this process that not everything is linear. The process of leadership, as with the process of the dissertation, is more like an entangled web of knowledge, analysis, inquiry, findings, conclusions and reflections. As I venture into my new position as Generalist Advisor, I will be working with teachers from all grade levels and all content. Therefore, I will implement a similar process of inquiry and knowledge to gain a schema to help other teachers besides math. I will need to analyze theory and practice in order to determine findings and conclusion on best practices of instruction. Lastly, I will use reflection to refine my process and my advise to other teachers.

\section{Leadership strengths}

During the coursework, I participated in six different questionnaires, which were used to assess my leadership characteristics and style. One questionnaire was The Leadership Trait Questionnaire (LTQ) uses 14 questions to measure traits of a leader, such as: dependable, diligent, friendly, and sensitive. Northouse (2016) states, "the LTQ quantifies the perceptions of the individual leader and selected observers" (p. 37). 
Considering my characteristic strengths as a leader, the LTQ indicated I am dependable, consistent and diligent. I value these traits as a person not just a leader. As a leader, however, my main goal is to always make sure my teachers have what they need and if not, they can depend on me to get it for them. The dissertation process has challenged my strengths of consistent and diligent. I recall one class when a Cohort 9 student talked with us about this process. He referred to it as "moving bails of hay". He said, "When you look at all the bails in the field, it's overwhelming. So just move one at a time. Before you know it, you've moved them all." This has helped me remain consistent and diligent. These are leadership traits I will focus on continuing in order to maintain relationships and lead the change process from content coordinators to generalist advisors.

\section{Leadership Development Areas}

Based on my deficits indicated through these questionnaires and my learning in the EdD program, I can improve on self-awareness, "deep understanding of one's emotions, strengths, weaknesses, needs, and drives" (Goleman, 2011, p. 7) and showing empathy for others. Both self-awareness and empathy are components of Goleman's (2011) emotional intelligence, which he explains can be learned. Self-awareness is a key component in my ability to work with other teachers. Based on the qualitative nature of my dissertation, I have been able to work on, regardless of my own feelings, listen and empathize with the participants through interviews and the focus group. 


\section{Dissertation Influencing Scholarship}

\section{Content and Context for Learning}

Learning, as defined by Merriam \& Bierema (2014), is “a change in knowledge, skills or attitudes" (p. 98). Reflecting on the dissertation process, I definitely have had a change in knowledge from the research, a change in skills by the analysis and synthesis of research and data, and a change in attitude of what is needed to prepare a novice teacher for secondary mathematics. "Leadership is about coping with change" (Kotter, 2011, p. 38). The knowledge of change I obtained from my dissertation research will help me cope with change in our district. However, to become a change agent means, "questioning the way things were" (Merriam \& Bierema, 2014, p. 89). This is the essence of the qualitative process. This process has helped me to ask questions in a way that seeks the participant's perceptions and not influenced by my own.

\section{Learning Reflection}

Learning is the center of who I am and what I have become. Everything I have done or continue to do is from something I have learned. My learning may have happened in a formal way through the doctorial coursework or an informal way through the experience of writing this dissertation. Either way, my learning is a product of two of my abilities: internal motivation and reflection.

My internal motivation comes from a desire to be the best person I can be. Merriam and Beierma (2014) explain how internal motivation stems from "enhanced self-esteem, improved quality of life and personal fulfillment" (p. 54). As indicated from my Strengths Quest (Gallop, 2010), my strength of significance validates my desire to achieve goals and to keep reaching higher. This was the driving force behind me seeking 
and completing this degree. As Taylor (2009) indicates, it is the interdependence of the experiences with reflection and dialogue. Discussions with my parents, siblings, husband and close friends aided me in changing my views and beliefs by "questioning and examining long-held assumptions about the self and the world in which one lives" (Merriam \& Bierema, 2014, p. 90). Each day and experience has the opportunity to provide transformational learning if given the time to reflect and discuss the experience of what it means to me and for me. Reflection has given me wisdom by thinking what my learning means and turning it into knowledge (Gill, 2010). This last section of the dissertation process has allowed me to reflect on what I have done and visualize its application to my experiences in my new position.

\section{Learning Leader}

As a leader, I balance between extrinsic and intrinsic motivation (Merriam \& Bierema, 2014; George, et al., 2011). Improving student performance is the extrinsic. I challenge teachers to improve their practice through various instructional strategies, preparing activities, and reflection. However, unless they posses the intrinsic motivation, it just becomes a checklist of something else to do. Therefore, as a leader of adult learners, it is my responsibility to motivate my fellow colleagues and create a "culture of learning" (Gill, 2010, p. 142).

Merriam and Bierema (2014) identify conditions for motivating adult learners: “establishing inclusion, developing attitude, enhancing meaning, and engendering confidence" (p. 156). As I reflect my leadership role, I have focus on making sure everyone feels respected and connected by inclusion in discussions. The second condition of developing attitude is providing a safe environment to help learners without 
humiliation and phony behavior. I rely on my strength of consistency strength of communicating clear expectations, following up on my expectations, and treating everyone the same. As an arranger, the third condition of enhancing meaning is maintained by my ability to always create "challenging and engaging experiences" (Merriam \& Bierema, 2014, p. 157) for the best way to accomplish new learning. The fourth condition of engendering confidence is a struggle with the lack of time and "ongoing feedback and reflection" (Gill, 2010, p. 141) I have to help my colleagues be successful. Therefore, I try to foster learning through common course cross-district conversation, collaboration, and dialogue (Bruffee, 1999; Merriam \& Bierema, 2014). However, one realization I had resonated from the following quote.

Merriam and Bierema (2014) stated the following:

Adult learners do not have motivation problems, but rather that the problem lies in the relationship between the learner and those providing the learning opportunities who have their own motives. (p. 162).

I assumed all teachers had the same motive to improve their teaching and I based my decisions of their learning on how I saw to fulfill that motive without initially seeking their ideas of what the learning should be based on, their own experiences. However, I now have an appreciation for seeking and listening to other's perspectives through collecting the data for this dissertation.

\section{Facilitation of Change}

One of my biggest pet peeves is the response, "that's how it's always been done." Choosing my dissertation topic was a driving force behind no longer accepting this response for the preparation of secondary mathematics teachers in the changing world of education. As a change agent for instruction in my district, I will focus on Mezirow's 
(1978) theory of transformative learning, "a rational, critical cognitive process that requires thinking, reflection, questioning, and examination of one's assumptions and beliefs" (at cited in Merriam \& Bierma, 2014, p. 86). A slight change of words from one's to others would define the qualitative process of writing a dissertation. As a generalist advisor, I will be change agent, by working to improve instruction in my district through reflection "by getting people to question and reflect on the practices of the workplace and their role in these activities and practices" (Merriam \& Bierema, 2014, p. 93) and communication (Bruffee, 1999). I plan to make a cultural change of creating an environment of collaboration and communication, similar to focus groups, between all colleagues across schools and grade levels. The use of focus groups is a way to discover perceptions and the rational about issues (Krueger \& Casey, 2015). Conducting focus groups allowed the opportunity to work with divergent personalities and appreciating their diversity and similarity, with the focus on openness, making sure everyone is included in discussions and contributes their input. The importance of practicing openness as a change agent is by creating possibility and fueling hope (Preskill \& Brookfield, 2009, p. 25).

\section{Conclusion}

Reflecting on my growth as a leader during the coursework and the completion of this dissertation, I have gained a broad and deep understanding of various leadership theories and practices, organizational analysis, policy analysis, and content and context for learning. More importantly, I have not only learned theory behind each of these four main themes, but I have experienced how to practice and apply these concepts to my career as a generalist advisor. The dissertation has continued my growth as an 
educational leader through practice in regards to change and as a process. Also, I know my strengths and weaknesses as a leader as part of my self-awareness and continued growth. The dissertation process has influenced me as a scholar through my own learning and me leading of learning and change. Basically, the entire EdD program has provided me the opportunity to reflect on my leadership style, the organization in which I am employed, the policies which guide our work, and myself as a leader. Zhao's (2012) study stated, "Only through reflection can she see clearly whether or not her methods are valid and lay a proper foundation for her own practice...” (p. 64). 


\section{References}

Alvey, C., Hudson, R. A., Newton, J., \& Males, L. M. (2016). Secondary pre-service teachers' algebraic reasoning about linear equation solving. Issues in the Undergraduate Mathematics Preparation of School Teachers, 1, 16. Retrieved from http://proxy.mul.missouri.edu/login?url=http://search.proquest.com/docview $/ 1871581930 ?$ accountid $=14576$

American Mathematical Society. (2012). The mathematical education of teachers II. v17, Providence, Rhode Island.

Association of Mathematics Teacher Educators. (2017). Standards for preparing teachers of mathematics. Retrieved June 9, 2017 from https://amte.net/sites/default/files/ SPTM.pdf.

Association of Public and Land-Grant Universities. (2011). The common core state standards and teacher preparation: The role of higher education. Retrieved on July 7, 2017 from http://www.aplu.org/projects-and-initiatives/stem-education/ SMTI_Library/APLU-SMTI-Paper-2.

Ball, D. L. (2000). Bridging practices intertwining content and pedagogy in teaching and learning to teach. Journal of Teacher Education, 51(3), 241-247. https://doi.org/ $10.1177 / 0022487100051003013$

Ball, D. L. \& Bass, H. (2000). Making believe: The collective construction of public mathematical knowledge in the elementary classroom. In D. C. Phillips (Ed.), Constructivism in education: Opinions and second opinions on controversial issues. Yearbook of the National Society for the Study of Education p. 193-224. Chicago: University of Chicago Press. 
Ball, D. L., \& Forzani, F. M. (2009). The work of teaching and the challenge for teacher education. Journal of Teacher Education, 60(5), 497-511.

https://doi.org/10.1177/0022487109348479

Ball, D. L., Thames, M. H., \& Phelps, G. (2008). Content knowledge for teaching what makes it special? Journal of Teacher Education, 59(5), 389-407. https://doi.org/ $10.1177 / 0022487108324554$

Bolman, L. G., \& Deal, T. E. (2013). Reframing organizations: Artistry, choices and leadership (5th Ed.). San Francisco, CA: Jossey-Bass.

Boyd, D. J., Grossman, P. L., Lankford, H., Loeb, S., \& Wyckoff, J. (2009). Teacher preparation and student achievement. Educational Evaluation and Policy Analysis, 31(4), 416-440.

Bruffee, K. A. (1999). Collaborative learning: Higher education, interdependence, and the authority of knowledge. Baltimore, MD: Johns Hopkins University Press.

Bryan, T. J. (1999). The conceptual knowledge and pre-service secondary mathematics teachers: How well do they know the subject matter they will teach? Issue in the Undergraduate Preparation of School Teachers. In University of Michigan (pp. $10-21)$.

Chalikandy, M. A. (2014). Reflection: A tool for professional development. Researchers World, 4(3), 117-124.

Cochran-Smith, M., \& Villegas, A. M. (2015). Framing teacher preparation research an overview of the field, part 1. Journal of Teacher Education, 66(1), 7-20. https://doi.org/10.1177/0022487114549072 
Common Core State Standards Initiative. (2009). Development process. Retrieved July 6, 2017 from http://www.corestandards.org/about-the-standards/developmentprocess/

Conference Board of Mathematical Sciences. (2001). National summit on the mathematical education of teachers: Meeting the demand for high quality mathematics education in America. Retrieved June 3, 2017 from http://www.cbmsweb.org/archive//NationalSummit/summary_article.htm Conference Board of Mathematical Sciences. (2017). The mathematical education of teachers. Retrieved June 3, 2017 from http://www.cbmsweb.org/themathematical-education-of-teachers/.

Corbo, J. C., Reinholz, D. L., Dancy, M. H., Deetz, S., \& Finkelstein, N. (2016). Framework for transforming departmental culture to support educational innovation. Physical Review Physics Education Research, 12(1), 10113-1-1011315.

Core Standards. (n.d.). Frequently asked questions. Retrieved on July 7, 2017 from http://www.corestandards.org/about-the-standards/frequently-asked-questions/

Core Standards (2012). Common core state standards. Retrieved on March 10, 2017 from http://www.corestandards.org/assets/CCSSI_Math\%20Standards.pdf

Core Standards (2016). Common core state standards key shifts in math.

Retrieved on March 10, 2017 from http://www.corestandards.org/otherresources/key-shifts-in-mathematics/

Crespo, S. (2017). So want to be an MTE author? A tool for writing your next MTE manuscript. Mathematics Educator, 5(2), 85-93. 
Creswell, J. W. (2014). Research design: Quantitative, qualitative, and mixed methods approaches $\left(4^{\text {th }}\right.$ ed.). Thousand Oaks, CA: Sage.

Cuban, L. (1990). Reforming again, again, and again. Educational Researcher, 19(1), 313. https://doi.org/10.3102/0013189X019001003

Department of Elementary and Secondary Education. (2006). Missouri standards for teacher education programs. Retrieved December 29, 2017 from https://dese.mo.gov/sites/default/files/MoSTEP_10-06.pdf

Department of Elementary and Secondary Education (2008). Certification requirements for secondary educations, grades 9-12. Retrieved December 29, 2017 from https://dese.mo.gov/sites/default/files/04\%20Secondary\%20Education04-08.pdf

Department of Elementary and Secondary Education. (2013a). Missouri educator evaluation system. Retrieved December 29, 2017 from https://dese.mo.gov/ sites/default/files/00-TeacherEvaluation-CompleteDoc.pdf

Department of Elementary and Secondary Education. (2013b). Missouri standards for the preparation of educators. Retrieved December 29, 2017 from https://dese.mo.gov /sites/default/files/MoSPEStandards.pdf

Department of Elementary and Secondary Education. (2017). Educator preparation. Retrieved December 29, 2017 from https://dese.mo.gov/educatorquality/educator-preparation/mo-standards-preparation-educators

Drake, P., \& Heath, L. (2011). Practitioner research at doctoral level developing coherent research methodologies. (First ed., pp. 46-58). London, New York: Routledge. 
Evans, B. R. (2011). Secondary mathematics teacher differences: Teacher quality and preparation in a new york city alternative certification program. Mathematics Educator, 20(2), 24-32.

Fullan, M. (1996). Professional culture and educational change. School Psychology Review, 25(4), 496-500.

Fullan, M. (2002). The Change Leader. Educational Leadership, 59(8), 16-20.

Fullan, M., Cuttress, C., \& Kilcher, A. (2005). Eight forces for leaders of change: Presence of the core concepts does not guarantee success, but their absence ensures failure. Journal of Staff Development, 26(4), 54-58.

Gallop Inc. (2010). Strengths insight report. Retrieved from https://www.strengthsquest.com/content/.../Resources.aspx

George, B., Sims, P., McLean, A.N., and Mayer, D. (2011). Discovering your authentic leadership. In HBR's 10 must reads on leadership (pp. 163-177), Boston, MA: Harvard Business Review Press. (Reprint R0702H, Originally published in February 2007).

Gill, S. J. (2010). Developing a learning culture in nonprofit organizations. Los Angeles: CA: Sage.

Goleman, D. (2011). What makes a leader? In HBR's 10 must reads on leadership (pp. 121), Boston, MA: Harvard Business Review Press. (Reprint R0401H, Originally published in June 1996).

Goodson, I. F. (2001). Social histories of educational change. Journal of Educational Change, 2(1), 45-63. doi: 10.1023/A:1011508128957 
Graham, K. J., \& Fennell, F. (2001). Principles and standards for school mathematics and teacher education: Preparing and empowering teachers. School Science and Mathematics, 101(6), 319-327. https://doi.org/10.1111/j.19498594.2001.tb17963.x

Graham, K. J., Li, Y., \& Buck, J. C., (2000). Characteristics of mathematics teacher preparation programs in the united states: An exploratory study. The Mathematics Educator, 5(1), 5-31.

Hanson, M. (2001). Institutional theory and educational change. Educational Administration Quarterly, 37(5), 637-661. doi: 10.1177/00131610121969451

Helland, M.R., \& and Winston, B.E. (2005). Towards a deeper understanding of hope and leadership. Journal of Leadership \& Organizational Studies, 12(2), 42-54.

Hill, H. C., Rowan, B., \& Ball, D. L. (2005). Effects of teachers' mathematical knowledge for teaching on student achievement. American Educational Research Journal, 42(2), 371-406.

Kotter, J.P. (2011). What leaders really do? In HBR's 10 must reads on leadership (pp. 37-55), Boston, MA: Harvard Business Review Press. (Reprint R0111F, Originally published in May 1990).

Krueger, R. A., \& Casey, M. A. (2009). Focus groups: A practical guide for applied research (5th ed.). Thousand Oaks, CA: Sage.

Lasley, T. J., Siedentop, D. \& Yinger, R. (2006). A systematic approach to enhancing teacher quality: the Ohio model. Journal of Teacher Education, 57, 13-21.

Latterell, C. M. (2008). A snapshot of ten pre-service secondary mathematics teachers. Issues in the Undergraduate Mathematics Preparation of School Teachers, 1, 13. 
Lawrence, R. L., \& Paige, D. S. (2016). What our ancestors knew: Teaching and learning through storytelling. New Directions for Adult and Continuing Education, 2016(149), 63-72. doi: 10.1002/ace.20177

Levine, A. (2006). Educating school teachers. New York: The Educaiton Schools Project.

Ma, L. (1999). Knowing and teaching elementary mathematics: Teachers understanding of fundamental mathematics in China and the United States. Mahwah, NJ: Lawrence Erlbaum.

Manning, K. (2013). Organizational theory in higher education. New York, NY: Routledge.

Merriam, S. B., \& Bierema, L. L. (2014). Adult learning: Linking theory and practice (2014) by Sharan B. Merriam and Laura L. Bierema. San Francisco, CA: JosseyBass.

Merriam, S. B., \& Tisdell, E. J. (2016). Qualitative research: A guide to design and implementation (4th ed.). San Francisco, CA: Joseey-Bass.

Mostofo, J., \& Zambo, R. (2015). Improving instruction in the mathematics methods classroom through action research. Educational Action Research, 23(4), 497-513. https://doi.org/10.1080/09650792.2015.1019903

National Council for Accreditation of Teacher Education. (2006). Certificate of incorporation of the national council for accreditation of teacher education. Retrieved November 19, 2017, from http://www.ncate.org/LinkClick.aspx ?fileticket=6NygpML8QjE\%3d\&tabid=412 
National Council for Accreditation of Teacher Education. (2010). What makes a teacher effective. Retrieved June 5, 2017, from http://www.ncate.org/Public/ResearchReports/TeacherPreparationResearch/What MakesaTeacherEffective/tabid/361/Default.aspx

National Council of Teachers of Mathematics. (2000). Principal and standards for school mathematics. Retrieved June 4, 2017 from http://www.nctm.org/Standards-andPositions/Principles-and-Standards/Principles,-Standards,-and-Expectations/ National Council of Teachers of Mathematics Council for the Accreditation of Educator Preparation. (2003). Standards for mathematics teacher preparation. Retrieved June 4, 2017 from http://www.nctm.org/Standards-and-Positions/CAEPStandards/

National Council of Teachers of Mathematics Council for the Accreditation of Educator Preparation. (2012). Standards for mathematics teacher preparation. Retrieved June 4, 2017 from http://www.nctm.org/Standards-and-Positions/CAEPStandards/

National Research Council. (2010). Preparing teachers: Building evidence for sound policy. Committee on the Study of Teacher Preparation Programs in the United States, Center for Education. Division of Behavioral and Social Sciences and Education. Washington, DC: The National Academies Press. National Watch and Clock Museum. (2016). How does it work? Retrieved on June 20, 2017 from https://nawcc.org/index.php/just-for-kids/about-time/how-does-itwork. 
Northouse, P.G. (2016). Leadership: Theory and practice (7th ed.) New Delhi, India: Sage.

Patton, M. Q. (2015). Qualitative research \& evaluation methods: Integrating theory and practice (4th ed.). St. Paul, MI: Sage Publications.

Peressini, D., Borko, H., Romagnano, L., Knuth, E., \& Willis, C. (2004). A conceptual framework for learning to teach secondary mathematics: A situative perspective. Educational Studies in Mathematics, 56(1), 67-96.

Podolsky, A., Kini, T., Bishop, J., \& Darling-Hammond, L. (2016). Solving the teacher shortage: How to attract and retain excellent educators. Palo Alto, CA: Learning Policy Institute. Retrieved from https://learningpolicyinstitute.org/ product/solving-teacher-shortage.

Preskill, S., \& Brookfield, S. D. (2009). Learning as a way of leading: Lessons from the struggle for social justice. San Francisco, CA: Jossey-Bass.

Reusser, J., Butler, L., Symonds, M., Vetter, R., \& Wall, T., (2007). An assessment system for teacher education program quality improvement. International Journal of Educational Management, 21(2), 105-113.

Ronfeldt, M., Schwartz, N., \& Jacob, B., (2014). Does pre-service preparation matter? Examining an old question in new ways. Teachers College Record, 116(10). Retrieved from http://search.proquest.com.proxy.mul.missouri.edu/eric/ docview/1651856494/FB83F21B4DD0446DPQ/23

Scherer, M. (2012). The challenges of supporting new teachers: A conversation with Linda Darling-Hammond. Educational Leadership, 69(8), 18-23. 
Schmidt, W. H., Burroughs, N. A., Cogan, L. S., \& Houang, R. T. (2016). The role of subject-matter content in teacher preparation: an international perspective for mathematics. Journal of Curriculum Studies, O(0), 1-21 http://doi.org/10.1080/ 00220272.2016 .1153153

Seidman, I. (2012). Interviewing as qualitative research: A guide for researchers in education and the social sciences (4th ed.). New York, NY: Teachers College Press.

Shen, Y. (2008). The effect of changes and innovation on educational improvement. International Education Studies, 1(3), 73-77.

Shulman, L. S. (1986). Those Who Understand: Knowledge Growth in Teaching. Educational Researcher, 15(2), 4-14.

Spillane, J. P. (2012). The more things change, the more things stay the same? Education and Urban Society, 44(2), 123-127.

Swafford, J. O. (1995). Teacher preparation. In I. M. Carl (Ed). Prospects for School Mathematics (p. 157-174). Reston, VA: The National Council for Teachers of Mathematics.

Taylor, E. W. (2009). Fostering transformative learning. In J. Mezirow \& E. W. Taylor (Eds.), Transformative learning in practice: Insights from community, workplace, and higher education (pp. 3-17). San Francisco: CA: Jossey-Bass.

Thames, M. H., \& Ball, D. L. (2010). What math knowledge does teaching require? Teaching Children Mathematics, 17(4), 220-229.

Waks, L. J. (2007). The concept of fundamental educational change. Educational Theory, 57(3), 277-295. doi: 10.1111/j.1741-5446.2007.00257.x 
Wasserman, N. H., \& Ham, E. (2013). Beginning teachers perspective on attributes for teaching secondary mathematics: Reflections on teacher education. Mathematics Teacher Education and Development, 15(2), 23.

Whitford, B. L., \& Villaume, S. K. (2014). Clinical teacher preparation: A retrospective. Peabody Journal of Education, 89(4), 423-435.

Whittington, D. (2002). 2000 National survey of science and mathematics education: Status of high school mathematics teaching. Horizon Research Inc.

Wilburne, J. M., \& Long, M. (2010). Secondary pre-service teachers' content knowledge for state assessments: Implications for mathematics education programs. Issues in the Undergraduate Mathematics Preparation of School Teachers, 1, 13.

Zhao, M. (2012). Teachers' professional development from the perspective of teaching reflection levels. Chinese Education \& Society, 45(4), 56-67.

Zoest, L. R. V., \& Bohl, J. V. (2005). Mathematics teacher identity: A framework for understanding secondary school mathematics teachers' learning through practice. Teacher Development, 9(3), 315-345. https://doi.org/10.1080/1366453050020025

Zuya, H. (2017). Prospective teachers' conceptual and procedural knowledge in mathematics: The case of algebra (PDF Download Available). (n.d.). https://doi.org/http://dx.doi.org/10.12691/education-5-3-12. 
Appendix A

\section{Interview/Focus Group Questions}

While an undergraduate student/cooperating teacher/program professor at Alpha/Beta

University you participated in the secondary mathematics teacher preparation program.

Please answer the questions below about the experience(s) you had with as much detail as possible.

Pseudonym

Date Interview/Focus Group Time

Interview/Focus Group Introduction

Description of Project

Discussion on Confidentiality

Approval to Continue

1. What do you know about the State Standards for mathematics teacher preparation? Do you know its components?

2. What do you think are the positive or negative effects of the State Standards for secondary mathematics teacher preparation?

3. What do you think are the positive or negative effects of the mathematics coursework required for preparation to teach secondary mathematics?

4. What do you think about the pedagogical mathematical coursework, courses for student learning of math, required for preparation to teach secondary mathematics?

5. What is the greatest strength of the secondary mathematics teacher preparation program? Why?

6. What is the greatest weakness of the secondary mathematics teacher preparation program? Why? 
7. Now that you have been teaching/have worked with as a cooperating teacher/instructed within the secondary mathematics teacher preparation program, if you could select and adapt the courses, curriculum and instructional materials, what would it be?

8. Do you have any additional perceptions you would like to share about secondary mathematics teacher preparation that might be helpful to this study?

9. * This question is only for University professors.

How is Annual Performance Review data for mathematics teacher preparation used within each University? 
Appendix B

\section{Recruitment Script/Letter}

Dear

Hello, my name is Angela Dorsey and I am a Doctoral Student at the University of Missouri-Columbia through the Northwest Missouri State University cohort. I am currently working on my dissertation, "Secondary Mathematics Preparation Program: Perceptions of Novice Teachers, Cooperating Teachers, and University Professors."

This research is being conducted to investigate the perceptions of novice teachers, cooperating teachers, and university professors regarding the secondary mathematics teacher preparation program at two Midwest universities. Your thoughts regarding secondary mathematics teacher preparation would be invaluable to gaining a better understanding of the program. Since this is a doctoral study, there is no direct benefit to you however; the results of the study may shed light on impacts and perceptions that may influence teacher preparation programs, institutions, teacher candidates, and teacher themselves. I hope you are willing to give your time and perspective.

Participants I am looking for include all of the following:

1. Recent graduates of the teacher preparation program who are now novice teachers who are within their first to sixth year of teaching.

2. Current mathematics teachers who have worked as a cooperating teachers of pre-service mathematics teachers within the last six years.

3. Current or former education and mathematics education university professors who have taught courses within the secondary mathematics teacher preparation program within the last six years.

If you meet one of the three criteria above, I would be happy to set up a time and date to speak with you about your experiences. Please use the information below to contact me to schedule an interview or participate in a focus group.

Thank you so much for your time.

Sincerely, Angela Dorsey

angela.dorsey@sjsd.k12.mo.us

(816) 262-7372 (Cell)

IRB Approved Date 2/9/2018

Expiration Date 2/9/2019

Project \#2010472 
Appendix C

\section{Recruitment Follow-up Phone Call Protocol}

Project: secondary mathematics teacher preparation: perceptions of novice teachers, cooperating teachers, and university professors

Researcher: "Hello, this is Angela Dorsey and I am a doctoral student at the University of Missouri. I recently sent you an email regarding participation in a study regarding Secondary Mathematics Teacher Preparation. I am calling to follow up on the email to answer any questions or clarify anything you have regarding the study."

Participant: Response

Researcher: Responding to questions and clarification. Possibly reiterating the study and the parameters of participation.

Researcher: "I would like to review the Informed Consent attached to the email to help reinforce confidentiality and anonymity of participation in the study." After reviewing the Informed Consent, "Do you have any questions or concerns in participating in this study?"

Participant: Response

Researcher: Responding to questions and concerns.

Researcher: "After this discussing, would you feel comfortable scheduling an interview sometime in the month of April this year? If so, the interview may take place on a date and time of your convenience."

Research: "Thank you for your willingness to participate, I will see you at (location) on (date) at (time)." 
Appendix D

\title{
Informed Consent
}

\section{Analysis of Content and Pedagogical Content Knowledge in Secondary Mathematics Teachers' Preparation Program: Perceptions of Novice Teachers, Cooperating Teachers, and University Professors}

You are invited to participate in a research study conducted by Angela Dorsey, a doctoral student at the University of Missouri-Columbia. This study is for a dissertation in practice, in completion of an Ed.D. in Policy Analysis and Educational Leadership. This research is being conducted to investigate the perceptions of novice teachers, cooperating teachers, and university professors with the preparation of secondary mathematics teachers during the novice teachers' training period. As an invitee to participate in the research, you have the right to know the purpose and procedure prior to consenting to participate. Please do not hesitate to ask the researcher to clarify or explain any words or information you do not understand.

\begin{abstract}
ABOUT THE STUDY
The purpose of this research is to investigate the perceptions of novice teachers, cooperating teachers, and university professors regarding ways in which the teacher preparation programs impacts their beginning teacher experiences. Your thoughts are valued and appreciated.
\end{abstract}

\section{RISKS, CONFIDENTIALITY AND BENEFITS}

There are no foreseen risks or discomforts associated with this research and any concern regarding confidentiality and responses traced back to an individual are addressed in all data gathered during the study will be kept strictly confidential. Your identity will be protected and concealed through a pseudonym within the data and final paper. Data will be kept secured for seven years per IRB requirements and then all original records will be destroyed. Approximately 20 people will contribute to the interviews and focus groups. All transcripts will be analyzed as a group. To participate, you will be asked to

1. Share your thoughts in a thirty-minute interview or sixty-minute focus group.

2. Review the transcript from your interview or focus group to clarify or correct any data. You may also receive a copy of the final dissertation.

Since this is a doctoral study, there is no direct benefit to you however; the results of the study may shed light on impacts and perceptions that may influence teacher preparation programs, institutions, teacher candidates, and teacher themselves.

\section{VOLUNTARY NATURE OF THE STUDY AND RIGHT TO WITHDRAW}

Your participation in this study is completely voluntary and will require only a minimal amount of time and effort. You do not have to be in the study if you do not want to. If you choose to participate you may refuse to answer any questions you choose or withdraw at any time during the study without any adverse affects. You are voluntarily making a decision whether or not to participate in this research study. Participation in the 
study indicates you are nineteen years of age or older, an understanding of the project and information presented, and consent to participate. Participation signifies also an understanding participation can be declined at any time. In addition, participation grants consent to be audio-recorded during the interview or focus group and the conversation transcribed verbatim by a paid transcriber.

\section{CONTACTS FOR QUESTIONS OR PROBLEMS}

If you have any questions or would like to meet with me to discuss the study, please contact me at akdqg9@mail.missouri.edu or by calling (816) 262-7372. In addition, the chair of my dissertation committee is Dr. Carole Edmonds; her email is CAKE@,nwmissouri.edu.

You are also welcome to contact the University of Missouri's Campus Institutional Review Board (IRB) by visiting their website https://research.missouri.edu/irb/or calling (573) 882-9585 if you have any questions regarding your rights as a research participant.

A copy of this Informed Consent form will be given to you before you participate in the research.

Thank you for taking time to participate in this study.

\section{AUTHORIZATION}

I have read and understand this consent form, and I volunteer to participate in this research study. I understand that I will receive a copy of this form. I voluntarily choose to participate, but I understand that my consent does not take away any legal rights in the case of negligence or other legal fault of anyone who is involved in this study. I further understand that nothing in this consent form is intended to replace any applicable Federal, state, or local laws.

Participant's Name (Printed or Typed):

Date:

Participant 's Signature:

Date:

Principal Investigator's Signature/ Person Obtaining Consent:

Date:

IRB Approved Date 2/9/2018

Expiration Date 2/9/2019

Project \#2010472 
Appendix E

Alpha State University Organization Chart 2016-2017

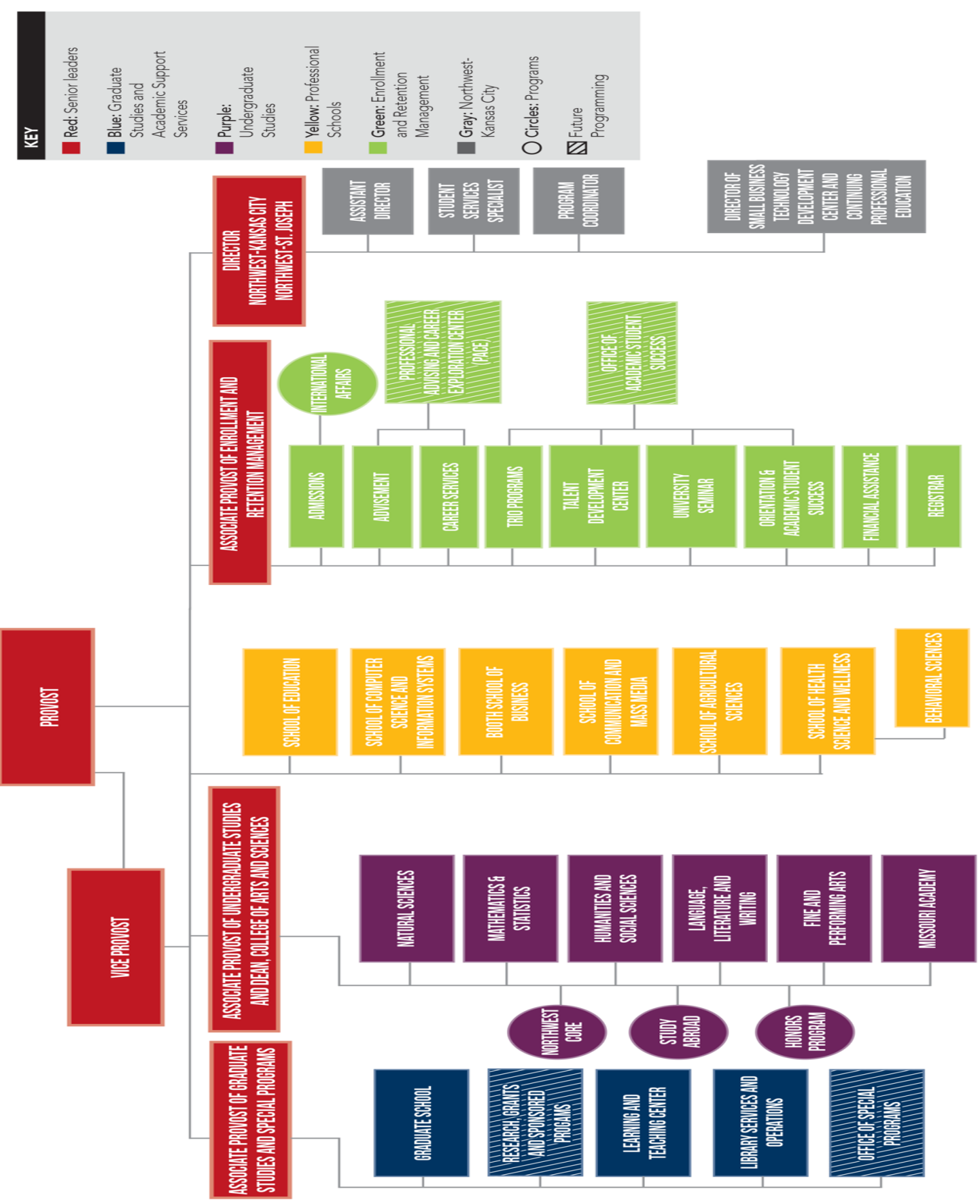


Appendix F

Beta University Organizational Chart 2016-2017

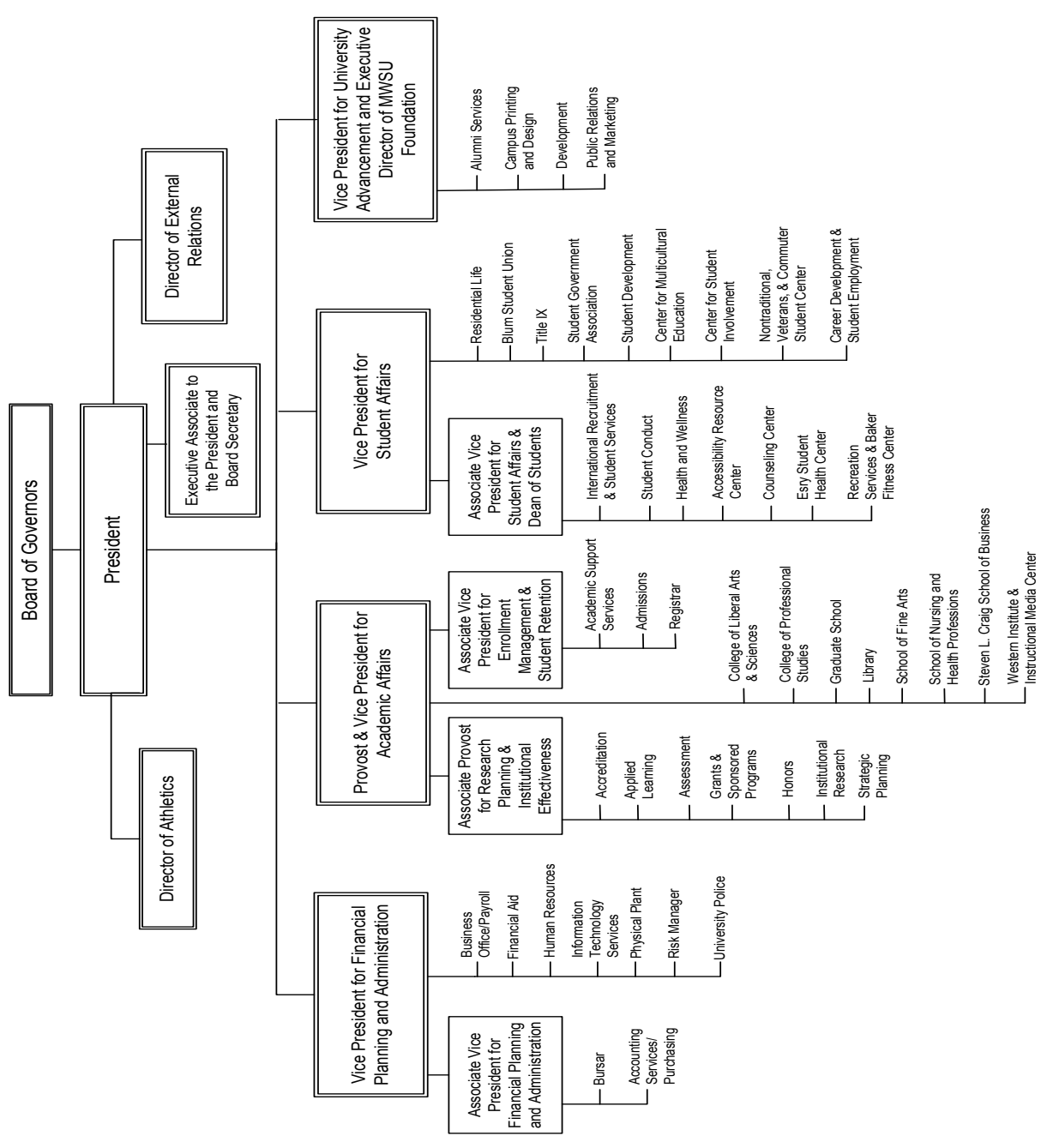




\section{National Council of Teachers of Mathematics Council for the Accreditation of Educator Preparation Standards}

\section{NCTM CAEP Standards (2012) - Secondary (Initial Preparation)}

\section{Standard 1: Content Knowledge}

Effective teachers of secondary mathematics demonstrate and apply knowledge of major mathematics concepts, algorithms, procedures, connections, and applications within and among mathematical content domains.

Preservice teacher candidates:

1a) Demonstrate and apply knowledge of major mathematics concepts, algorithms, procedures, applications in varied contexts, and connections within and among mathematical domains (Number, Algebra, Geometry, Trigonometry, Statistics, Probability, Calculus, and Discrete Mathematics) as outlined in the NCTM CAEP Mathematics Content for Secondary.

\section{Standard 2: Mathematical Practices}

Effective teachers of secondary mathematics solve problems, represent mathematical ideas, reason, prove, use mathematical models, attend to precision, identify elements of structure, generalize, engage in mathematical communication, and make connections as essential mathematical practices. They understand that these practices intersect with mathematical content and that understanding relies on the ability to demonstrate these practices within and among mathematical domains and in their teaching.

Preservice teacher candidates:

2a) Use problem solving to develop conceptual understanding, make sense of a wide variety of problems and persevere in solving them, apply and adapt a variety of strategies in solving problems confronted within the field of mathematics and other contexts, and formulate and test conjectures in order to frame generalizations.

2b) Reason abstractly, reflectively, and quantitatively with attention to units, constructing viable arguments and proofs, and critiquing the reasoning of others; represent and model generalizations using mathematics; recognize structure and express regularity in patterns of mathematical reasoning; use multiple representations to model and describe mathematics; and utilize appropriate mathematical vocabulary and symbols to communicate mathematical ideas to others.

2c) Formulate, represent, analyze, and interpret mathematical models derived from real-world contexts or mathematical problems.

2d) Organize mathematical thinking and use the language of mathematics to express ideas precisely, both orally and in writing to multiple audiences.

2e) Demonstrate the interconnectedness of mathematical ideas and how they build on one another and recognize and apply mathematical connections among mathematical ideas and across various content areas and real-world contexts.

2f) Model how the development of mathematical understanding within and among mathematical domains intersects with the mathematical practices of problem solving, reasoning, communicating, connecting, and representing. 
Standard 3: Content Pedagogy

Effective teachers of sccondary mathematics apply knowledge of curriculum standards for mathematics and their relationship to student learning within and across mathematical domains. They incorporate research-based mathematical experiences and include multiple instructional strategies and mathematics-specific technological tools in their teaching to develop all students' mathematical understanding and proficiency. They provide students with opportunities to do mathematics - talking about it and connecting it to both theoretical and real-world contexts. They plan, select, implement, interpret, and use formative and summative assessments for monitoring student leaming, measuring student mathematical understanding, and informing practice.

Preservice teacher candidates:

3a) Apply knowledge of curriculum standards for secondary mathematics and their relationship to student learning within and across mathematical domains.

3b) Analyze and consider rescarch in planning for and leading students in rich mathematical learning experiences.

3e) Plan lessons and units that incorporate a variety of strategies, differentiated instruction for diverse populations, and mathematics-specific and instructional technologies in building all students" conceptual understanding and procedural proficiency.

3d) Provide students with opportunitics to communicate about mathematics and make connections among mathematics, other content areas, everyday life, and the workplace.

3e) Implement techniques related to student engagement and communication including selecting high quality tasks, guiding mathematical discussions, identifying kcy mathematical ideas, identifying and addressing student misconceptions, and employing a range of questioning strategies.

3f) Plan, select, implement, interpret, and use formative and summative assessments to inform instruction by reflecting on mathematical proficiencies essential for all students.

3g) Monitor students' progress, make instructional decisions, and measure students" mathematical understanding and ability using formative and summative assessments. 
Appendix $\mathrm{H}$

\section{Association of Mathematics Teacher Educators Standards For Well-Prepared Beginning Teachers of Mathematics}

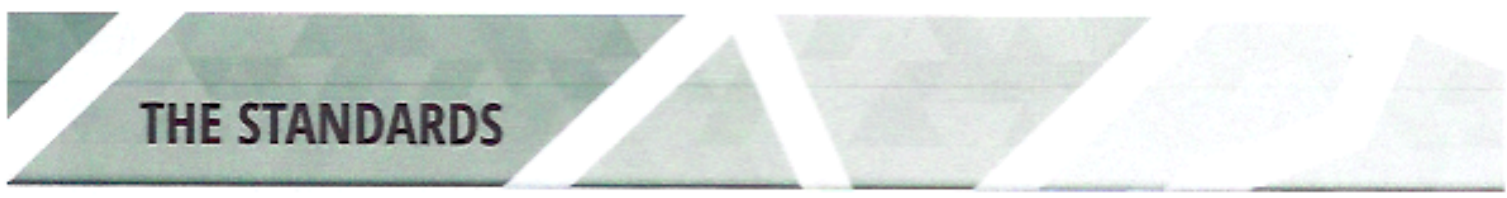

SPTM articulates a set of high expertarions licr what well-prepared begnning teachers of mathermutics should know and be ahle to do ws well as characteristics for effective proprams that prepare teachers. As such, the standards abdrews, candidate knowledge, skills, and dispositions and the program characteristics that will vappurt the dirvelonment of candidate knowkctege, skills, jnd dispositions. Each standand is assoxisted with a set of indicators that elaborate the stundard in more detal and prowicle a guife for stakcholders to interpret and apply the stantiart

\section{CANDIDATE KNOWLEDGE, SKILLS, AND DISPOSITIONS}

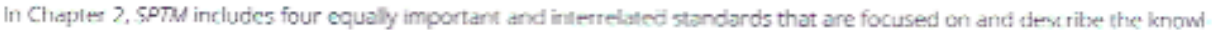
cojge, shills, and dispositions that well prepur ed beginners should artain. The forus on the importance of mathematical undersundirg throughout all four candidate stancarch ond ocross all grade bands is intentional. Well prepared beginning tearhers of mathematics need roul only to have deep mathematcal knowleuge rekwart to tesarhing, hut also to situate their mathematical knowledge for teaching, in thrit licuming of effectwe strategles for texaching, mathematics and in understanding their students' muthematical knowledge, skills, and dispositions. Initial preparation that is focused on candicides' knowledge of the subjext, of curriculum, and of how students learn mathemarics is more elfective than general methods cours, work forused on generic teacher behaviors that mighr be urmelaled to the content itself. Well prepared begirning teachers should have knowiefge of the social, historical, and instnuminnal contexts that dffect teaching and learning, thus, the revder will sce the themes of equity and arress interwoven throughout the standards.

\section{STANDARDS FOR WELL-PREPARED BEGINNING TEACHERS OF MATHEMATICS}

\section{C.1 MATHEMATICS CONCEPTS, PRACTICES, AND CURRICULUM}

\section{C.2 PEDAGOGICAL KNOWLEDGE AND PRACTICES FOR TEACHING MATHEMATICS}

\section{C.3 STUDENTS AS LEARNERS OF MATHEMATICS}

\section{C.4 SOCIAL CONTEXTS OF MATHEMATICS TEACHING AND LEARNING}

Well-prepared beginning teachers of mathematics possess rckust knowicdge of mathematical and statisxit al corxcepts that underlie what they encounter in teaching. They engage in appropnate mathematical and statistical practices and supgort their students in doing the same. They can rwark, andalye, and discuss cumculum, ussessmast, and standiards documents as well as students mathernatical productions.

Well grepsed beginning teachers of mathematics have foundaticens of pedagceicul knowledge effectwe and equitable mathematics tcuching practices, and positive and productive dospositions toward teaching mathematics to support students sense mukinge, understanding and reasoning

Well prepured beginning teachers of mathemarics have foundutional undersharcfirns of students mathematical knowedge, skills, arxd disposi tions. They know how these understandings can contribute to effective texchirg and are committed to expanding and deepering their knowledge of students as learners of mathematics.

Well-prepared beginning teachers of mathemalics realize that the social, histcrical, and irstitutional contests of mathematics affect teaching and lear ring and know about and are committed to their crilit al roles as advocates for each and every sturient 


\section{Appendix I}

\section{State Educator Evaluation System Quality Indicators of the Academic Standard}

Teacher Growth Guide 1.1

Standard 1: Content knowledge aligned with appropriate instruction.

The teacher understands the central concepts, structures, and tools of inquiry of the discipline(s) and creates learning experiences that make these aspects of subject matter meaningful and engaging for students.

Quality Indicator 1: Content knowledge and academic language

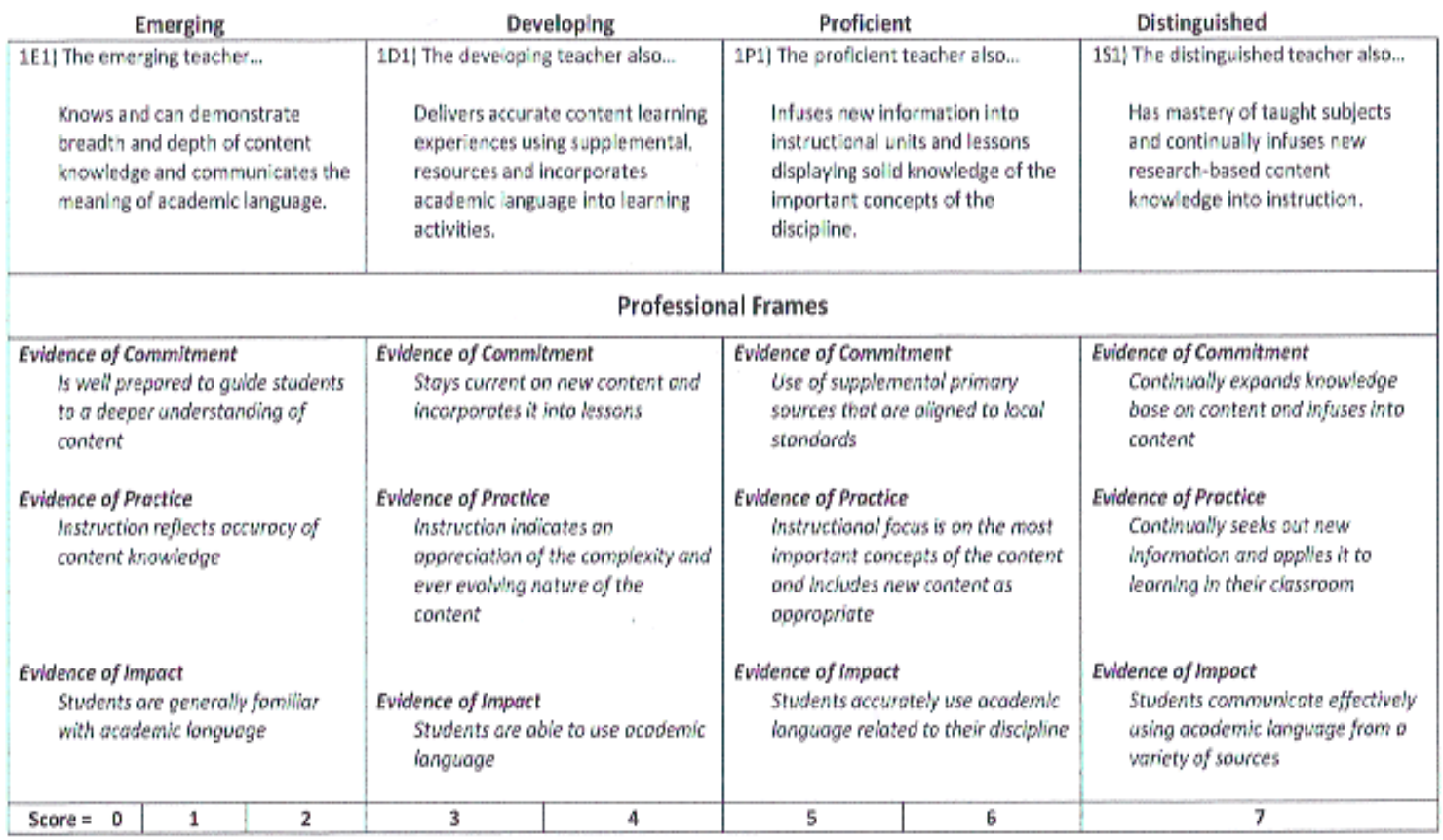




\section{Teacher Growth Guide 1.3}

Standard 1: Content knowledge aligned with appropriate instruction.

Quality Indicator 3: Disciplinary research and inquiry methodologies

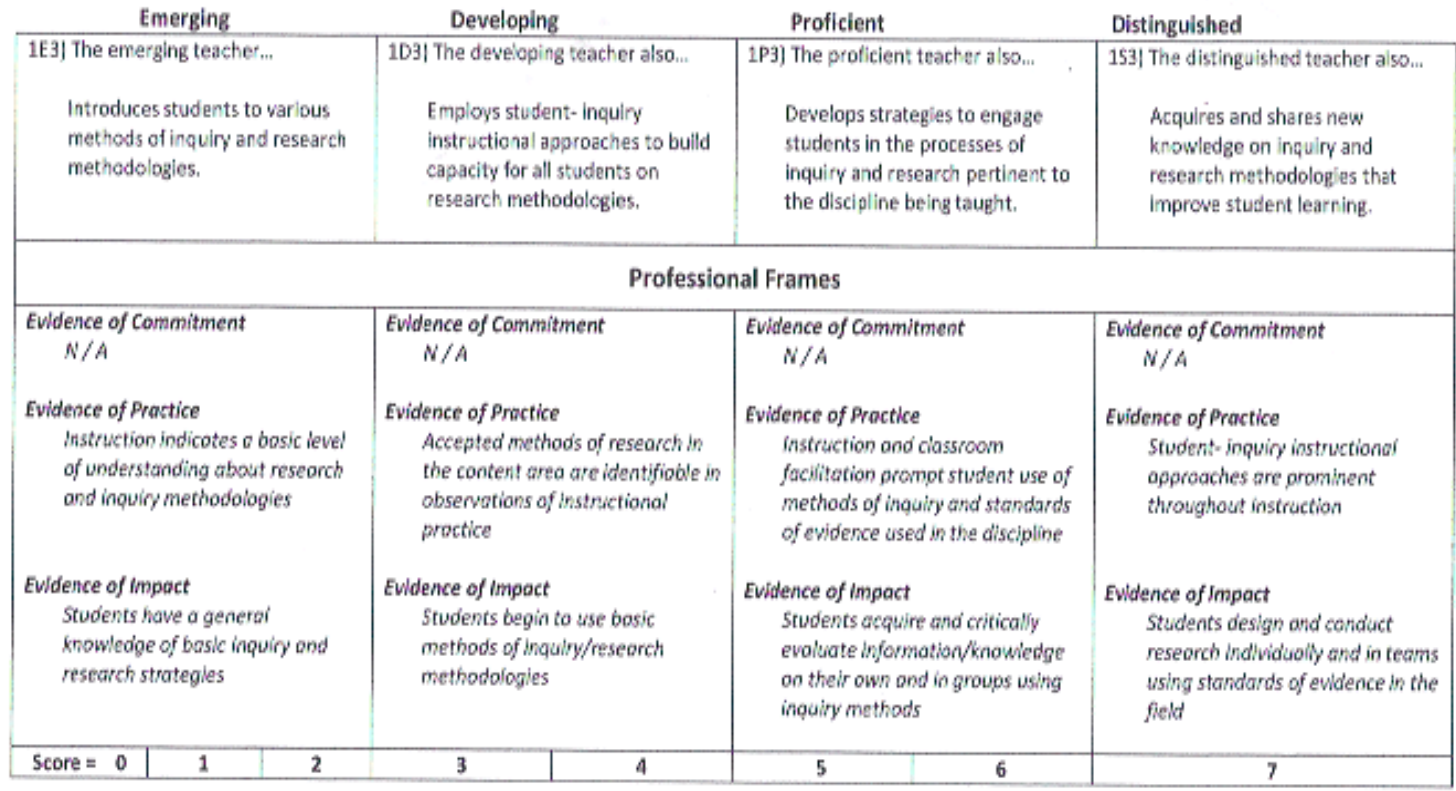




\title{
Appendix $\mathbf{J}$
}

\section{National Council of Teachers of Mathematics Council for the Accreditation of Educator Preparation Mathematics Content for Secondary}

\author{
NCTM CAEP Mathematics Content for Secondary \\ Addendum to the NCTM CAEP Standards 2012
}

\section{A. Secondary Mathematics Teachers}

All secondary mathematics teachers should be prepared with depth and breadth in the following mathematical domains: Number, Algebra, Geometry, Trigonometry, Statistics, Probability, Calculus, and Discrete Mathematics. All teachers certified in secondary mathematics should know, understand, teach, and be able to communicate their mathematical knowledge with the breadth of understanding reflecting the following competencies for each of these domains.

\section{A.1. Number and Quantity}

To be prepared to develop student mathematical proficiency, all secondary mathematics teachers should know the following topics related to number and quantity with their content understanding and mathematical practices supported by appropriate technology and varied representational tools, including concrete models:

A.1.1 Structure, properties, relationships, operations, and representations including standard and non-standard algorithms, of numbers and number systems including integer, rational, irrational, real, and complex numbers

A.1.2 Fundamental ideas of number theory (divisors, factors and factorization, primes, composite numbers, greatest common factor, least common multiple, and modular arithmetic)

A.1.3 Quantitative reasoning and relationships that include ratio, rate, and proportion and the use of units in problem situations

A.1.4 Vector and matrix operations, modeling, and applications

A.1.5 Historical development and perspectives of number, number systems, and quantity including contributions of significant figures and diverse cultures

\section{A.2. Algebra}

To be prepared to develop student mathematical proficiency, all secondary mathematics teachers should know the following topics related to algebra with their content understanding and mathematical practices supported by appropriate technology and varied representational tools, including concrete models:

A.2.1 Algebraic notation, symbols, expressions, equations, inequalities, and proportional relationships, and their use in describing, interpreting, modeling, generalizing, and justifying relationships and operations

A.2.2 Function classes including polynomial, exponential and logarithmic, absolute value, rational, and trigonometric, including those with discrete domains (e.g., sequences), and how the choices of parameters determine particular cases and model specific situations 
A.2.3 Functional representations (tables, graphs, cquations, descriptions, recursive definitions, and finite differences), characteristics (e.g., zeros, intervals of increase or decrease, extrema, average rates of change, domain and range, and end behavior), and notations as a means to describe, reason, interpret, and analyze relationships and to build new functions

A.2.4 Patterns of change in linear, quadratic, polynomial, and exponential functions and in propurtional and inversely proportional relationships and types of real-world relationships these functions can model

A.2.5 Linear algebra including vectors, matrices, and transformations

A.2,6 Abstract algebra, including groups, rings, and ficlds, and the relationship between these structures and formal structures for number systems and numerical and symbolic calculations

A.2.7 Historical development and perspectives of algebra ineluding contributions of significant figures and diverse cultures

\section{A.3. Geometry and Trigonometry}

To be prepared to develop student mathematical proficiency, all secondary mathematics teachers should know the following topics related to geometry and trigonometry with their content understanding and mathematical practices supported by appropriate technology and varied representational tools, including concrete models:

A.3.1 Core concepts and principles of Fuclidean geometry in two and three dimensions and two-dimensional non-Fuclidean geometries

A.3.2 Transformations including dilations, translations, rotations, reflections, glide reflections; compositions of transformations; and the expression of symmetry in terms of transformations

A.3.3 Congruence, similarity and scaling, and their development and expression in terms of transformations

A.3.4 Right triangles and trigonometry

A.3.5 Application of periodic phenomena and trigonometric identitics

A.3.6 Identification, classification into categories, visualization, and representation of two- and three-dimensional objects (triangles, quadrilaterals, regular polygons, prisms, pyramids, cones, cylinders, and spheres)

A.3.7 Formula rationale and derivation (perimeter, area, surface area, and volume) of two- and three-dimensional objects (triangles, quadrilaterals, regular polygons, rectangular prisms,

NCTM CAEP Mathematics Content for Secondary (2012) - Revised 3/24/2015 
pyramids, cones, cylinders, and spheres), with attention to units, unit comparison, and the iteration, additivity, and invariance related to measurements

A.3.8 Geometric constructions, axiomatic rcasoning, and proof

A.3.9 Analytic and coordinate geometry including algcbraic proofs (e.g., the Pythagorean Theorem and its converse) and equations of lines and planes, and expressing geometric properties of conic sections with cquations

A.3.10 Historical development and perspectives of geometry and trigonometry including contributions of significant figures and diverse cultures

\section{A.4. Statistics and Probability}

To be prepared to develop student mathematical proficiency, all secondary mathematics teachers should know the following topics related to statistics and probability with their content understanding and mathematical practices supported by appropriate technology and varied representational tools, including concrete models:

A.4.1 Statistical variability and its sources and the role of randomness in statistical inference

A.4.2 Creation and implementation of surveys and investigations using sampling methods and statistical designs, statistical inference (estimation of population parameters and hypotheses testing), justification of conclusions, and generalization of results

A.4.3 Univariate and bivariate data distributions for categorical data and for discrete and continuous random variables, including representations, construction and interpretation of graphical displays (e.g., box plots, histograms, cumulative frequency plots, scatter plots), summary measures, and comparisons of distributions

A.4.4 Empirical and theoretical probability (discrete, continuous, and conditional) for both simple and compound events

A.4.5 Random (chance) phenomena, simulations, and probability distributions and their application as models of real phenomena and to decision making

A.4.6 Historical development and perspectives of statistics and probability including contributions of significant figures and diverse cultures

\section{A.5. Calculus}

To be prepared to develop student mathematical proficiency, all sccondary mathematics teachers should know the following topics related to calculus with their content understanding and mathematical practices supported by appropriate technology and varied representational tools, including concrete models: 
A.5.1 Limits, continuity, rates of change, the Fundarnental Theorem of Calculus, and the meanings and techniques of differentiation and integration

A.5.2 Parametric, polar, and vector functions

A.5.3 Sequences and series

A.5.4 Multivariate functions

A.5.5 Applications of function, geometry, and trigonometry concepts to solve problems involving calculus

A.5.6 Historical development and perspectives of calculus including contributions of significant figures and diverse cultures

\section{A.6. Discrete Mathematics}

To be prepared to develop student mathematical proficiency, all secondary mathematics teachers should know the following topies related to diserete mathematics with their content understanding and mathematical practices supported by appropriate technology and varied representational tools, including concrete models:

A.6.1 Discrete structures including sets, relations, functions, graphs, trees, and networks

A.6.2 Enumeration including permutations, combinations, iteration, recursion, and finite differences

A.6.3 Propositional and predicate logic

A.6.4 Applications of discrete structures such as modeling and designing data structures

A.6.5 Historical development and perspectives of discrete mathematics including contributions of significant figures and diverse cultures 


\title{
Appendix K
}

\section{State Department of Elementary and Secondary Education Certification Requirements for Secondary Education (9-12)}

\author{
DEPARTMENT OF ELEMENTARY AND SECONDARY EDUCATION \\ CERTIFICATION REQUIREMENTS FOR \\ SECONDARY EDUCATION (GRADES 9-12)
}

\section{GENERAL REQUIREMENTS:}

A. A baccalaureate degree from a college or university having a teacher education program approved by the Department of Elementary and Secondary Education;

B. Must have recommendation of designated official for teacher education in the college or university;

C. Must have a grade point average of 2.5 on a 4.0 scale overall and in the major area of study;

D. Must complete the content knowledge or specialty area test designated by the State Board of Education with a score equal to or greater than the qualifying score. If no content knowledge or specialty area test is designated for the area of concentration, completion of the Principles of Learning and Teaching: Grades 7-12 test is required with a score equal to or greater than the qualifying score;

E. Completion of professional requirements as determined by the recommending college or university, which may exceed these minimum requirements; and

F. Individuals who completed their teacher education program outside of the United States shall provide documentation of completion of course work in the following:

1. English Composition, two (2) courses, each a minimum of two (2) semester hours;

2. U.S. History, three (3) semester hours; and

3. U.S. Government, three (3) semester hours.

II. PROFESSIONAL REQUIREMENTS: A minimum requirement of twenty-six (26) semester hours in professional education as follows:

A. Foundations of Teaching (Minimum requirement of eight (8) semester hours):

1. The Pupil/Society--A minimum of six (6) semester hours with knowledge acquired and competency developed to the satisfaction of the teacher preparation institution in the following content areas:

a. *Adolescent Growth and Development (Physical-Mental-Social);

b. Adolescent Behavior Management Techniques;

c. Psychology of Learning (must include adolescent learning);

d. Adolescent Interaction with Others; and

e. *Psychology and/or Education of the Exceptional Child (including the Gifted); and

2. The School/Society--A minimum of two (2) semester hours with knowledge acquired and competency developed to the satisfaction of the teacher preparation institution in the following content areas, including multi-cultural aspects:

a. Legal Foundations of Education;

b. Historical Foundations of Education;

c. Philosophical Foundations of Education; and

d. Sociological Foundations of Education; and

B. Secondary Methods and Techniques (Minimum requirement of eight (8) semester hours): A minimum of eight (8) semester hours with knowledge acquired and competency developed to the satisfaction of the teacher preparation institution in the following content areas:

1. "Basic Reading Techniques for Secondary Teachers;

2. Instructional Strategies for Secondary Teachers;

3. *Curriculum, Methods, and Techniques in each subject area specialty;

4. Measurement and Evaluation; and

5. Microcomputer Applications in Education; and

C. Clinical Experiences (Minimum requirement of ten (10) semester hours):

Certification in grades 9-12 should include clinical experience at the secondary level. A minimum of two (2) semester hours prior to student teaching ${ }^{* \star}$ and a minimum of eight (8) semester hours

"Denotes minimum of two (2) semester hours required.

"Required separate verification on transcripts; may be two (2) separate courses.

Revised January 2008 
of student teaching in grades $9-12$ is required, except that $K-9$ or $K-12$ certification must also include K-6 experience in student teaching. A fully certificated elementary or middle school toacher with two (2) or more years of elementary or middle school teaching may salisly this requirement through the completion of a two (2) or more semester hour practicum at the secondary level.

\section{SUBJECT MATTER REQUIREMENTS AS SPECIFIED FOR SPECIFIC AREA(S) OF CERTIFICATION}

P. MATHEMATICS GRADES

$9-12$

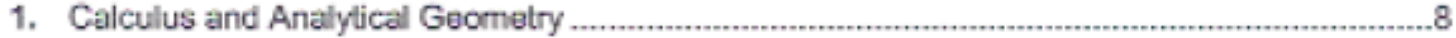

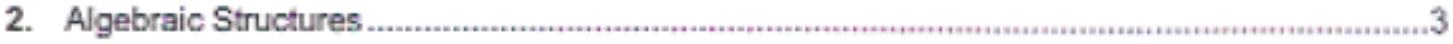

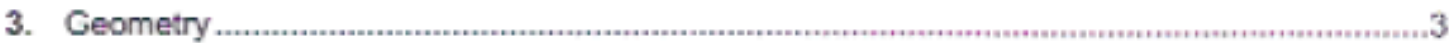

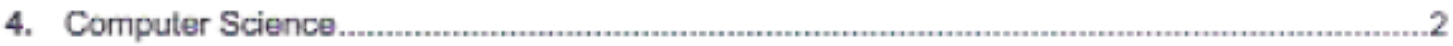

5. Electives from the above course work ............................................................................

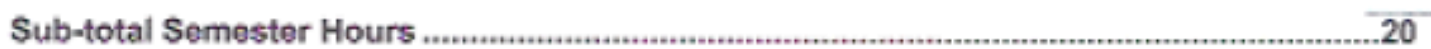

6. A minimum of ten (10) semester hours from at least 3 (three) areas of Mathematics such as the following:

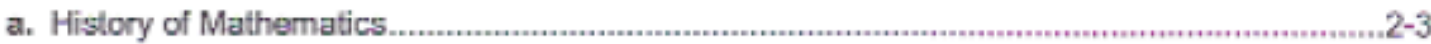

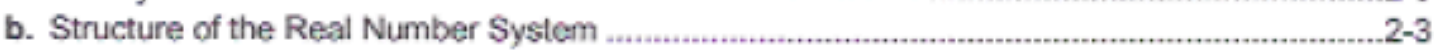

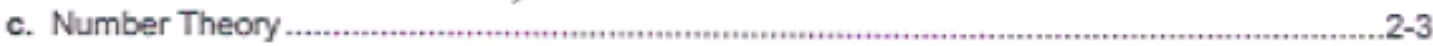

d. Completion Calculus Sequence.

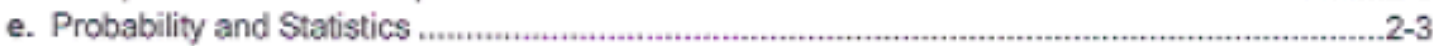

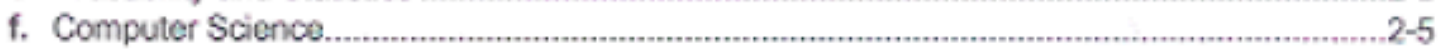

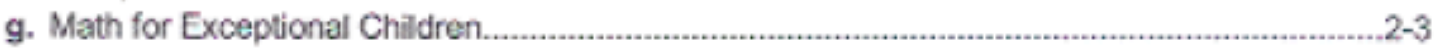

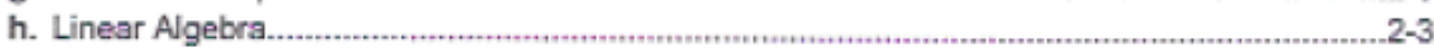

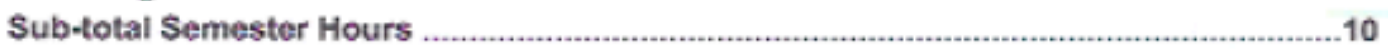

MINIMUM GRAND TOTAL SEMESTER HOURS .......................................................................30 


\section{Appendix L}

\section{Alpha University Mathematics Education Requirements}

Mathematics Education Comprehensive Major, 46 hours:

\section{B.S.Ed.-No Minor Required (Certifies Grades 9-12)}

CIP: 131311

Requirements

The $\quad$ Core (48-52 hours)

Must include the following:

MATH $17120 \quad$ Calculus ।

Recommended:

$\begin{array}{lll}\text { CSIS } 44101 & \text { Foundations of Computing } & 3\end{array}$

CSIS $44130 \quad$ Computers and Information Technology 3

Foundational Requirements

To achieve the common objectives, all majors in Mathematics are required to complete a common foundational set of 21 semester hours and participate in senior assessment. The area's common foundational requirements are:

Required Courses

MATH $17120 \quad$ Calculus

MATH 17121

MATH $17230 \quad$ Probability and Statistics

MATH $17311 \quad$ Linear Algebra

MATH 17495 Seminar in Mathematics

MATH 17120: This course fulfills a requirement as well as a requirement of the major, but

the number of credit hours may be counted only once toward the 124 required for graduation.

A Discrete course chosen from:

$\begin{array}{lll}\text { MATH } 17215 & \text { Discrete Mathematics } & 3 \\ & \text { OR } & 3 \\ \text { MATH } 17319 & \text { Graph Theory }\end{array}$

A Professions course chosen from:

INCO $77297 \quad$ Profession-Based Work Experience 1 to 3

MATH $17197 \quad$ Exploring Mathematics-Related Fields

Mathematics Education

$\begin{array}{llr}\text { CSIS } 44149 & \text { Scientific Computing } & 3 \\ \text { MATH } 17390 & \text { Transition to Proofs } & 3 \\ \text { MATH } 17351 & \text { College Geometry } & 3 \\ \text { MATH } 17497 & \text { Connections to Teaching Mathematics } & 1 \\ \text { MATH } 17280 & \text { Methods in Teaching with Technology } \\ \text { MATH } 17580 & \text { Methods in Secondary School Mathematics } & 3 \\ \text { Note: CSIS } 44149 \text { has a } & 3 \\ \text { An Algebra course chosen from: } & \\ & \\ \text { MATH } 17415 & \text { Modern Algebra-Rings } & 3 \\ \text { MATH } 17416 & \text { Modern Algebra-Groups } & 3 \\ & \\ \text { An Analysis course chosen from: } & 3 \\ \text { MATH } 17421 & \text { Introduction to Analysis } & 3 \\ \text { MATH } 17520 & \text { Applied Analysis }\end{array}$


Appendix M

\section{Beta University Teacher Education in Mathematics Requirements}

\section{TEACHER EDUCATION IN MATHEMATICS (BACHELOR OF SCIENCE, B.S.)}

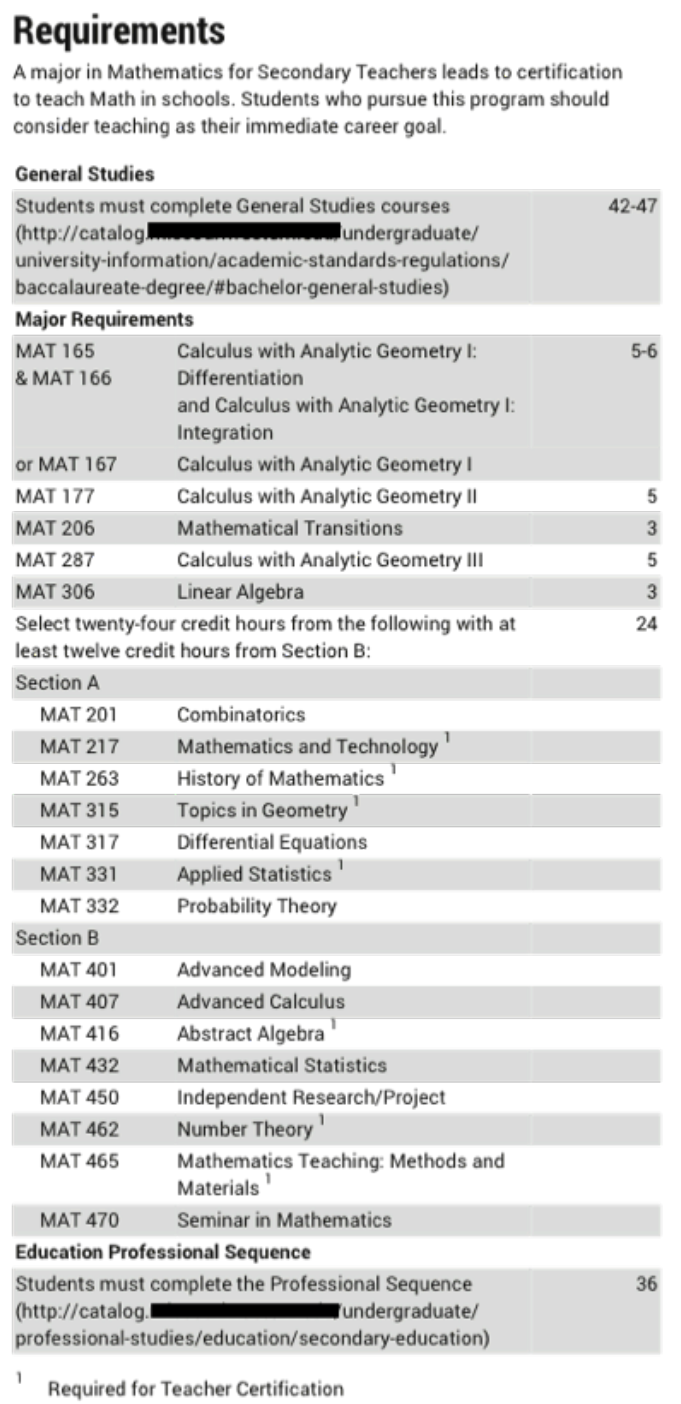

\section{Graduation Requirements}

1. Earn a minimum of 124 credit hours, including 60 from a senior college (100 level and higher, maximum of 6 CED credit hours applicable).

2. Earn a minimum of 30 credit hours in upper-division courses. Lower-division transfer courses accepted as meeting upper-division departmental course requirements cannot be used to fulfill this requirement.

3. Earn 30 of the last 45 credit hours at in institutional coursework (exclusive of credit by examination).

4. Participate in required departmental and campus wide assessments.

5. Earn a grade of $\mathrm{C}$ or higher in all major coursework.

6. Earn an overall GPA of at least 2.75 , a major GPA of 3.0 and a minimum 3.0 GPA in Education coursework.

7. Fulfill the requirement.

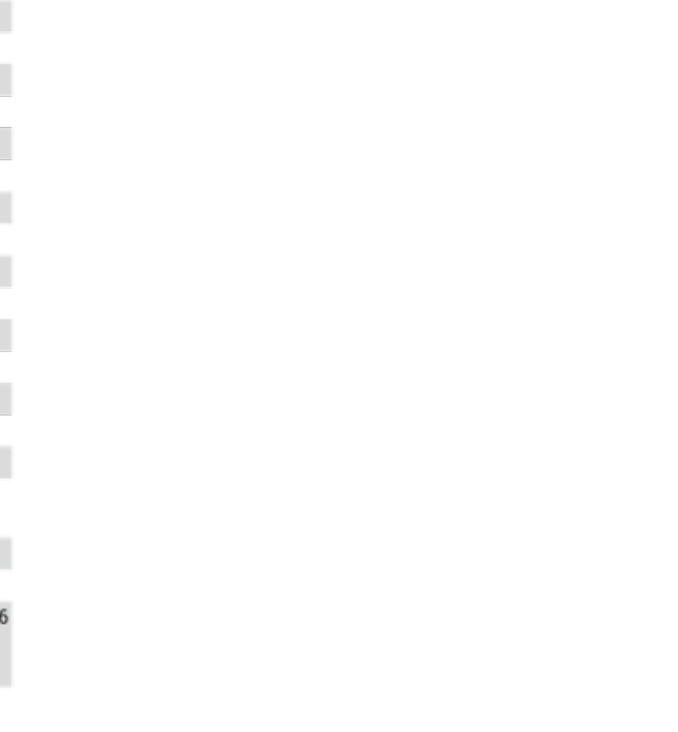




\section{Appendix N}

\section{IRB Approval}

February 10, 2018

Principal Investigator: Angela K Dorsey

Department: Educational Leadership-EDD

Your IRB Application to project entitled Secondary Mathematics Teacher Preparation Program: Perceptions of Novice Teachers, Cooperating Teachers, and University Professors was reviewed and approved by the MU Institutional Review Board according to the terms and conditions described below:

$\begin{array}{ll}\text { IRB Project Number } & 2010472 \\ \text { IRB Review Number } & 233724 \\ \text { Initial Application Approval Date } & \text { February 09, 2018 } \\ \text { IRB Expiration Date } & \text { February 09, 2019 } \\ \text { Level of Review } & \text { Expedited } \\ \text { Project Status } & \text { Active - Open to } \\ & \text { Enrollment } \\ \text { Expedited Categories } & 45 \text { CFR 46.110.a(f)(6) } \\ \text { Risk Level } & 45 \text { CFR 46.110.a(f)(7) } \\ \text { Type of Consent } & \text { Minimal Risk } \\ \text { Internal Funding } & \text { Written Consent } \\ & \text { Personal funds }\end{array}$

The principal investigator (PI) is responsible for all aspects and conduct of this study. The PI must comply with the following conditions of the approval:

1. No subjects may be involved in any study procedure prior to the IRB approval date or after the expiration date.

2. All unanticipated problems and deviations must be reported to the IRB within 5 business days.

3. All changes must be IRB approved prior to implementation unless they are intended to reduce immediate risk.

4. All recruitment materials and methods must be approved by the IRB prior to being used.

5. The Continuing Review Report (CRR) must be submitted to the IRB for review and approval at least 30 days prior to the project expiration date. If the study is complete, the Completion/Withdrawal Form may be submitted in lieu of the CRR.

6. Maintain all research records for a period of seven years from the project completion date.

7. Utilize the IRB stamped consent documents and other approved research documents located within the document storage section of eCompliance. These documents are highlighted green. 
If you are offering subject payments and would like more information about research participant payments, please click here to view the MU Business Policy and Procedure:

http://bppm.missouri.edu/chapter2/2_250.html

If you have any questions, please contact the IRB at 573-882-3181 or irb@missouri.edu.

Thank you,

MU Institutional Review Board 


\section{Appendix 0}

\section{Permission to Conduct Research (Alpha)}

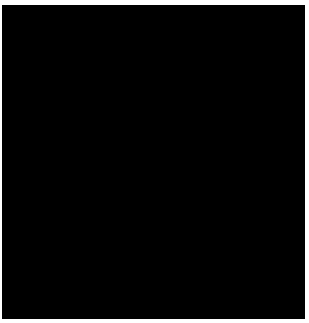

Institutional Review

Board
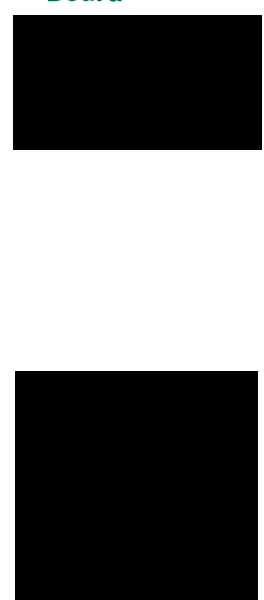

Date: 12 March 2018

IRB Project \#: 1718-044

Primary Investigator: Angela Dorsey

Project Title: Secondary Mathematics Teacher Preparation Program Perceptions of Novice Teachers, Cooperating Teachers, and University Professors

The Institutional Review Board has approved your research proposal.

You are required to submit a status report to the IRB Chair on several occasions. The status report form is available on the IRB website.

- If your methodology changes, you must file a status report within 10 days.

- If negative incidents pertaining to human participants occur, you must file a status report within 10 days.

- Upon completion of your project, you must file a status report.

- At the end of your approved research period, you may file a status report to request additional time.

Please contact us at if you have any questions or concerns, and please include your IRB Project number in all correspondence.

Thank you for your interest in research at

We wish you the best with your important research.

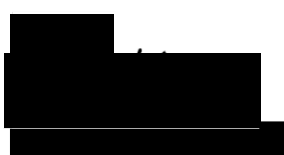

Chair, Institutional Review Board AY2017-18 
Appendix $\mathrm{P}$

Permission to Conduct Research (Beta)

Monday, January 29, 2018 at 6:45:09 PM Central Standard Time

Subject: Re: Dissertation information/approval requested

Date: Monday, January 29, 2018 at 5:50:50 PM Central Standard Time

From:

To:

Angela Dorsey

Angela,

Please see the forwarded reply from the

have questions, please contact

Thank you and I wish you well in completing your dissertation and degree.

Regards,

On Fri, Jan 26, 2018 at 9:27 AM

$\mathrm{Hi}$

Sorry for the delayed response on this. My understanding is that approval is required from

IRB if the research is being conducted on our campus, or if any faculty, staff, or student is conducting (or even coconducting) the research project. So if our involvement on this project is limited to just identifying individuals who'll participate in the study (i.e., faculty, former students), I don't think Ms. Dorsey would need IRB approval from us (but of course would need IRB approval from her institution). If the interviews happen here on campus, then yes she'd need our approval. If any of our employees or students are considered collaborators on her project (which seems unlikely as she'd described it in her e-mail), then the project would need approval. Otherwise, it wouldn't need to go through our IRB.

Hopefully that makes sense - if not please let me know.

Hope you're having a great Friday so far.

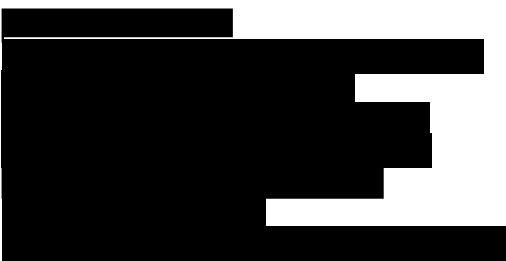


VITA

Angela Dorsey was born October 12, 1968 in Saint Joseph, Missouri, and graduated from LeBlond High School in 1986. She completed her Bachelor of Science Degree in Mathematics at Missouri Western State University with a Secondary Teaching Certificate for Missouri in 1990. In 1996, she completed her Master's in Mathematics Education from Northwest Missouri State University.

During the time she was completing her graduate degrees, she was a full-time mathematics teacher at Central High School in Saint Joseph, Missouri where she still lives. In 1998, along with teaching, she became the Secondary Mathematics Curriculum Coordinator for the Saint Joseph School District.

Mrs. Dorsey is currently one of five, full-time K-12 Advisors for the Saint Joseph School District working with teachers with regards to curriculum, instruction, and assessment. She is an organized professional and dedicated to progressive teaching methods while maintaining supportive relationships with her colleagues. She also advocates for continual improvement of math education through statewide organizations. 